\title{
EFFECTS OF SETTING NEW SOURCE PERFORMANCE STANDARDS FOR FLUIDIZED-BED COMBUSTION SYSTEMS
}

\author{
Draft Final Memorandum
}

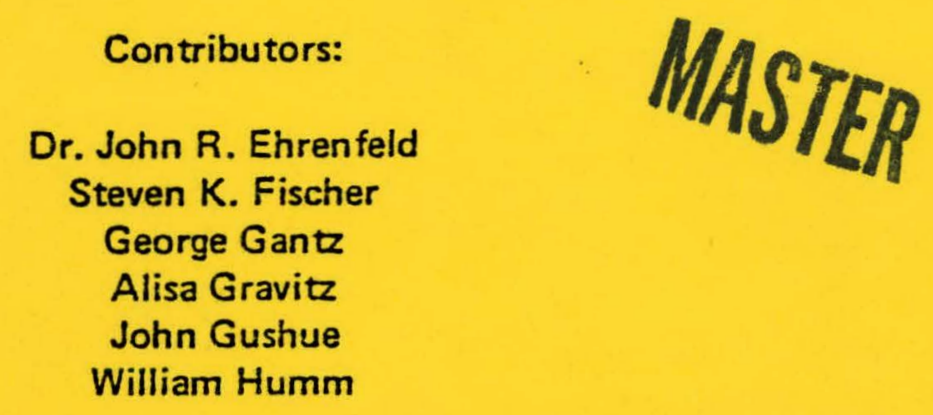

ENERGY RESOURCES COMPANY INC. 185 ALEWIFE BROOK PARKWAY CAMBRIDGE, MASSACHUSETTS 02138

February 1978

Prepared for:

THE UNITED STATES DEPARTMENT OF ENERGY

\author{
8 ACOI.78PE O2529 \\ Under Contract No. EL-77-C.01-2529 \\ Task Order No. 002
}




\section{DISCLAIMER}

This report was prepared as an account of work sponsored by an agency of the United States Government. Neither the United States Government nor any agency Thereof, nor any of their employees, makes any warranty, express or implied, or assumes any legal liability or responsibility for the accuracy, completeness, or usefulness of any information, apparatus, product, or process disclosed, or represents that its use would not infringe privately owned rights. Reference herein to any specific commercial product, process, or service by trade name, trademark, manufacturer, or otherwise does not necessarily constitute or imply its endorsement, recommendation, or favoring by the United States Government or any agency thereof. The views and opinions of authors expressed herein do not necessarily state or reflect those of the United States Government or any agency thereof. 


\section{DISCLAIMER}

Portions of this document may be illegible in electronic image products. Images are produced from the best available original document. 


\title{
EFFECTS OF SETTING NEW SOURCE PERFORMANCE STANDARDS FOR FLUIDIZED-BED COMBUSTION SYSTEMS
}

\author{
Draft Final Memorandum
}

\section{Contributors:}

Dr. John R. Ehrenfeld Steven K. Fischer George Gantz Alisa Graviz John Gushue William Humm

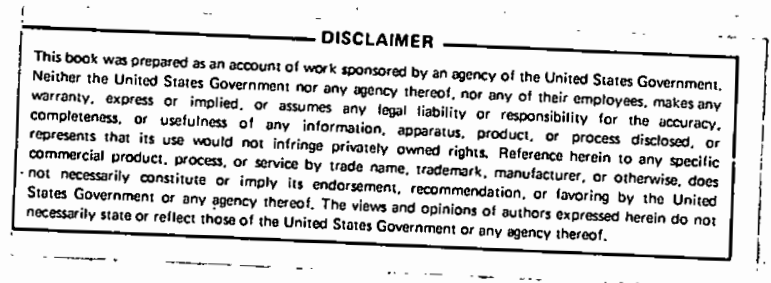

ENERGY RESOURCES COMPANY INC. 185 ALEWIFE BROOK PARKWAY CAMBRIDGE, MASSACHUSETTS 02138

February 1978

Prepared for:

THE UNITED STATES DEPARTMENT OF ENERGY

Under Contract No. EL-77t-C-01-2529

Task Order No. 002 
This report has been reviewed by EPA and approved for publication. Approval does not signify that the contents necessarily peflect the views and policies of the Environmental protection Agency, nor does mention of trade names or comercial products constitute endorsement or recommendation EOT use. 
CHAPTER ONE INTRODUCTION AND SUMMARY $1-1$

1.1. Introduction/Objectives 1-1

1.2 Principal Technical Findings $1-2$

1.3 Principal. Policy Findings $1-14$

1.3.1 Regulatory Options $1-14$

1.3 .2 Beriefits $1-17$

1.3.3 R\&D Needs $1-22$

GHAPTER TWO OVERVIEW: THE PROS AND CONS OF UTIIITY - $2-1$ SIZED FLUIDIZED-BED COMBUSTORS

2.1 Introduction 2-1

2.2 Overview of FBC Pros and Cons 2-3

CHAPTER THREE TECHNICAL CONSEQUENCES OF NEN SOURCE ${ }^{\circ}$ PERFORMANCE STANDARD ALTERNATIVES

3.1 Introduction

$3-1$

3.2 Engineering Considerations $3-2$

3.2.1 Sulfur Dioxide Aspects 3-2

$3.2 .2 \mathrm{NO}_{\mathrm{x}}$ Aspects $\quad 3-16$

3.2.3 Particulate Aspects $3-17$

3.3 Cost Comparison Between Fluidized-Bed and 3-20 Conventional Systems

3.3.1 Costing Methodology 3-20

3.3 .2 Scenarios for cost Comparisons 3-31

3.3 .3 Cost of Electricity Estimates 3-34

3.4 Energy Penalty Effects 3-59

3.5 Solid Waste Aspects 3-63

3.5 .1 Sludge Composition 3-63

3.5 .2 Quantities of Solid Waste $3-67$

3.5 .3 Disposal Considerations $3-70$ 
TABLE OF CONTENTS (COnt'd.)

PAGE

CHAPTER FOUR POLICY IMPLICATIONS CONCERNING NEW SOURCE $4-1$ PEREORMANCE STANDARDS FOR STEAM-EIECTRIC GENERATORS

4.1 Introduction

$4-1$

4.2 Policy Options in Setting New Source Performance 4-4 Standards and Possible Consequences

4..2.1 Set NSPS Based Essentially on Conventional 4-6 System Performance (Option A)

4.2.2 Set New Source Performance Standards But $4-11$ Promise to Waive Fluidized-Bed Combustion Demonstration Plants (Option B)

4.2.3 Exclude Fluidized-Bed Combustion Technology in the Standard-Setting Process (Option B)

4.2.4. Set Separate Standards for Fluidized-Bed Combustor Demonstration Projects (Option D)

$4-14$

$4-16$

4.3 Future Actions

$4-17$

4.4. Effects of FBC Development Timetable

$4-19$

4.5 Social Benefits of Fluidized-Bed Combustors $4-22$

4.5.1 Beneficial Technical Characteristics 4-22

4.5 .2 Social Benefits. $\quad 4-28$

4.5 .3 Other Benefits . . $4-36$

4.6. Unsatisfied Environmental Research and Development 4-38 Needs

APPENDIX A DETAIIS OF COST MODELS $A-1$

A.1 Conventional System with FGD A-I

A.1.1 Cost Components A-1

A.1.2 Scrubber and Boiler Adjustments A-4

A.1.3 Capital Cost Formula A-6

A.1.4 Energy Loss Formula A-7

A.1.5 Energy Cost Formula A-9

A.1.6 Other Model Outputs A-10

A.2 Cost Model for Atmospheric Fluidized Bed A-10

A.2.1. Plant Capital Cost A-11 
TABLE OF CONTENTS (CONT'd.)

PAGE

A.2.2 Plant Bower Calculation

$A-17$

A.2.3 Cost of Electricity

A- 17

A.3 Cost Model for Pressurized Fluidized Bed

$A=18 \quad$ C

A.3.1 Plant Capital Costs

$A-19$

A.3.2 Plant Power Calculation

$A-23$

A.3.3 Cost of Electricity (COE)

$A-24$.

APPENDIX B COMPARISON OF ERCO RESUITS WITH OTHER . B-I

B.1 Cost of a Conventional System

$B-1$

B.2 Fluidized-Bed System costs

$B-10$ 


\section{LIST OF TABLES}

PAGE

CHAPTER ONE INTRODUCTION AND SUMMARY $1-1$

1-1. Sumnary Cost and Performance Comparison: 800 MWe $1-3$ Fluidized Bed Combustors and an 800 MWe Conventional Boiler with FGD

1-2. Regulatory Options for NSPS. 1-15

1-3 Important Technical Characteristics of Fluidized- 1-18 Bed Combustors Relative to Conventional Coal Boilers with Scrubbers

I-4 Potential Social Benefits of Fluidized Beds Rela- 1-20 tive to Conventional Coal Burning Plants with Scrubbers

1-5 Environmental Objectives for FBC R\&D Program 1-24

CHAPTER TWO OVERVIEW: THE PROS AND CONS OF UTILITYSIZED FLUIDIZED-BED COMBUSTORS

CFAPTER THREE TECHNICAL CONSEQUENCES OF NEW SOURCE $3-1$ PERFORMANCE STANDARD ALTERNATIVES

3-1 Sources

$3-23$

3-2 Basis for Scenarios

$3-32$

3-3 Percent Removal Requirements

$3-33$

3-4. Typical Chemical Compositions of Coal Ash, 3-65 FGD Sludge, and FBC Solid Wastes

3-5 Comparison of Solid waste Generation in Conventional Systems with Limestone FGD and FluidizedBed Systems

3-6 Disposal Options and Environmental Effects PERFORMANCE STANDARDS FOR STEAM-ELECTRIC GENERATORS

4-1 Regulatory Options for NSPS

4-2 Important Technical Characteristics of Fluidized- 4-23 Bed Combustors Relative to Conventional Coal Boilers with Scrubbers 
$4-3$ Potential Social Benefits of Fluidized Beds 4-29 Relative to Conventional Coal Burning Blants with Scrubbers

4-4 Environmental Objectives for FBC R\&D Program 4-40

APPENDIX A DETAIIS OF COST MODELS $A-1$

A-1 Capital Cost Formula Components for Conventional A-3 System

A-2 Capital Cost Breakdown - AFBC

A-3 Elements of AFBC cost Formula

$A-12$

A-4. Capital Cost Breakdown - PEBC

$A-15$

A-5 Elements of PFBC Cost Fomula

$A-20$

$A-21$

APPENDIX B COMPARISON OF ERCO RESULTS WITH OTHER $\quad B \rightarrow 1$

B-1 ERRI and ERCO Capital Costs : B-5

B-2 Scrubber Capital Costs B-7

$B-3$ Estimates fOr $A F B C$ and PFBC systems $B-13$ 
CHAPTER ONE INTRODUCTION AND SUMMARY $1-1$

1-1' Cost Estimates Using Westinghouse $\mathrm{Ca} / \mathrm{S}$ Ratios 1-5

1-2 Costs of Electricity: Case 1 1-6

1-3 Costs Differentials for Current and Proposed · 1-8 NSPS Standards.

1-4 Plant Efficiencies 1-10

1-5 Cost Penalty for Overdesign in the $\mathrm{SO}_{2}$ Removal $1-11$ System (Assuming New NSPS)

1-6 Sensitivity of Costs to Changing Assumptions 1-13 for Conventional and Fluidized-Bed Systems with Base Case Coal

CHAPTER TWO OVERVIEW: THE PROS AND CONS OF UTIIITYSIZED FLUIDIZED -BED COMBUSTORS

\section{CHAPTER THREE TECHNICAL CONSEQUENCES OF NEW SOURCE PERFORMANCE STANDARD ALTERNATIVES}

3-1 SO, Removal Requirements as a Function of NSPS . 3-4 Stipulations and $\mathrm{SO}_{2}$ Production

3-2 $\mathrm{SO}_{2}$ Production as a Function of Coal Sulfur 3-5 Content and Heating Value.

3-3 Sulfur Content Variations as a Function of 3-7 Averaging Time

3-4 Sources for Cost Model Methodology and Assumptions 3-22

3-5 Conceptual Design of Cost Models 3-28

3-6 Flow Chart of Cost Model 3-29

3-7 Costs of Electricity: Case 1 3-35

3-8 Costs of Electricity: Case $2 \quad 3-36$

3-9 Costs of Electricity: Cașe 3 3-37

3-10 Costs of Electricity: Case 4 3-38

3-11 Costs of Electricity: Case 5 3-39

3-12 Costs of Electricity: Case $6 \quad 3-40$

3-13 Costs of Electricity: Case 7 3-41 
IIST OF FIGURES (CONt'd.)

PAGE

- 3-14 Cost Estimates Using Westinghouse Ca/s Ratios 3-45

3-15 Cost Differentials. for Current and Proposed 3-46 NSPS Standards

3-16 Sensitivity of Costs to Changing Assumptions $3-49$ for Conventional and Fluidized-Bed Systems with Base Case Coal

3-17 Cost Penalty for Overdesign in the $\mathrm{SO}_{2}$ Removal 3-54 System (Assuming New NSPS)

3-is plant Efficiencies

$3-60$

CHAPTER FOUR POLICY IMPLICATIONS CONCERNING NEW SOURCE 4-1 PERFORMAINCE STANDARDS FOR STEAM-ELECTRIC GENERATORS

4-1 Time Line for Development of FBCs

$4-20$

APPENDIX A DETAIIS OF COST MODEIS

APPENDIX B COMPARISON OF ERCO RESULTS WITH OTHER B-1 STUDIES

B-1 Conventional System Cost Comparison with $83 \quad$ B-2 Pescent Removal.

B-2 Comparison of Westinghouse and ERCO Costs for a B-9 Conventional system

B-3 Atmospheric Fluidized Bed Costs B-14

B-4 Pressurized Fluidized Bed.Costs B-15

B-5 Comparison of Westinghouse and ERCO Capital Invest- B-19. ment for AFBC with Eastern Coals

B-6. Comparison of Westinghouse and ERCO Capital B-20

Investment for PFBC with Eastern Coals

B-7 Comparisn of Westinghouse and ERCO Energy Costs B-2I for AFBC with Eastern Coals

B-8 Comparison of ERCO and Westinghouse Energy Costs B-22 for PFBC with Eastern Coals 
THIS PAGE

\section{WAS INTENTIONALLY \\ LEFT BLANK}


CHAPTER ONE

\section{INTRODUCTION AND SUMMARY}

\subsection{Introduction/Objectives}

This study was undertaken for the U.S. Environmental Protection Agency to examine the potential consequences of revisions in New Source Performance Standards (NSPS) on fluidized-bed combustor (FBC) based steam electric generators of greater than 250,000,000 Btu. Secondly, a study of the appropriateness and differential effects of altemate regulatory approaches to the standards-setting process was made. Problems dealing with an emerging technology such as fluidized-bed combustion were emphasized. Finally, an examination was made of the potential benefits of fluidized-bed systems relative to conventional coal-fired systams equipped with scrubbers.

The part of the study that examined the potential impact of various levels of NSPS considered general engineering consequences, environmental effects, and particularly, capital cost of facilities and cost of electricity. A computer-based model to develop estimates of capital cost and cost of electricity was developed. The model, using cost data developed primarily as part of a major previous study on advanced power generating technologies (ECAS) and expansion of that work by the TVA and Westinghouse, facilitates the examination of the cost sensitivity to a large number of parameters. The major parameters include coal and sorbent cost, calcium-to-sulfur ratio ( $\mathrm{Ca} / \mathrm{S}$ ratio), coal composition (ash and sulfur content; heating value), disposal mode, and percent sulfur recovery required under the standards. 
The parametric approach was chosen because of great uncertainty in developing specific design criteria for FBC systems vis-a-vis specific levels of sulfur removal. FBC system performance and costs are very sensitive to the $\mathrm{Ca} / \mathrm{S}$ ratio. Westinghouse, under a separate, but coordinated, EPA contract, prepared a set of designs to meet specificl levels of standards at conditions believed to be most favorable with regard to cost minimization. Both the parametric results and results. at the Westinghouse design level are presented in the report.

Substantial guidance was provided by the office of Research and Development (ORD) of EPA. Westinghouse, under their direction, made avallable substantial data previously developed for ORD and, further, provided specific new data consistent with the framework for this project.

Chapter Two presents a brief overview of the pros and cons of FBC systems vis-à-vis conventional coal-fired systems with scrubbers. Chapter Three develops a set of NSPS scenarios, and then presents a discussion of their engineering and technical consequences and sost impacts. Chapter Four presents the policy implications, including a discussion of four scparate options to follow in the NSPS revisions; a discussion of $F B C$ benefits; and, finally, an enumeration of environmental RED needs for the continuing FBC program. Appendix A contains a detailed discussion of the cost model and assumptions. Appendix B contains a discussion comparing the cost estimates developed in this study to those on which the work was based.

\subsection{Principal Technical Findings}

Table 1-1 presents a summary of the principal cost and performance characteristics of atmospheric (AFBC) and pressurized (PFBC) fluidized-bed combustion systems and conventional 
TABLE $1-1$

SUMMARY COST AND PERFORMAICE COMPARISON: 800 MHE FLUIDIZED BED

COMBUSTORS AND AN 800 MWe CONVENTIONAL BOILER WITH FGD

\begin{tabular}{|c|c|c|c|c|c|c|}
\hline \multirow{2}{*}{$\begin{array}{l}\text { Coal Type: } \\
\text { Emission Reduction Level: } \\
\text { System Design Ca/S Ratio }\end{array}$} & \multicolumn{3}{|c|}{$\underset{90 \%}{\text { Il inois }} \# 6$} & \multicolumn{3}{|c|}{$\begin{array}{l}\text { Wyoming Subbituminous } \\
83.3 \%\end{array}$} \\
\hline & $\begin{array}{l}\text { Conventional } \\
1.3\end{array}$ & $\begin{array}{l}\mathrm{AFBC} \\
2.9 *\end{array}$ & $\begin{array}{l}\text { PFBC } \\
1.7^{*}\end{array}$ & $\begin{array}{l}\text { Conventional } \\
\quad 1.3\end{array}$ & $\begin{array}{l}\mathrm{AFBC} \\
2.4^{*}\end{array}$ & $\begin{array}{l}\text { PFBC } \\
1.2^{\star}\end{array}$ \\
\hline \multicolumn{7}{|l|}{ Performance Comparison } \\
\hline $\begin{array}{l}\text { Net Efficiency (percent) } \\
\text { Coal Consumption ( } 1000 \text { tons/yr) } \\
\text { Sorbent Consumption ( } 1000 \text { tons/yr) } \\
\mathrm{SO}_{2} \text { Emissions ( } 1000 \text { tons/yr) } \\
\mathrm{Solid}^{\circ} \text { Waste Produced (1000 tons/yr) } \\
\text { Land for. } 30 \text { Year Disposal (acres) }\end{array}$ & $\begin{array}{r}33 \\
2200 \\
340 \\
17 \\
620 \\
1500\end{array}$ & $\begin{array}{r}35 \\
2010 \\
760 \\
16 \\
780 \\
800\end{array}$ & $\begin{array}{r}39 \\
1800 \\
700 \\
14 \\
700 \\
700\end{array}$ & $\begin{array}{r}34 \\
2900 \\
60 \\
5 \\
250 \\
600\end{array}$ & $\begin{array}{r}37 \\
2600 \\
100 \\
4 \\
250 \\
260\end{array}$ & $\begin{array}{r}40 \\
2400 \\
80 \\
4 \\
220 \\
220\end{array}$ \\
\hline \multicolumn{7}{|l|}{ Cost Comparison } \\
\hline Plant Capital Cost $\underset{(\$ K W)}{(\$ M)}$ & $\begin{array}{l}630 \\
780\end{array}$ & 580 & $\begin{array}{l}650 \\
810\end{array}$ & 580 & 530 & 540 \\
\hline FGD Capital cost $\left(\begin{array}{l}\$ M)^{\prime} \\
\$ K W)\end{array}\right.$ & $\begin{array}{l}100 \\
130\end{array}$ & $\begin{array}{ll}-- \\
-\end{array}$ & -- & 57 & $\begin{array}{ll}-- \\
-\end{array}$ & -- \\
\hline Solid Waste Disposal (\$M) & 32 & 11 & 10 & 14 & 4 & 3 \\
\hline Capital Cost (\$KW) & 34 & 14 & 12 & 18 & 5 & 4. \\
\hline Cost of Electricity (mills/KW) & 38.1 & 35.9 & 37.9 & 35.5 & 32.6 & 32.2 \\
\hline Annual cost of Electricity $(\$ M) \star \star$ & 174 & 163 & 173 & 162 & 148 & 147 \\
\hline $\begin{array}{l}\text { Annual Dollar Benefits Over } \\
\text { Conventional System (\$M) }\end{array}$ & - & 11 & 1 & -- & 14 & 1.5 \\
\hline
\end{tabular}

*From Westinghouse draft report "Assessment of the Impact of Sulfur Oxide, Particulate and Nitrous Oxide Emission Standards on FBC Power Plant Energy Costs."

**Plant factor -0.65 
systems with scrubbers. Results presented in the report have been normalized to an $800 \mathrm{MWe}$ (net) plant in this presentation. This size was chosen in order to be consistent. with much of the previous analyses of projected FBC costs; although the size is larger than the size of many of the FBC plants that would be built if the technology becomes. widely accepted. The NSPS scenario on which these data are based contains a 90 percent continuous $\mathrm{SO}_{2}$ reduction requirement and a $0.2 \mathrm{lb} / \mathrm{MMBtu}$ floor (maximum reduction required). On this basis the high sulfur Illinois coal ( 3.9 percent) will require the full 90 percent, but the emissions from the low sulfur coal 10.48 percent, "compliance coal" under the current NSPS) will reach the floor at a removal of 83.3 percent. Values in this table were calculated at Ca/s Iatios letermined by Westinghouse as optimum for the design configuration chosen and for a typical sorbent (see Figure 1-I). Given the great sensitivity of çost and other system performance parameters to Ca/S ratios (see Figure 1-2), is is important to note that these represent only a single. estimate subject to a high degree of uncertainty. Still, in terms of the general pattern of results, FBC systems appear to provide benefits in. terms of costs, land use, total emissions, etc., relative to current conventional technology.

Sulfur capture in fluidized-bed combustion systems is very sensitive to the nature of the specific limestone or dolomite fed to the system. Data available to date show a large range in reactivity, over several orders of magnitude. In sorbents of lower than average characteristics, the results based on the Westinghouse values of $\mathrm{Ca} / \mathrm{S}$ will be optimistic. In these cases the parametric presentations indicate the sensitivity to increased Ca/s ratios.

It is important also to note that AFBC systems for power generation will not likely achieve widespread commercial 


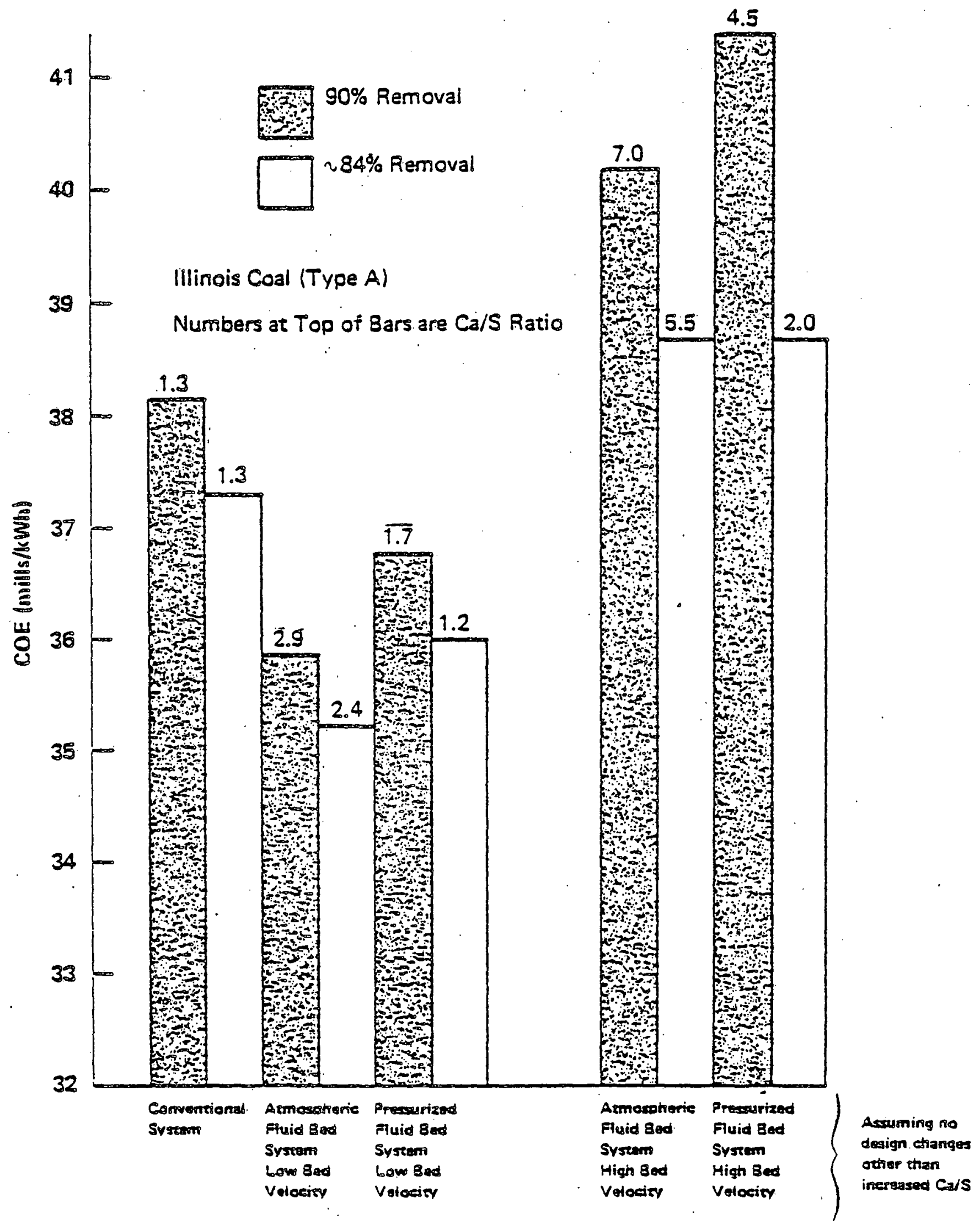

Figure 1-1. Cost Estimates Using Westinghousa $\mathrm{Ca} / \mathrm{S}$ Ratios. 


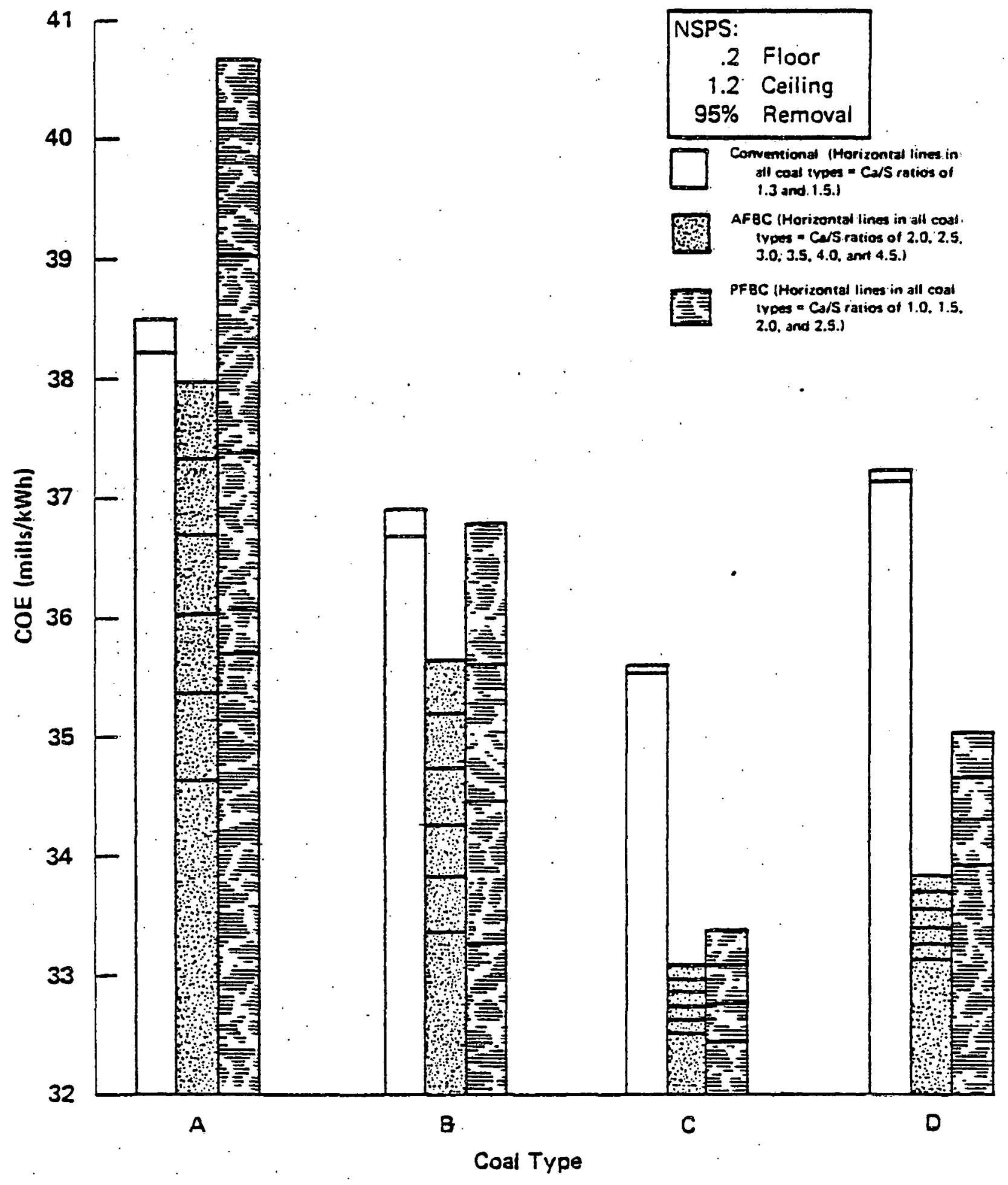

Figure 1-2. Costs of Electricity: Case 1. 
status until 1990 or beyond. By then the performance of conventional systems may be improved. Current R\&D goals are aimed at such improvements, and, if successful, several of the positive benefits of FBC, at least atmospheric systems, may be diminished or even disappear.

Figure 1-2, above, illustrates the high degree of sensitivity of the estimates made in this analysis to the $\mathrm{Ca} / \mathrm{S}$ ratio. Uncertainty as to the proper $\mathrm{Ca} / \mathrm{S}$ ratio for economic design, in future systems, is attributable to some lack of understanding about the processes occurring in FBC systems, but also to a focus on a narrow range of operating parameters in much of the experimental and conceptual design development in past U.S. programs. High tatios of $\mathrm{Ca} / \mathrm{S}$ (and high operating costs) have been projected as necessary to meet NSPS of the order of 90 percent sulfur removal using such design bases. In order to develop more meaningful data for this analysis, Westinghouse developed a set of cost and operating conditions for $A F B C$ and $P F B C$ systems under assumed performance conditions more closely approaching optimal performance. Those projections displayed in Figure $1-1$ show cost advantages for both $A F B C$ and $P F B C$ systems relative to conventional pulverized coalfired utility boilers equipped with scrubbers, for both present NSPS levels and at more stringent levels.

Revising the present NSPS for utility steam electric power plants would result in a cost penaity in conventional pulverized coal-fired power plants and in FBC-based plants (see Figure 1-3). In this figure, incremental costs for achieving a 90 percent sulfur removal; with a floor of 0.2 lbs $\mathrm{SO}_{2} / \mathrm{MP}$ H tu are shown relative to the existing NSPS standard ( 1.2 lbs $\mathrm{SO}_{2} / \mathrm{MMBtu}$ ). The results indicate that AFBC systems should be least impacted by more stringent standards. Conventional systems show a very large penalty for current compliance 


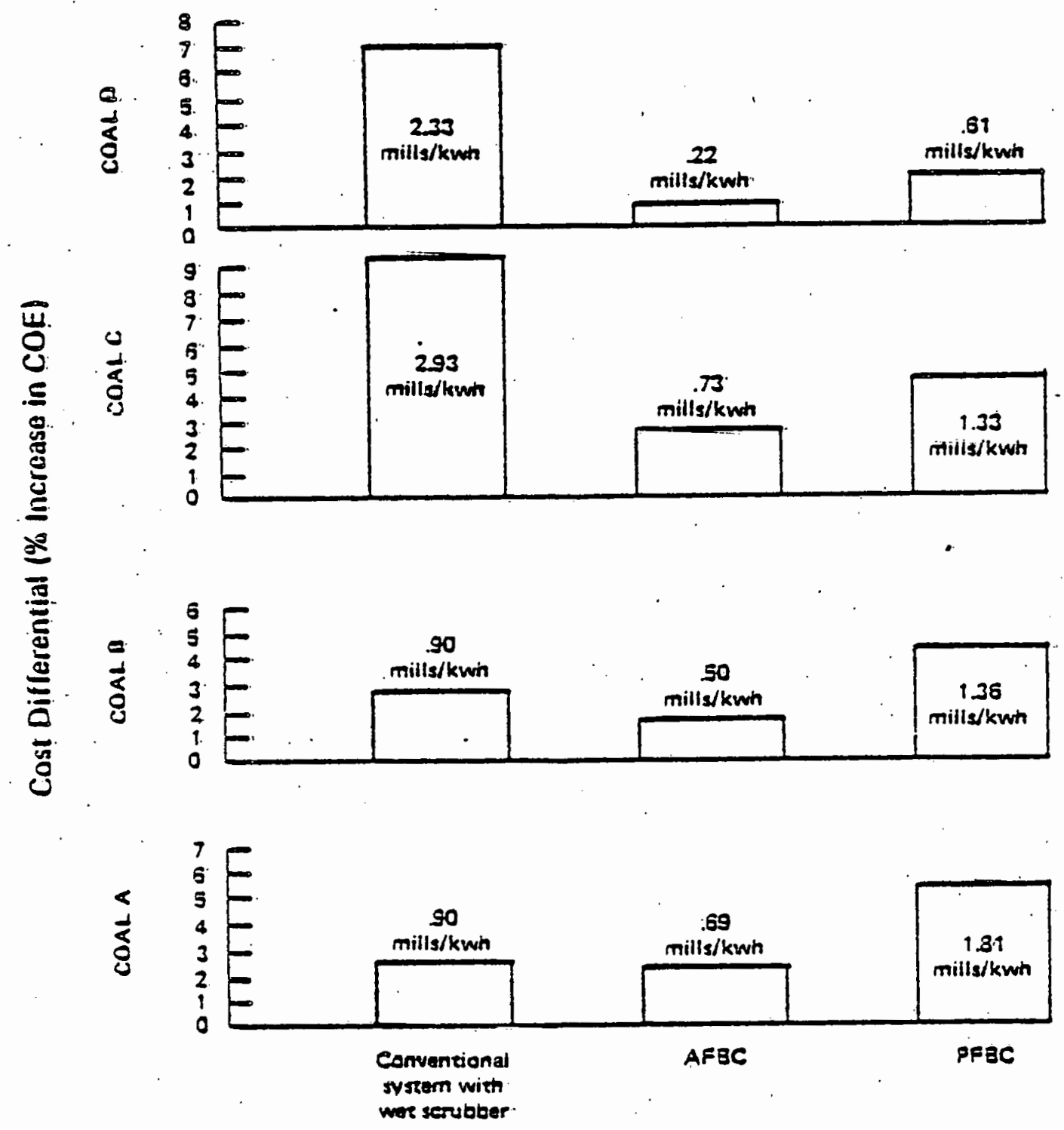

Figure 1-3. Cost differentials for current and proposed NSP standards. Percent increase in cost resulting from proposed NSPS. 
coal (Type $C$ ), which coal would require a FGD system under the new continuous percent removal requirements. These results are very sensitive to the values of $\mathrm{Ca} / \mathrm{S}$ used in the calculation, and, in view of present uncertainty in FBC performance, should be viewed cautiously. Higher requirements for $\mathrm{Ca} / \mathrm{S}$ than those developed in the Westinghouse analysis would reduce the apparent advantage of FBC systems.

More stringent, revised NSPS would not only add to the cost-of-electricity by increasing capital and operating costs, but also would reduce the efficiency of an electric utility plant. The energy penalty. impact of NSPS revisions is illustrated in Figure 1-4, showing plant efficiency versus $\mathrm{Ca} / \mathrm{S}$ ratio. Comparisons of proposed revisions to the existing NSPS are also depicted. For high sulfur coals (Types $A$ and $B$ ), the energy penalty is strongly infuenced by $\mathrm{Ca} / \mathrm{S}$ ratio in FBC systems. Increasing percent removal from 70-80 percent (existing NSPS) to 90 percent would reduce efficiency by about 0.3 to 0.4 percentage points (out of an efficiency of $35-36$ percent). A similar increase in a conventional system would, on the other hand, result in a very small change in efficiency.

For low sulfur coal in FBC systems, the effect on energy penalty would be less severe. But for conventional systems, the peralty would be very large. Systems burning compliance coal (Type C), formerly not requiring scrubbers, would be most severely impacted. The efficiency would decrease nearly a whole percentage point. Lignite systems formerly requiring limited sulfur removal would be lass severely, but significantly, impacted.

The averaging time over which compliance will be determined may exert a significant effect on system design and costs. Figure $1-5$ shows the percent increase in cost-of-electricity 


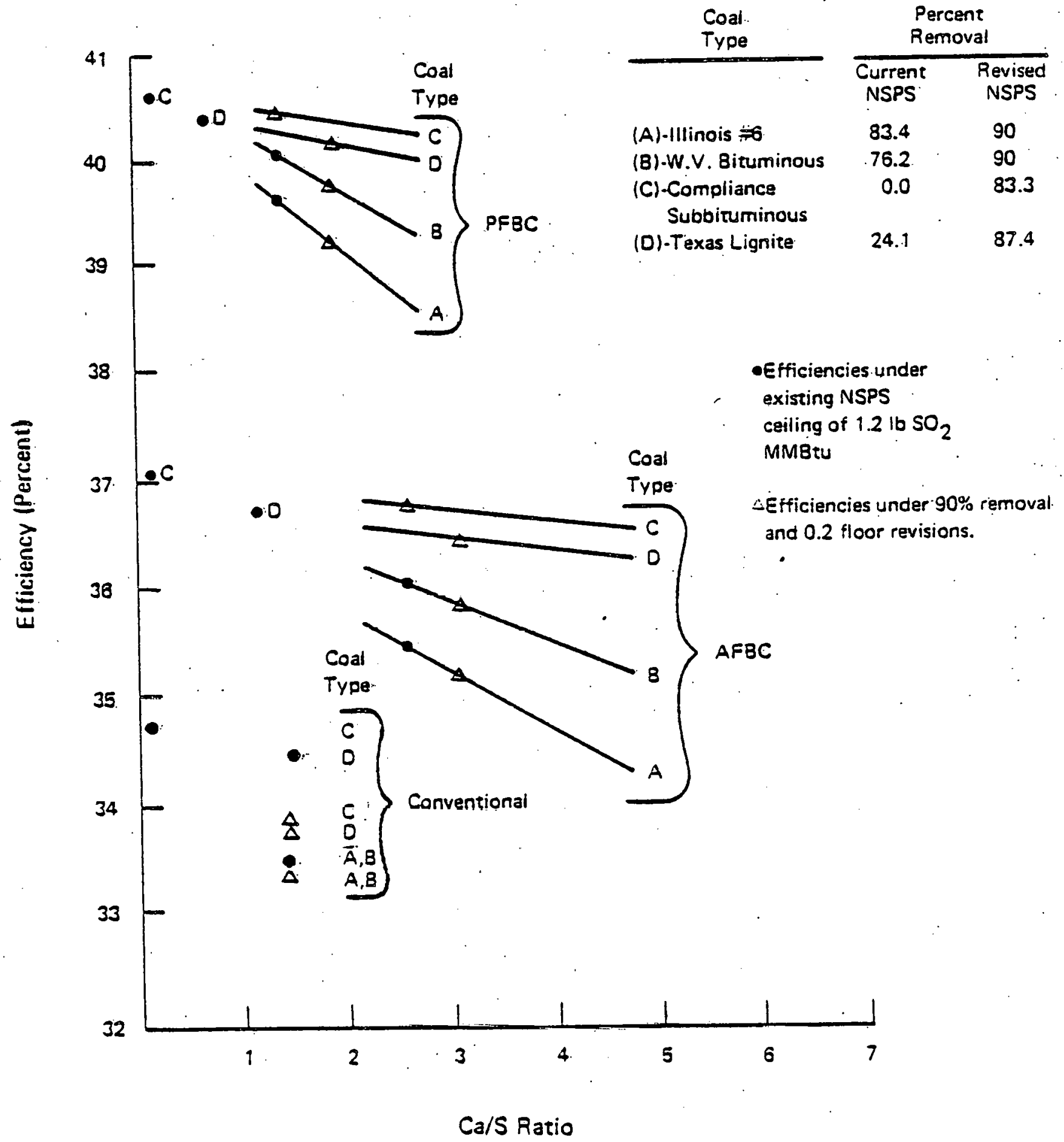

Figure 1-4. Plant efficiencies. 


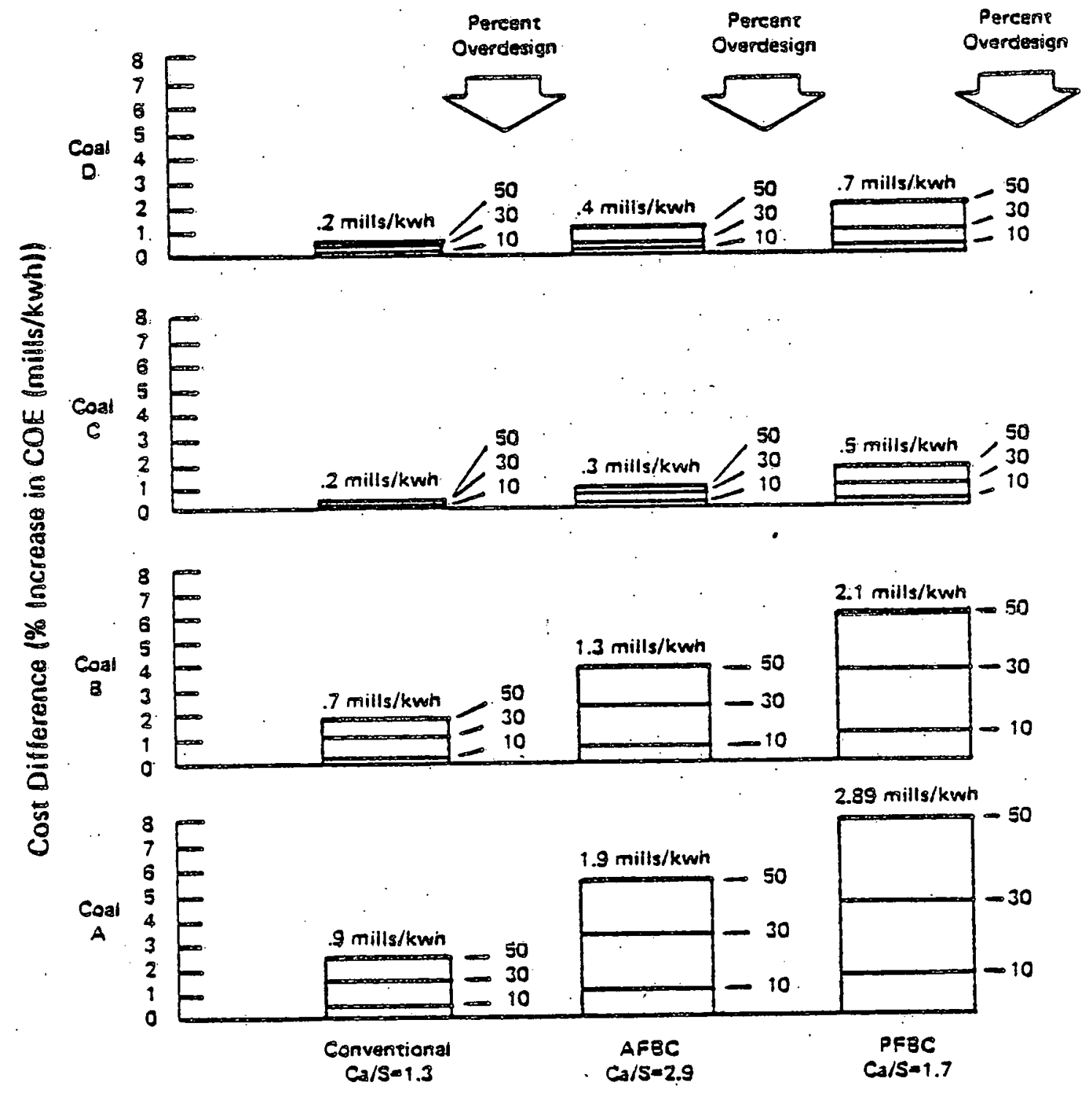

Figure 1-5. Cost penalty for overdesign in the $\mathrm{SO}_{2}$ removal system (assuming new NSPSI. 
that would result by overdesigning system capacity to accommodate the maximum excursion in sulfur content from long-term mean value over the averaging period. In high sulfur eastern coals (Types $A$ and $B$ ), the penalty can be quite high. Costs for low sulfur coals (Types $C$ and $D$ ) are considerably less similarly affected: The competitive effects of the cost consequences implicit in averaging these provisions appears to have an opposite trend to that caused by the percent removal feature of the NSPS (Figure 1-3). Conventional systems appear less impacted by overdesign than do FBCs. The same caveat made above as to the sensitivity of this projection to $\mathrm{Ca} / \mathrm{S}$ ratio holds for this set of results.

Solid waste disposal costs and impacts are a significant factor in evaluating both FBC and conventional systems. Table 1-1, above, presented comparable data for the two systems. The cost impacts depend on the mode of disposal, whether onsite or offsite, ponding versus landfill, local land costs, etc. Figure 1-6 shows the effects of several choices on costs. The figure also illustrates the sensitivity of the cost of electricity to coal and sorbent prices.

There is a correspondence between the sulfur dioxide standard and the ability of the fluidized-bed system to meet the particulate standard. Particulate loading in a fluidized bed will depend markedly on the sorbent requirements. Setting a more stringent sulfur dioxide standard would increase sorbent requirements and in turn place a higher set of requirements on the particulate control system. In that sense the cost of the sulfur dioxide standard would be reflected not only in the sulfur dioxide control parts of the system, but also in increased costs for particulate control. This is not true in the case of most conventional systems where the sulfur dioxide and particulate control systems operate essentially independently 


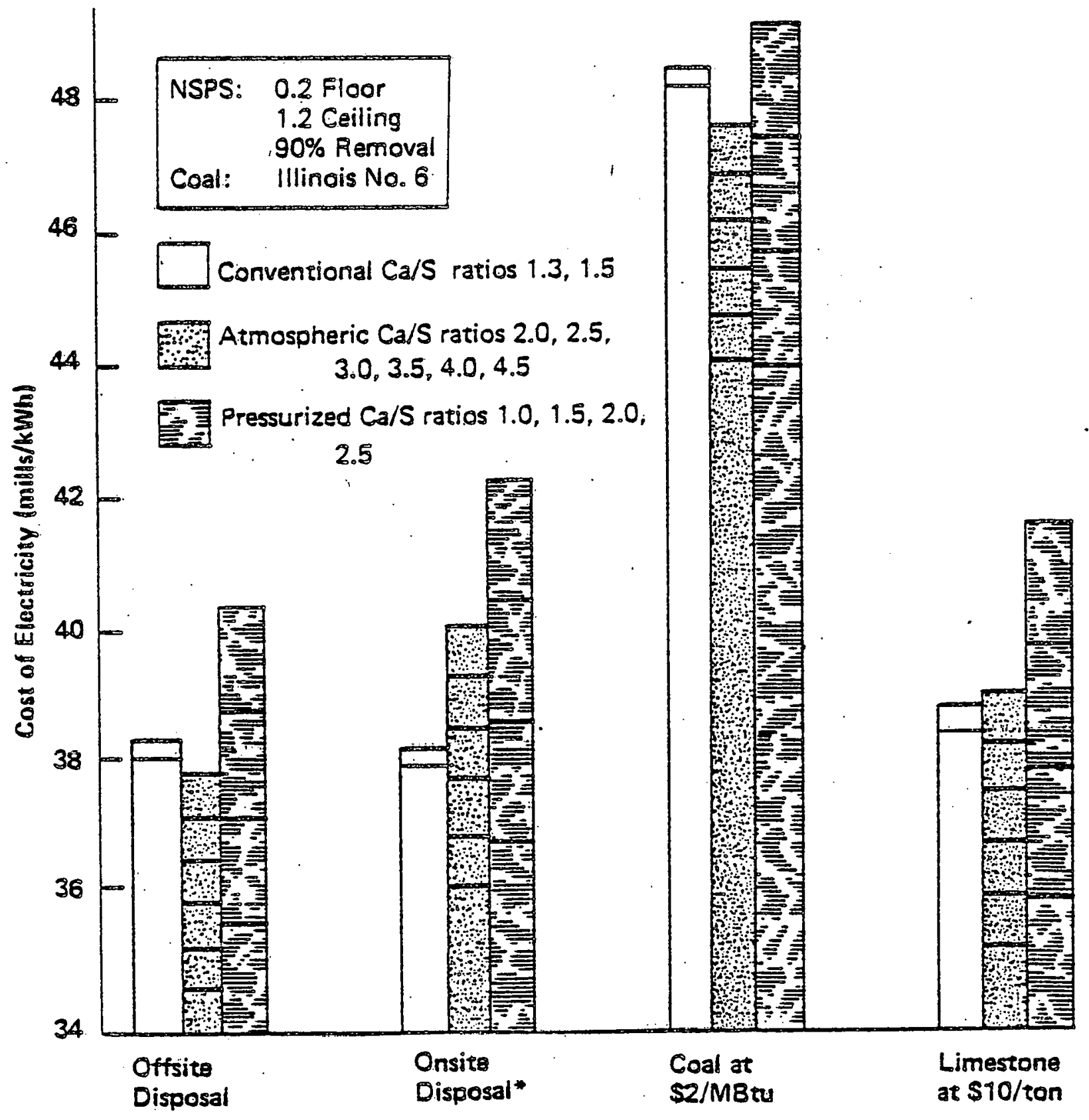

Figure 1-6. Sensitivity of costs to changing assumptions for conventional and fluidized-bed systems with base case coal.

- Most expensive alternative for FBC 


\subsection{Princioal Policy Findings}

\subsubsection{Regulatory Options}

Regulating emerging technologies is fraught with many problems-inadequate or; at best, limited data; arguments about adequacy of demonstrated capability; conflicts among multiple project objectives (energy efficiency vs. emission levels). Focusing on fluidized-bed systems not only as a good example of an emerging technology but also in terms of a real, near-term problem in the current NSPS revisions, a set of four regulatory options was examined. The appropriateness, technology-forcing nature, and potential impact on FBC development of each was. analyzed. The options and several salient points of each are summarized in Table 1-2.

Option A (setting a NSPS applicable to FBC on the same basis as conventional systems) raises questions of the adequacy of demonstrated FBC capability, but note that there appear to be no fundamental technical grounds for FBC systems not to meet the same stringency of sulfur and particulate removals being considered for conventional systems, although, perhaps, not at a competitive cost.

Option $B$ is not very different from option A except that the ERA would announce, in advance, its intention to grant an innovative technology waiver. Restrictions to granting waivers written into the 1977 Clean Air Act Amendments may limit the usefulness of this approach. The waiver cannot be used to forgive environmental performance in order to achieve other technical objectives. It seems an appropriate vehicle in the case of an AFBC demonstration profect, as such a system is projected to be able to meet or exceed the performance capabilities of current conventional systems. 


\section{Option}

Degree of

Technology

Forcing

\section{Conments}

A. Set NSPS based on conventional system performance, apply to FBC demonstrations

B. Set NSPS, give advance notfce of intention to waive requirements for demonstration plants.

C. Exclude FBCs in current revisions

D. Set separate standard for FBC demonstration projects
High

Developers may become discouraged and shut down or delay programs; given the apparent advantages of FBC and apparent ability to meet ISPS at all levels being considered, this is an unlikely consequence; advances in the stateof-the-art for conventional and FBC systems will create pressure for further revisions of the ISPS.

High* Restrictions limit use of the waiver, for emerging energy technology projects, can provide only limited relief in multi-objective projects; cannot permit easing standards or excusing compliance in order to meet general project goals-reliability, efficiency, etc.; waiver process complex and requires state as well as EPA approval; not substantially different, even with advance rotice, from option A.

Low Provides substantial (perhaps excessive) rellef from enyironmental constraints during development. Maximum flexibility in dealing with trade-offs on mult-objec- . tive projects (FBC demonstrations, for example) between air emissions and energy, economic and other environmental benefits; requires very close llaison with EPA; step toward separate standard at next stage.

Moderate
Treat demonstration of emerging technologies on caseby-case basis: could lead to separate standard for commercial FBC; accommodate trade-offs as above.

*Waiver cannot be granted unless system promises at least as great a degree of continuous emission reduction as is currently aval table through demonstrated technology. 
Excluding, by an appropriate mechanism, FBC systems in the current. round of NSPS revisions is the next option. It provides maximum flexibility to the developer but least adherence to environmental technology-forcing goals. External means of introducing sufficient environmental control objectives would be required.

The last option, to set a separate standard now for FBC demonstration plants, strikes a balance between the tougher options ( $A$ and $B$ ) and the one least protective of the environment $(C)$. A number of legal questions concerning the feasibility of this option must be answered. "This and option $C$ provide opportunities to gather a broader data base during demonstration on which a more definitive standard can be set in the future.

One point, not made explicitly in the main body of the report, is the contradictory nature of NSPS for the demonstration phase of FBC development vis-a-vis the commercial phase. As the standards that the demonstration project must meet become more stringent and are truly technology-forcing, the opposition of the developers becomes more vocal and the prospects'for systems competing with existing technology may dim. Real technical problems in meeting combined environmental and principal energy technology goals at this stage become more difficult. The cost of demonstration may increase. Cancellation or delay of programs may cause potential economic or environmental benefits derived from the overall system (including non-air pollution aspects) to be foregone.

On the other hand, looking ahead toward ultimate commercialization of FBC technology, particularly atmospheric fluidized beds, the competitive advantages of FBC systems appears to increase with the stringency of standards (see 
Figure $1-3$ and discussion above). Future developments in convertional systems and actual experience in FBC development (in contrast to projections) may change this conclusion, but, given that estimated trend, tough standards should promote the ultimate commercialization of FBC systems. The absolute costs of control will be high in both systems and other technologies may become competitive, but then that is the intent of the NSPS process.

\subsubsection{Benefits}

The social benefits. (disbenefits) associated with fluidized-bed combustion systems selative to conventional systems with scrubbers flow from the relative technical advantages (disadvantages) of the systems. Table 1-3 presents a sumary of the principal technical characteristics of the two technologies, rating the FBC characteristic relative to conventional technology.

Based on this set of technical factors (and others of less importance), a set of potential social benefits was identified and analyzed. No quantitative estimate of total benefits was made. Table $1-1$ above includes comparative costs, land requirements, annual $\mathrm{SO}_{2}$ emissions for an example 800 MWe plant. No aggregation of such data on a national level was made.

Table 1-4 summarizes the social benefits examined. Based on the many assumptions about future FBC design and performance made throughout the study, the table shows positive benefits for FBC for almost every category. The realization of these benefits depends, however, on the achievement of real performance consistent with the assumptions. 
TABLE I-3

IMPORTANT TECHNICAL CHARACTERISTICS OF FLUIDIZED-BED COMBUSTORS RELATIVE TO CONVENTIONAL COAL BOILERS WITH SCRUBBERS

\begin{tabular}{|c|c|c|c|}
\hline \multirow{2}{*}{ Characteristics } & \multicolumn{2}{|c|}{---Relative Rating--- } & \multirow[b]{2}{*}{ Conments } \\
\hline & $A F B C$ & PFBC & \\
\hline Cost of Electricity & Lower & See Comments & $\begin{array}{l}\text { PFBC costs range from higher to lower } \\
\text { as function of } \mathrm{Ca} / \mathrm{s} \text { ratio and coal type; }\end{array}$ \\
\hline System Rèliability & lligher & Unknown & $\begin{array}{l}\text { Conventional systens now lfmited by } \\
\text { current scrubber technology, improved } \\
\text { scrubber availability may offset cur- } \\
\text { rently projected difference; }\end{array}$ \\
\hline Fuel flexibility & Gieater & Greater & $\begin{array}{l}\text { FBC can burn almost all fuels, in- } \\
\text { cluding gas or oil, wastes and others; } \\
\text { turbine constraints could limit use } \\
\text { of high ash fuels for PFBC's; }\end{array}$ \\
\hline $\begin{array}{l}\text { Thermal (Cycle) } \\
\text { Efficiency }\end{array}$ & $\begin{array}{l}\text { ligher } \\
(4-8 \%)\end{array}$ & $\begin{array}{l}\text { Higher } \\
(15-21 \%)\end{array}$ & $\begin{array}{l}\text { Advanced scrubbers not needing reheat } \\
\text { could el iminate advantage relative to } \\
\text { AFBC; }\end{array}$ \\
\hline${ }^{N O_{x}}$ Finissions & Lower & Lower & $\begin{array}{l}\text { Improvenients in conventional systems } \\
\text { from current R\&D on low } N 0_{x} \text { burners } \\
\text { could reduce or eliminate advantage; } \\
\text { ellissions from full-scale AFBC witl } \\
\text { carbon burnout cell could approach } \\
\text { that of conventional system; no data } \\
\text { presently available; }\end{array}$ \\
\hline $\begin{array}{l}\text { Solidd Waste Quantity } \\
\text { (Ory) }\end{array}$ & Greater & Greater & \\
\hline
\end{tabular}


TABLE $1-3$ (COHT.)

\begin{tabular}{|c|c|c|c|}
\hline \multirow{2}{*}{ Characteristics } & \multicolumn{2}{|c|}{--.-Relative Rating--- } & \multirow[b]{2}{*}{ Conunents } \\
\hline & AFBC & PFBC & \\
\hline Solid Waste quality & Better & Better & $\begin{array}{l}\text { Dry output easter to dispose of than } \\
\text { slurry; adyanced dry or regenerable } \\
\text { scrubber systems could reverse } \\
\text { advantage. }\end{array}$ \\
\hline
\end{tabular}


TABLE $1-4$

POTEMTIAL SOCIAL BENEFITS OF FLUIDIZED BEDS RELATIVE TO CONVENTIONAL COAL DURNING PLANTS WITH SCRUBBERS

\begin{tabular}{|c|c|c|}
\hline Benefit. Type & Basis & Comments \\
\hline \multirow[t]{3}{*}{$\begin{array}{l}\text { 1. National Economic } \\
\text { Development } \\
\text { Efficiency }\end{array}$} & $\begin{array}{l}\text { Lower cost of electricity with } \\
\text { FBC increases consumer surplus-- } \\
\text { on a per plant basis }\end{array}$ & $\begin{array}{l}\text { Lower costs may not be passed through } \\
\text { due to regulatory lag--equity issues } \\
\text { involved; }\end{array}$ \\
\hline & $\begin{array}{l}\text { lligher reliability may lead to } \\
\text { speedy capture of market }\end{array}$ & $\begin{array}{l}\text { Temporal behavior of benefits impor- } \\
\text { tant from public investment point of } \\
\text { view }\end{array}$ \\
\hline & $\begin{array}{l}\text { Less systein redundancy due to } \\
\text { higher FBC reliability }\end{array}$ & $\begin{array}{l}\text { Operational rellability of full-scale } \\
\text { FBC's unknown }\end{array}$ \\
\hline \multicolumn{3}{|l|}{ 2. Envirommental } \\
\hline${ }^{110} x$ & $\begin{array}{l}\text { Lower } N 0 \text { ellisstons--continuous } \\
\text { better fđel flexibility }\end{array}$ & $\begin{array}{l}\text { Nay not maintain edge considering } \\
\text { research goals/program for low NO } \\
\text { "conventional" burners. May be } \\
\text { linited to selected fuels, e.g., lig- } \\
\text { nite }\end{array}$ \\
\hline $\mathrm{SO}_{2}$ & $\begin{array}{l}\text { Lower } \mathrm{SO}_{2} \text { emissions--annual } \\
\text { basis }\end{array}$ & $\begin{array}{l}\text { Bypass of scrubbers leads to standards } \\
\text { being exceeded }\end{array}$ \\
\hline Toxics in TSP & $\begin{array}{l}\text { Lower toxic components in } \\
\text { particular emissions }\end{array}$ & $\begin{array}{l}\text { Conjectural--linitted data--importance } \\
\text { unknown }\end{array}$ \\
\hline
\end{tabular}


TABLE - -4 (CONT.)

\begin{tabular}{|c|c|c|}
\hline Benefit Type & Basis & Comments \\
\hline \multicolumn{3}{|l|}{ 2. Environmental (cont.) } \\
\hline $\operatorname{TSB}$ & About even $\mathrm{rSP}$ & 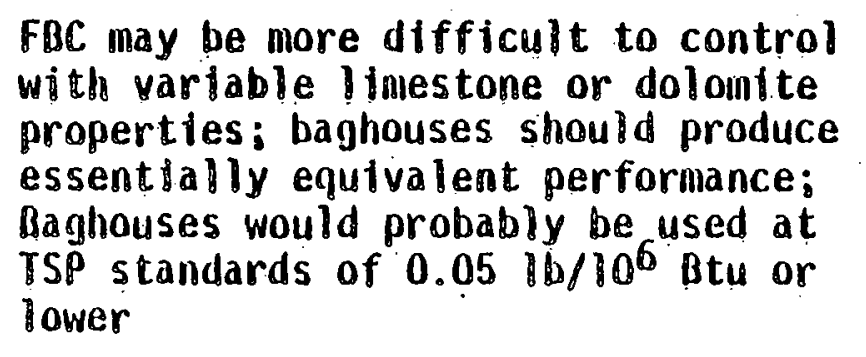 \\
\hline $\begin{array}{l}\text { Total Atmospheric } \\
\text { Euitssions }\end{array}$ & $\begin{array}{l}\text { Less overall atmospheric emis- } \\
\text { stons/kth; Higher energy } \\
\text { efficlency }\end{array}$ & $\begin{array}{l}\text { Scrubbers not requiring reheat could } \\
\text { essentfaliy eliminate advantage of } \\
\text { FBC }\end{array}$ \\
\hline $\begin{array}{l}\text { Solid Waste } \\
\text { Output }\end{array}$ & $\begin{array}{l}\text { Higher quantity dry solids; } \\
\text { Dry (FBC) vs. slurry (FGO) } \\
\text { Smaller land area--landf } 1 \text { I! } \\
\text { (FBC) vs. ponding (FGD) }\end{array}$ & $\begin{array}{l}\text { Future scrubber developments may } \\
\text { el iminate slurry output; fixation } \\
\text { makes land use difference disappear }\end{array}$ \\
\hline $\begin{array}{l}\text { Occupational } \\
\text { ltealth }\end{array}$ & $\begin{array}{l}\text { Less coal mining transporting } \\
\text { injuries/deaths: } \\
\text { lligher energy efficiency }\end{array}$ & $\begin{array}{l}\text { Advanced scrubbers could essentially } \\
\text { eliminate advantage of AFBC }\end{array}$ \\
\hline \multicolumn{3}{|l|}{ 3. other } \\
\hline $\begin{array}{l}\text { Dependence on } \\
0 \text { il/Gas }\end{array}$ & $\begin{array}{l}\text { Reduce dependence by accele- } \\
\text { rating coal conversion process }\end{array}$ & $\begin{array}{l}\text { More advantageous operating charac- } \\
\text { teristics of FBC Ireliability, dry) } \\
\text { may overcome reluctance to shift from } \\
\text { oil/gas in industrial MFBI cases }\end{array}$ \\
\hline
\end{tabular}


TABLE 1-4 (CONT.)

Benefit Type

Basis

Comments

3. Other (cont.)

Total Enviranmental/0ccupa-

tional Effects

Extended Life

for Coal Reserves

Increase total inpact due to acceleration of coal conversion process

$011 /$ gas use is less environmentally and occupationally danaging

lligher energy efficiency

Shorten Limestone/ Dolomite Reserves

Utilize "Waste"

Energy Sources

\section{Larger $\mathrm{Ca} / \mathrm{S}$ ratio}

Fuel flexibility of FBC's
$\mathrm{CO}_{2}$ emisstions from coal greater than from oil/gas per kWhi Much greater TSP and solid waste

May be. positive or negative depending on future value of coal as energy source or hydrocarbon feedstock 


\section{$1.3 .3 \quad$ R\&D Needs}

In order to assure adequate attention to environmental. objectives and to satisfy the technology-forcing intent of the Clean Air Act, EPA may, under several of the regulatory options, seek to influence the R\&D activities of technology developing groups. Several mechanisms (memoranda of understanding, for example) are available to accomplish this.

In particular, a number of technical areas involving the enviconmental control capabilities of FBC systems are enumerated and discussed. Table $1-5$ sumarizes this discussion. 
TABLE $1-5$

ENVIRONMENTAL OBJECTIVES FOR FBC R\&D PROGRAM

\section{Design Studies}

Alternative system designs - cost and performance analys is

$\left.\begin{array}{l}\text { Low fluidization velocity } \\ \text { Deep beds. }\end{array}\right\}$ Longer gas dwell time

Fly ash reinjection vs. carbon burnup cell

$\mathrm{NO}_{x}$ formation model-scale up

$\mathrm{SO}_{2}$ capture models

Regenerative systen studies

Experimental Studies

$\mathrm{SO}_{2}$ Capture

Reactivity characterization of limestones/dolomites

$\mathrm{SO}_{2}$ capture kinetic model development

$\mathrm{SO}_{2}$ release in carbon burnout cell

$\mathrm{Ca} / \mathrm{S}$ ratio for $90-95$ percent removal as function of coal, stone, operating conditions

Behavior at partial load conditions

Use of limestone in PFBC

Sorbent regeneration studies

Particulate

Particulate load and size distribution as function of stone, operating conditions

Fly ash characterization before and after carbon burnup . $\operatorname{cs} 11$

$$
\begin{aligned}
& \text { ESP - resistivity; composition, size } \\
& \text { Filter - hygroscopicity, abrasiveness, electric } \\
& \text { properties }
\end{aligned}
$$

Characterize stone friability, etc. 
TABLE $1-5$ (cont.)

Experimental Studies (cont.)

Behavior at partial load conditions

Loss of eyclone efficiency

Organic composition of f7y ash - PNAs, ete.

Toxie metal composition

NO $x$

Effect of carbon burnup cell (temperature/dwell time)

Effect of $\mathrm{Ca} / \mathrm{S}$ ratio on $\mathrm{NO}_{x}$ formation

Behavior at partial load conditions

Solid Naste.

Leachability

Composition 


\section{THIS PAGE \\ WAS INTENTIONALLY \\ LEFT BLANK}


CHAPTER TWO

OVERVIEW: THE PROS AND CONS OF

UTIIITY-SIZED FIUIDIZED-BED COMBUSTORS

\subsection{Introduction}

Under the Clean Air Act Amendments of 1977 (PI 95-95), the U.S. Environmental Protection Agency. (EPA) has the responsibility to develop revised. New Source Performance Standards (NSPS) for fossil-fuel-fired steam generators with heat input rates of $250 \mathrm{MMBtu} / \mathrm{hr}$ or greater. Revised $\mathrm{NSPS}$ for $\mathrm{SO}_{2}, \mathrm{NO}_{X}$, and particulate emissions are to be proposed early in 1978 and. promulgated by fall, 1978. The overall objective of this study is to evaluate the policy implications of applying the revised NSPS to coal-fired fluidized-bed combustion (FBC) technology.

FBC systems may be described in terms of the location of the heat transfer surfaces in the combustor and the bed operating pressure. There are three basic systems: (1) atmospheric pressure, tubes in the bed, $15-25$ percent excess air; (2) pressurized combustion (6-10 atm), tubes in the bed, 15-25 percent excess air; and (3) adiabatic pressurized combustion, no tubes in bed, 300 percent excess air. In the pressurized, low excess air case, either air or water can be employed as the working fluid in the tubes.

Research into the development of fluidized-bed coal combustion technology for large industrial and utility applications has been ongoing in the United States (and England) since the 1950's. The initial incentive for FBC development (in England where most early research was carried out) was the 
potential for combustor size reduction, based on higher heat transfer rates compared to conventional coal-fired boilers. Size reduction would diminish the cost disadvantage between coal and oil or gas-fired boilers. Additionally, lower combustion temperature and greater fuel flexibility were perceived as further advantages. Subsequent to enactment of the Clean Air Act in 1970, requiring significant reductions in sulfur emissions, the principal incentive for FBC research has been utilization of the excellent gas/solids contact in the fluidized bed to effect in situ absorption of gaseous sulfur compounds by using limestone (atmospheric) or dolomite (pressurized) as the bed material. R\&D and even commercial activities related to inert FBC systems continue outside of the United States.

First, the Office of Coal Research, then EPA, and subsequently the Energy Research and Development Administration, have been responsible for funding and directing the U.S. FBC development program. The largest atmospheric pressure fluidized-bed combustor ( $A F B C$ ) unit constructed to date is Pope, Evans, and Robbins' 30 MWe unit in Rivesville, West Virginia which has yet to achieve a stable level of operation. Limited data, available from a 45,000 pounds of steam per drum FBC installation at Renfrew, scotland indicate successful continuous removal of $\mathrm{SO}_{2}$ at about 90 percent efficiency.

Widespread commercialization of electric utility size units (500-1000 MWe) is not likely until the late $1980 \mathrm{~s}$. Construction prior to 1980 of one or more approximately 200 MWe demonstration plans is planned, currently as the next major stepping-stone in the commercialization of AFBC systems. Current EPA deliberations and decisions concerning NSPS for steam electric plants could affect these plants. Several 
smallex PFBCs (0.5-1.0 MWe) have been constructed both in America and abroad, and U.S. Government research timetables indicate the late 1980 s for a demonstration PFBC unit. Industrial and utility interest in AFBC technology is high, primarily because of expected economic, environmental, and operational advantages relative to conventional combustion technology. These potential advantages, as well as some possible disadvantages, are briefly outlined below to introduce the principal areas of uncertainty associated with FBC cost and performance.

\subsection{Overview of FBC Pros and Cons}

Fluidized-bed combustion systems operate on the simple principle that if a gas is forced upwards through a bed of particles in a confined space, then eventually a point will be reached at which the total upward drag force equals the total weight of particulates. At this point movement of the particles is free and the bed behaves like a heavy fluid. Increasing the gas velocity further results first in expansion of the bed and then in formation of "bubbles" of fluid, creating the illusion of a cauldron of boiling liquid. The turbulence of the fluidized bed affords intense mixing of gaseous and solid constituents, which results in heat release and heat transfer characteristics significantly improved over conventional combustors. 1

The primary implications of enhanced combustion characteristics are that combustor capital costs will be lowered since boiler volume, steam tubing, and structural support requirements are reduced, and that plant construction time will be shortened, and associated interest costs reduced, as a result of factory-assembled, modular construction designs. 
In addition, coal handing costs may be reduced since coarsely pulverized coal can be used in a fluidized bed, eliminating the need for fine grinding.

A widely claimed advantage for FBC over conventional systems is fuel flexibility; i.e., the ability to burn coals of varying sulfur, ash, and heat content without significant boiler modifications and derating.

Two types of additional cost advantages claimed for FBC are derived from the fact that optimum FBC operating temperatures are in the $1500-1600^{\circ} \mathrm{F}$ range. (By comparison, conventional pulverized coal boilers are typically operated in the 2000-2600 $\mathrm{F}$ range.) First, operating and maintenance costs may be reduced since corrosion and fouling of boiler tubes is lessened. This results because the lower temperatures inhibit ash slag and clinker formation, and sharply decrease the volatilization of highly corrosive alkali salts and trace metals. (This corrosion and fouling reduction has a secondary beneficial effect in that overall efficiency is improved. ${ }^{2}$ ) Second, nitric oxide $\left(\mathrm{NO}_{x}\right.$ ) emissions appear to be intrinsically lower than that generated in conventional systems. Solid waste handing and disposal costs may be reduced since FBC waste is a dry solid composed of fly ash and spent sorbent. In contrast, conventional systems employing flue gas desulfurization (FGD) for $\mathrm{SO}_{2}$ emission control produce waste material composed of ash and FGD sludge (40-50 percent solids). Although the total weight of solid waste produced by $F B C$ and conventional systems with FGD are of the same order of magnitude, the land requirements for landfiling FBC waste are potentially much less than those for disposing of FGD wastes in lined ponds. 
From an environmental standpoint, FBC systems appear to offer a variety of advantages relative to conventional systems. In terms of solid waste disposal, the ability to landfill EBC wastes represents reduced land impacts. However, sufficient data on EBC waste leachate characteristics have not yet been gathered.

Another important advantage of the fluidized-bed combustion process is the ability to effect in situ $\mathrm{SO}_{2}$ emission control by using a sulfur absorber (limestone or dolomite) as the basic bed material. Many factors affect the retention of sulfur by the sorbent, including bed temperature sorbent reactivity, gas/solids contact dynamics, and the amounts of calcium and sulfur present. $\mathrm{SO}_{2}$ emission reductions of $85-$ 9.0 percent for $\mathrm{Ca} / \mathrm{S}$ molar ratio of $3.0-4.0$ (AFBC) and 2.0-3.0 ( $P F B C$ ) have been reported from a variety of experimental programs. These high retention results must be viewed cautiously in terms of extrapolation to large-scale systems. Also, little experimental work has been done to examine $\mathrm{SO}_{2}$ control characteristics when low sulfur coals are used. ${ }^{3}$

The amount of sorbent material required to achieve a given level of sulfur reduction is difficult to specify and, consequently, there is much uncertainty in the sizing and costing of fluidized-bed systems. Primary determinants are sorbent characteristics and bed fluid dynamics. At present, little is known about sorbent reactivity, a complex parameter determined by such factors as the sorbent source (or type), particle sizes, localized bed temperatures, sorbent residence time, and sorbent attrition and decrepitation characteristics. similarly, there are little data on the gas/solids contact characteristics for FBCs. This makes it very difficult to predict the size of a fluidized bed, the bed depth, the necessafy $\mathrm{Ca} / \mathrm{S}$ ratio, the fan size, and, as a result, the actual net power output and electricity cost for a given size unit. 
The sulfur capture feature of FBC provides an alternative to the use of FGD systems to meet $\mathrm{SO}_{2}$ emission standards. Given the intrinsic sulfur capture mechanism, FBC plant operational reliability will not be dependent on tail-end FGD system reliability. Furthermore, internal energy loss in the FBC plant is reduced relative to the conventional system primarily since plume reheat is not needed. Plume reheat requires about 2-4 percent of output. FBCs are projected to be able to achieve higher overall coal pile-to-busbar efficiencies (32-34 percent for conventional systems with FGD, 36 or more percent for $A \overline{B C}, 39$ or more percent for $\mathrm{PFBC}$ ).

Emission of $\mathrm{NO}_{\mathrm{x}}$ from fluidized-bed combustors has been shown in most small-scale experiments to be less than those from conventional combustors. However, the implications of large-scale fluidized beds in terms of No ${ }_{x}$ emissions are unknown. Furthermore, the factors controlling $\mathrm{NO}_{x}$ emission in coal combustion processes are not fully understood. It is known that the lower FBC operating temperatures reduce the thermal fixation of nitrogen in the combustion air, and so the principal source of No $_{x}$ emission is the fuel-bound nitrogen. Several factors have been shown experimentally to influence the conversion rate of fuel nitrogen to $\mathrm{NO}_{x}$ including maximum bed temperature, the location and extent of reducing zones within the combustor, sorbent type (i.e., reactivity), molar ratio $\mathrm{Ca} / \mathrm{S}$, and gas residence time.

For PEBCs, the few data that are available through bench and pilot scale experiments indicate that existing and proposed $\mathrm{NO}_{\mathrm{x}}$ emission standards will be achievable. However, there is clearly a paucity of empirical data characterizing the FBC system variables that could cause high NO $x$ emission levels. In conventional combustors, No $\mathrm{N}_{\mathrm{x}}$ emissions have been observed to increase with unit size, but this "scale-up" effect 
on NO $x$ emissions in FBCs is now an unknown. Overall, relative to present conventional combustor systems., FBC systems should be able to achieve significantly lower $\mathrm{NO}_{x}$ emission levels.

Particulate emission from a fluidized-bed combustor is composed of coal ash, unburned coal particles, unreacted sorbent particles, and fine sorbent particles formed by decrepitation during calcination/sulfation and by attrition in the bed. At this time, there are little data available on the physical, chemical, size distribution, and mass loading characteristics of FBC particulate emissions. It is generally conceded, however, that the uncontrolled AFBC particulate emission will be 2 to 5 . times the level for conventional pulverized-coal fired boilers. Furthermore, the effectiveness of electrostatic precipitators for AFBC particulate control has not been demonstrated, and the design of precipitators and baghouses for AFBCs is hampered by the lack of data on particulate properties.

For PFBCs, the prevention of turbine blade erosion requires very high particulate removal efficiencies ( 99.9 percent in current U.S. plans) under conditions of high temperature and high pressure. Cyclone collectors, the only proven technology for that set of conditions, cannot provide the degree of removal needed, even in two-stage installations. Research on hot gas cleanup particulate control systems has been initiated but feasibility has not yet been demonstrated. Hot gas particulate cleanup is a critical objective in U.S. programs for the development of PFBCs. ${ }^{3}$

The design (and cost) of FBCs is dominated by three factors (although other engineering considerations are involved with lesser impact and cost): bed height, superficial gas velocity through the bed and calcium-to-sulfur ratio. 
Increasing the velocity, within the allowable range set by fluidizing and combustion constraints, lowers the necessary bed cross section and would lead to a smaller (and cheaper) installation. Fan power, a much larger requirement in FBC systems compared to conventional pulverized coal boilers varies directly with bed height, independent of gas velocity. Gas contact (or residence) time, the parameter which governs the rates of both combustion and sulfur removal, is directly proportional to bed height and inversely proportional to gas velocity. Sufficient residence must be provided to achieve the desired level of sulfur capture which is the limiting reaction as the combustion process occurs much more quickly than the $\mathrm{SO}_{2}$ capture process.

The rate of sulfur capture depends not only on the contact time, but on the amount of unreacted sorbent in the bed, and on the reactivity of that sorbent. For a given sorbent, the amount of unreacted material in the bed depends directly on the rate at which sorbent is added, higher sorbent feeds leading to higher sulfur capture. This is equivalent to stating that, for a given coal feed rate, sulfur capture increases with increasing calcium-to-sulfur ratios, although this relationship is quite complex and non-linear.

To control combustor size and cost in AFBC systems, gas velocities have been set in the range of 10-15 feet per second in both real experimental systems, including the Rivesvilie pilot plant and also in most design studies. In this velocity range, there is substantial carry over of unburned carbon, 10-15 percent of total carbon in the gases leaving the top of the bed. To be competitive with conventional systems this carbon must be recovered and burned. Two approaches to accomplish this have been considered, (1) fly ash reinjection and (2) subsequent combustion in a separate carbon burnout cell ( $C B C$ ). At this high range of velocities, fly ash 
reinjection appears ineffective. The carbon burnout cell is designed to operate at lower gas velocities, higher excess air, and higher temperatures $\left(1800-2000^{\circ} \mathrm{F}\right)$, are of which conditions promote the combustion reactions. At these higher operating temperatures, the inherent FBC advantage of low No emission is diminished and the release of captured $\mathrm{SO}_{2}$ appears possible if excess air conditions are not carefully controlled.

A second consequence of high fluidization velocities is a requirement for relatively high Ca/s ratios to achieve high levels (about 90 percent) of sulfur removal. The operating cost of sorbent under these conditions tends to offset the capital cost savings gained by designing for high velocities. High $\mathrm{Ca} / \mathrm{S}$ ratio also lead to increased particulate loadings due to sorbent elutriation, attrition, and decrepitation.

Other destgn approaches, based on lower fluidization velocity, are possible, and, considering the costs of meeting standards requiring high sulfur removal peicentage, are likely to offer overall economies balancing operating costs versus capital costs. Little attention has been paid to such alternatives in the united State, up to now.

The pressurized $F B C$ is quite different in this respect. In the primary PFBC modules, fluidizing velocities are typically in the range of 2-8 feet per second; the pressurization results in bigher gas densities, which allow the lower velocities. At the lower fluidizing velocities, carbon utilization is improved to the point where it is believed that collected carbon fines can be recycled to the primary combustors to achieve the needed carbon burnup. 
With respect to emission of trace elements, fluidizedbed combustors are expected to represent an improvement relative to conventional combustors. The reason is the lower combustion temperatures characteristic of FBC. It should be recognized, however, that the trace elements present in coal, while not vaporized, are present in the solid waste stream. Thus, trace element leaching is a potential. FBC environmental hazard that has not yet been adequately examined.

One of the most troublesome problems of large-scale FBC design and operation is coal feeding. To control bed combustion characteristics, coal (and sorbent) feeding must occur at uniform rates across the entire bed. Early experience at the Rivesville 30 MWe pilot facility (15 tons per hour coal input to three $14^{\prime} \times 12^{\prime}$ bed modules), which was designed to feed coal via a series of in-bed pipes spaced evenly across the bed, has been discouraging at best. This problem has precluded operation of the facility for any extended periods of time. Coal and sorbent feeding may be even more difficult in the case of pressurized FBCs.

In summary, FBC systems have the potential of offering. a number of operational, environmental and economic advantages over conventional systems with FGD. FBC design, operation, environmental performance, and cost features are highly interdependent. The current state of knowledge regarding that interdependence is not sufficient to select optimum approaches to achieve cost-effective performance constrained to meet stringent environmental performance standards, or even to estimate costs, operating data, etc. with high precision. 


\section{REFERENCES TO CHAPTER TWO}

IElliott, D.E., and M.J. Virr, "Small-Scale Applications of Fluidized-Bed Combustion and Heat Transfer," Proceedings of 3rd International Conference on Fluidized-Bed Combustion, EPA 65072-73-053 (December 1973).

2"Fluidized-Bed Combustion: Full steam!" Environmental Science and Technology, Volume 10 (February 1976): 120-121.

${ }^{3}$ Gilbert Associates, Inc., and MITRE Corporation/METREK Division, Technical Document on Applying Tentative New Source Performance Standards fOr Coal-Fired Steam Generators to Fluidized-Bed Combustors, DOE draft (November 1977).

${ }^{4}$ Babcock and Wilcox Company, Summary Evaluation of Atmospheric Fluidized Bed Combustion Applied to Electric Utility Large Steam Generators, Volumes I and II, EPRI (October, 1976). 


\section{THIS PAGE}

\section{WAS INTENTIONALLY \\ LEFT BLANK}


CHAPTER THREE

TECHNICAI CONSEQUENCES OF NEW

SOURCE PERFORMANCE STANDARD ALTERNATIVES

\subsection{Introduction:}

This chapter develops estimates of the effects of setting. New Source Performance Standards (NSPS) of varying degrees of stringency on the operating characteristics of coal-fired. fluidized-bed steam-electric plants. Conventional coal-fired plants equipped with scrubbers are analyzed similarly as a basis for comparison. The NSPS scenarios considered reflect the new mandates set down in the extensive set of Clean Air Act Amendments passed by the 95 th Congress (PI 95-95). The principal feature of the new regulatory approach is the inclusion of a percent removal requirement.

NSPS for coal-fired utility plants will contain, based on plans at the time of this study, provisions specifying a continuous removal percent, a ceiling (that is, maximum allowable emission limit), and (for $\mathrm{SO}_{2}$ ) a floor (that is, a lower emission level which does not have to be surpassed thereby reducing the percentage removal requirements for low sulfur fuels). In addition, the averaging time over which compliance with these provisions is to be determined will be specified. Different averaging times ranging upwards from three hours are under consideration. Different times may be specified for each of the above provisions. Another aspect of the NSPS also considered here is the malfunction policy, which determines how system unceliability and randomness in operation will affect design and operational procedures. Possible consecuences of 
different policies for crediting sulfur retention in ash were considered, but not in detail.

Other aspects of the NSPS such as requirements for continuous monitoring, applicability, etc., are not considered in this analysis.

The analysis that follows. first examines the effects of different NSPS scenarios on the engineering aspects or design of FBC and conventional systems, then turns to a detailed look at costs of electricity, and concludes. with. a discussion of environmental and resource consequences.

\subsection{Engineering Considerations}

\subsubsection{Sulfur Dioxide Aspects}

\section{Temporal and General Effects}

The operational consequences of setting a New Source Performance standard for sulfur dioxide arise from four parts of the standard as it is proposed to be developed. These are (1) the percent continuous reduction required, (2) the floor value, (3) the averaging time over which the standard is to be measured, and (4) the malfunction policy. The ceiling value (maximum emission limitation) plays essentially no part in establishing system performance required to comply with the standard, except for coal of very high sulfur content. Before considering the consequences of different standards for both fluidized-bed systems and conventional systems with scrubbers, it is interesting to note that these features interact in different manners depending on the type 
of coal. Figure 3-1 shows the actual degree of sulfur removal which would be required in an operating system versus the amount of sulfur which would be emitted in an uncontrolled system for various cases of floor values and percent reductions. Figure 3-2 relates this to coal type by displaying values of uncontrolled sulfur emissions as a function of sulfur percentage of coal, heating value, and percentage of sulfur retained in the ash.

- .....For floor values less than 0.4 lb $\mathrm{SO}_{2} /$ million Btu the specified percentage removal will be the binding constraint for coals of about 3 percent sulfur and higher. Stated alternatively, high sulfur coals, that is, coals of 3 percent: sulfur or greater, will require the full percentage removal as specified in the standard because even after removing that much sulfur, the emissions will still be above the floor value. Therefore, for high sulfur coals which account for the majority of the reserves in the East, particularly in IIIinois and Ohio, setting the floor value is of little consequence and the critical aspect of the standard to examine is the percentage reduction. However, at a floor of about $0.6 \mathrm{lb} /$ milion Btu, the constraint passes to the floor value from the percent reduction even within the high sulfur coal range.

At the other extreme, that is, for low sulfur coals, the converse, in general, applies. For uncontrolled emissions less than about 3.0 ib $\mathrm{so}_{2} /$ million Btu, the design percent reduction required in the system is determined by the floor and not by the percent reduction part of the standard itself. Thus, for these low sulfur coals, in almost every case, less percent reduction is required in practice than is specified by the standard. At the very lowest value being considered 


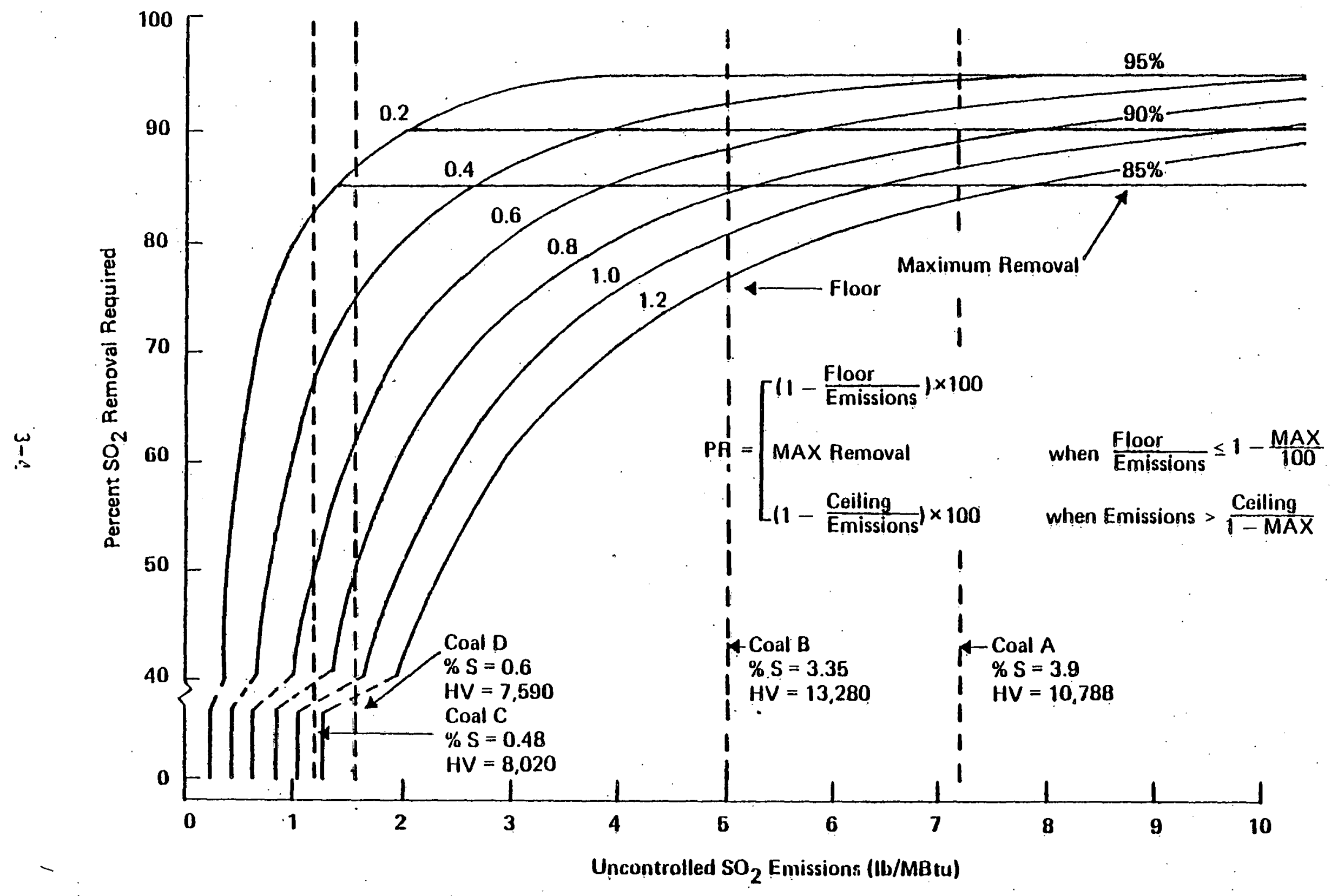

Figure 3-1. $\mathrm{SO}_{2}$ removal requirements as a function of NSPS stipulations and $\mathrm{SO}_{2}$.production. 


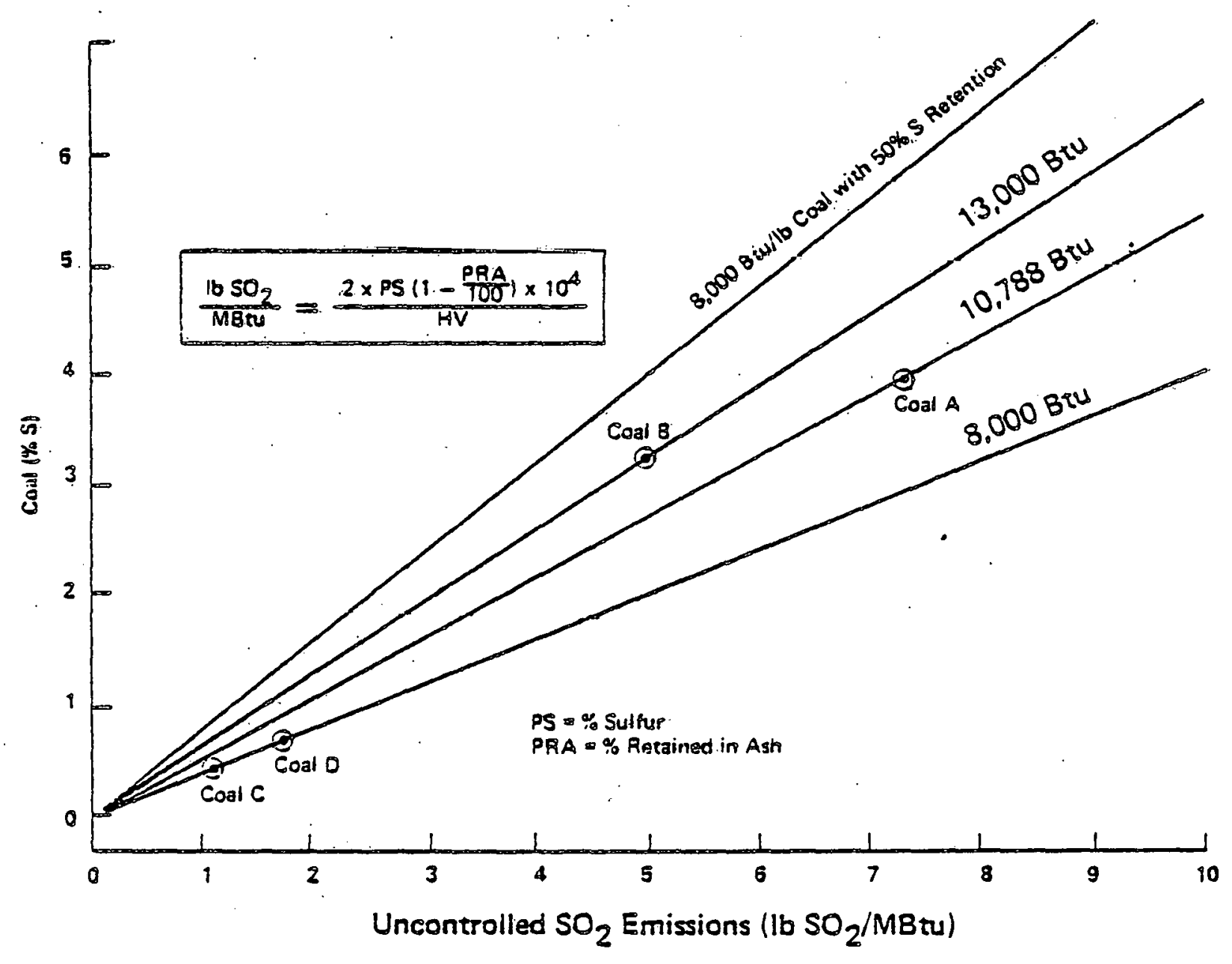

Figure $3-2$. $\mathrm{SO}_{2}$ production as a function of coal sulfur content and heating value. 
for the floor, that is, $0.2 \mathrm{lb} . \mathrm{SO}_{2} /$ million $\mathrm{Btu}$, the constraint depends on the sulfur content in the low sulfur range.

For much of the low sulfur resources of the country, that is, much of the lignite and low sulfur subbituminous (compliance) coals in the West, the critical aspect of the standard will be the value of the floor that is chosen, not the percent reduction.

For much of the intermediate sulfur coal which is found both in the East and West, the constraint depends on the specifics of the case. Iittle generalization can be made as above. Reference to Figures $3-1$ and $3-2$ would indicate which is the binding aspect of the standard for any given coal.

The situation as described above is complicated somewhat by the averaging time feature of the proposed standard. Averaging time affects a system in that the design specification for percent removal must be higher than that corresponding to the average sulfur content due to the variability of sulfur in coal (even from a single mine). Data obtained by the TVA indicate maximum deviations above the long-term mean value of the order of 30 to 50 percent on a three-hour basis for eastern coals. Others have reported greater variations (of perhaps as much as 100 percent) at the short averaging time for western coals. The deviation from the long-term mean value, of course, becomes smaller as the averaging time is increased. This behavior is illustrated in Figure 3-3.

Deviations from design specifications can arise from other causes as well. Reactivity of sorbent will vary in both FBC and FGD systems. The calcium content of stone varies within a mine in much the same way as in coal. There are 


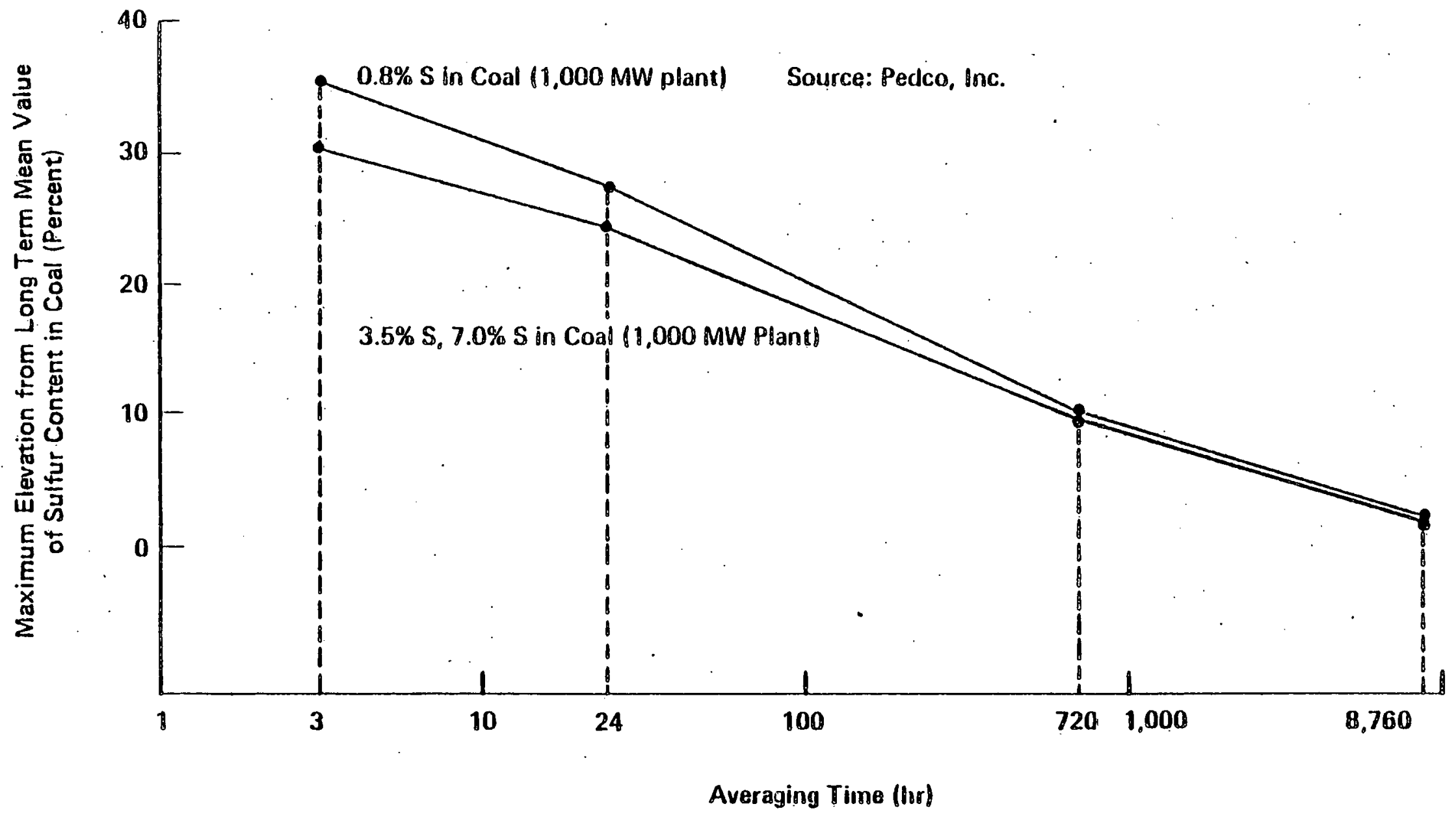

Figure 3-3. Sulfur content variations as a function of averaging time. 
little data available providing quantitative estimates of the degree of variability. Reactivity in an FBC depends on largely unknown characteristics of the stone and may show variations even for stone of relatively uniform calcium content.

FGD performance also shows highly variable results. I The causes of the variations are not always identifiable but include factors other than randomness in the coal or limestone.

The consequences of this feature of coal characteristics is that the system must be designed more stringently than the standard would indicate. The consequences of such overdesign are discussed in the general section on cost of electricity below. Given higher variability, overdesign requirements for western coals will be generally larger than for eastern coals. Thus, some of the advantages of using lower sulfur coal, that is, requiring less actual percent sulfur removal, may be diminished. On the other hand the high calcium content and alkaline nature of ash in western subbituminous and lignites may provide significant retention of sulfur in the ash and reduce requirements for sorbent.

Note that the requirements of a percent reduction, per se, will change the coal mining patterns drastically. The value of so-called compliance coal (western low sulfur subbituminous) will decrease and that of less costly-totransport, local high sulfur coal will increașe.

Maintaining low sulfur fuel reserves that could be used through substitutions for or blending with the normal coal feed to counterbalance higher-than-average emissions over part of the averaging time would be an 
alternative which could reduce the need for overdesign for compliance. Even this approach would be difficult to apply for very short averaging periods, certainly those on the order of several hours, as it takes a while to determine that the emissions will exceed the standard and to shift feed locations. The response time of the sulfur dioxide control systems on both fluidized-bed combustors and scrubbers is quite long. As a consequence, using a dynamic means of adjusting the level of control to accomodate excursions in sulfur percent in the coal fed to the system would be quite difficult.

Considerations of averaging time and malfunction policy (discussed below) may have to deal with a set of problems coupling the random nature of performance and component failure. Assume that for some reason a unit, either FGD or FBC, operates at less than the required percent removal for the first half of the average time perfod. Then, before corrective action can be taker - for example, $\mathrm{Ca} / \mathrm{S}$ ratio is increased or low sulfur coal is substituted-the system goes down for a non- $\mathrm{SO}_{2}$ system problem. EEI statistics show a mean time between all outages of about 480 hours. ${ }^{2}$ Given the random nature of forced outages, this occurrence is likely to happen at some time. If the outage persists over all or much of the remaining part of the averaging time period, it will be impossible for the plant to meet the standard.

Incorporating suffictent overdesign to avoid falling below the required percent reduction should eliminate even this possibility. The cost would be high, as shown below. Alternatively, the standard might be constructed around a statistical basis, permitting a small but finite number of excursions above the standard reflecting the random nature of system performance. Such an approach could reduce overdesign 
requirements and the cost thereby introduced. The longer the averaging time over which compliance is to be determined, the less effect coal variability or outages will have.

In any case, whether the floor value or the percent reduction part of the standard is controlling, the result in a coal-fired utility system will be the degree of sulfur removal designed into the system. With respect to this it is possible to state a number of general consequences relating to the relative stringency of the standard.. The next several paragraphs discuss both fluidized-bed systems. and conventional systems with scrubbers.

Effects of Magnitude of Percent Removal Reguirements

The combustion and sulfur removal processes in fluidizedbed systems are closely linked and depend on a complex set of relationships involving bed height, gas velocity, excess air, sorbent to coal feed rate (equivalent to $\mathrm{Ca} / \mathrm{S}$ molar ratio), bed temperature and several parameters of lesser importance. Designing to meet standards of increasing stringency affects the whole system design, unlike FGD systems where the scrubber can be designed more or less independently from the combustor.

Experience to date in the United States in a wide variety of laboratory and lesser pilot scale systems has shown that sulfur removal for fixed velocity and bed height depends strongly on Ca/s ratio. Most work in AFBC systems has been done at fairly high gas velocities (of the order of 10 feet per second), at which range combustion size (and cost) is minimized based on combustion rate considerations alone. On the other hand, these conditions lead to high limestone requirements, i.e., Ca/s ratios in excess of thrae or four. 
Although limited data exist at other conditions, it is possible to develop alternate FBC design by combining laboratory sorption data with models for bed behavior. Westinghouse Corporation, under a separate but coordinated study, applied such models to develop estimates of $\mathrm{Ca} / \mathrm{s}$ ratio for a system approaching an optimum with regard to the cost of electricity. ${ }^{3}$ Lower fluidization velocities were assumed, with the result that estimated $\mathrm{Ca} / \mathrm{S}$ ratio is considerably lower than that projected by extrapolation of existing experimental data.

In the development of cost estimates following, the Westinghouse projections were used in combination with a parametric analysis developed by ERCO to deal with the uncertainty characteristic of present understanding. The cost of electricity is quite sensitive to sorbent-to-coal ratio.

The consequences of using a higher calcium-to-sulfur ratio are quite straightforward. More sorbent is required per kWh produced, leading to a more expensive system in terms of capital requirements and in terms of operating costs. This aspect of standard setting is examined in considerable detail in later sections of this report with specific estimates of capital cost and electric costs as a function of the coal types, calcium-to-sulfur ratios, and other system parameters.

Fluidized-bed combustion system sulfur capture is very sensitive to the nature of the specific limestone or dolomite fed to the system. Data available to date show a large range in reactivity, over several orders of magnitude. Although limestone is available in essentially all parts of the united states and dolomite in many parts, that which is locally available is not always of high reactivity. In cases where local limestone is quite unreactive, the epparent advantage of fluidized beds relative to standard systems would be decreased. 
Malfunction and Reliability Considerations

The type of malfunction provision ultimately adopted by the EPA will most likely affect the commercial application of fluidized beds, vis-à-vis conventional systems with scrubbers. The consequence of this provision is not of particular concern in the research, development and demonstration phases. During these stages, malfunctions can be dealt with by shutdown without upsetting production schedules or affecting reliability of an electrical utility network. The discussion that follows is directed toward the effects on the use in a commercial sense.

There are two aspects of this provision to be considered.

1. The availability of the system or, in more customary utility terms, the expecter outage rate;

2. The probability of operating at less than the required percentage removal even when the FBC or scrubber systems are available and on stream.

Given an unforgiving malfunction policy, that is, the system must meet the standards all the time or shut down, except during start-up periods, there are several consequences as discussed below.

Fluidized-bed systems differ substantially from conventional boilers equipped with scrubbers in terms of the independence of the sulfur removal system from the rest of the system. The sulfur removal part of a fluidized-bed system is intimately linked to the combustion and steam raising components. In a conventional syster, however, the scrubber is more or less a completely independent component. Given the characteristics of a fluidized-bed system, it would be essentially impossible for the sulfur removal system to cease operation entirely without the combustion aspects also shutting down. It is possible, however, that the removal efficiency could drop below the level specified in the standard during more or 
less normal operations. This could be a consequence of a combination of coal with higher than average sulfur content matched up with a portion of the limestone supply containing stone of less than average reactivity.

In the case of the conventional system, the case is quite different. The scrubber, operating more or less independently from the boiler, can have malfunctions of various types without affecting the rest of the system. Such malfunctions have been a major problem in the development of scrubbers and would be expected to be a problem in the future as well.

A malfunction provision that would require the whole process or unit to shut down during periods of time that the sulfur removal components canrot meet the required removal over the averaging period would place a considerable premium on reliability. Reliability is a design constraint placed on utility systems by national policy such that the probability of having insufficient generating capacity to meet peak load conditions is essentially zero. A design probability of loss of load, that is, inadequate generating capacity, of one day in ten years is customarily used in designing large electric utility systems.

Given the coupling of sulfur removal and combustion in an FBC system; malfunctions in the sulfur removal components will force the system to shut down.. Thus, if the limestore handling, crushing, or feed system breaks down, power generation will cease. These elements are expected to be among the more unreliable in the system, although no estimates of the potential forced outage rate due to these elements can be developed at present. Large FBC systems, at least the first generations of units, will brobably be built on a modular concept, using 150-200 Mwe building blocks. The ECAS designs were based on a 200 WWe module. Malfunction in a single module would not require the entire unit to shut down but only to reduce the 
load to compensate for the lost module. In this regard modular FBC plants would be similar to modular scrubber systems as discussed below, except that no spares would be incorporated.

The boiler is already the least reliable element in a power plant, with a forced outage rate of 9.3 percent. Edison Electric Institute data indicate that over half of forced outages are due to failures in the boiler compared to failures in the turbine, condenser, generator, or other parts of the unit. ${ }^{2}$ Their data include all fossil units (oil, gas and coai). Given the less reliable character of coal-fired units, these data probably understate the outage rate for coal-fired boilers.

Outages attributable to the sulfur removal components in an FBC boiler will force the use of older, less efficient and probably poorer controlled units to pick up the power lost by shutting down the malfunctioning unit.

Fluidized-bed combustor units must ultimately achieve reliability levels at least as great as that. for existing systems in order to achieve significant penetration of the utility boiler market. If they can provide availability of the order of 85-90 percent (boiler availability in the EEI report was 82.2 percent), then that feature alone will probably be the major determinant in a utility's decision to install an FBC system, overshadowing even consideration of capital and operation cost, environmental effects., and energy efficiency.

Malfunctions in a scrubber system do not necessarily lead to the same consequences. Scrubbers are currently being designed and constructed in modular format with some four to seven modules used in an 800 MWe plant. A malfunction in a sinça 
module can be offset by bypassing the faulty module and utilizing a spare if it has been included and is available. In this case, the system can continue to operate at essentially full load while the fault is repaired. Note that in the cost analysis presented below provision for a spare was included.

Even if no spare module is available, the unit does not have to shut down completely; load can be reduced by whatever percent of scrubber capacity is unavailable (25 percent in a four-module setup and so on). Only if the entire scrubber system became inoperable would the unit have to shut down completely. Other units (older and less efficient as in the case of FBCs) would have to be brought on line to pick up the load aropped by the malfunctioning units.

Design availability of scrubbers, reflecting current practice, is 90 percent. In a system of four modules plus a spare, the overall scrubber availability would be about 91 percent. Thus, load would have to be reduced about 9 percent of the time. Projections for FBC systems are fraught with uncertainty. As a result, no quantitative estimate of the relative advantages of one system or the other has been made.

Questions conceming the failure to meet the percent removal (or ceiling) requirement due to less than design performance were discussed earlier. Although related to malfunctions, where an element of the system is inoperative, corrective actions for insuficient performance are different.

With existing information there is no basis to predict that the reliability of fluidized beds in commercial operation will be significantly greater than that of conventional systems with scrubbers, provided proper spare modules are 
included. The current perception of industry, however, is that this will be true. One of the major determinants driving the current development of fluidized-bed systems is indeed the promise of higher reliability. Given this perception, whether correct in the long run or not, setting a tough malfunction policy should promote the current development efforts toward fluidized-bed combustion systems.

\section{2 .2 NO $\times$ Aspects}

Fluidized-bed combustors are intrinsically low. No $x$ emitters compared to conventional systems currently being used. Although emissions from fluidized-bed combustors as low as $0.2 \mathrm{lb} / \mathrm{milli}$ ion Btu have been observed, these very low levels are unlikely to be achieved in any full-scale practical system. No $x$ emissions from fluidized-bed combustors like those in conventional systems depend on the system operating temperature, uniformity within the system, and the amount of nitrogen found in the fuel itself..

Few data are available on the performance of fluidized beds of any substantial scale or on fluidized-bed systems containing a carbon burnout cell. At the time of writing, data on nitrogen oxide emissions from the Rivesville installation are not available. There is some question as to the level which will be achievable in large-scale systems with carbon burnout cells. A carbon burnout cell operates at approximately $2000^{\circ} \mathrm{F}$, at which temperature the fixation of nitrogen could theoretically reach levels on the order of 0.5 to $0.6 \mathrm{lb} /$ miliion Btu. The exhaust gases from the burnout cell represent only a small fraction of the total effluent stream, however. Thus, although fluidized-bed systems, in theory, should have intrinsic $\mathrm{NO}_{x}$ characteristics superior to current conventional systems, their advantage should be watched very closely as more data become available in the future. 
For certain limited cases, such as the combustion of lignite, fluidized-bed combustors appear to offer even more significant advantages in meeting lower standards than can be achieved by cyclone units which are now used as the principal system for lignite combustion. The existing NSPS for cyclones is $0.8 \mathrm{lb} / \mathrm{million}$ Btu.

\subsubsection{Particulate Aspects}

The technical consequences of the stringency of the particulate standard are very complex and depend on the specific combustion and particulate control system design being examined. Primary particulate emission, levels from FBCs, that is, uncontrolled emissions from the combustor, are greater than emissions from conventional coal boilers. This is due in part to higher levels of unburned carbon and to carryover of fines from sorbent attrition and decrepitation (particle disintegration due to internal pressure from $\mathrm{CO}_{2}$ generated in the initial calcination stage). Use of mechanical collectors (several stages of cyclones) will reduce the level to a point where a high-efficiency device (electrostatic precipitator or baghouse) can operate effectively. Some claims have been made that the fine particulate (less than about three nanometers (microns)] portion of emissions of FBCs will be lower than that from conventional systems. There are, however, virtually no particle size data on either the uncontrolied or controlled emissions to support that argument.

Coal is crushed to a larger size for feeding a FBC than the finer size resulting from pulverization in conventional units. In theory, this should result in fly ash with a particle 
size distribution containing less in the fine particle range than fly ash from pulverized-coal boilers. Little is known currently about the contributions of dust from sorbent degradation.

In spite of the uncertainty relative to particulate emissions from FBCs, several general comments can be made. At some level for the standard, probably at about $0.05 \mathrm{lb}$ particulate/million Btu, baghouses will become the preferred means of control relative to the customary approach of today, the electrostatic precipitator. This will be the case for both fluidized-bed systems and conventional systems. Even at higher levels, the application of electrostatic precipitators to fluidized-bed systems is quite uncertain. The properties of the fly ash emitted from fluidized-bed combustors are poorly characterized at this point in time. The major design parameter, the resistivity of the fly ash, depends on the sulfur content and the carbon content of the fly ash (as well as other mineral components). Because of the high intrinsic capture of sulfur within the combustor itself, fluidized-bed ash would tend to be very resistive, higher than that which would lead to economic electrostatic precipitator performance. The presence of carton in the ash at levels potentially higher than conventional systems could offset this high resistivity characteristic, returning to the range at which electrostatic precipitators operate well, but also may produce resistivities below the optimum range.

Baghouses depend much less on the properties of the fly ash. They are more insensitive to variations in inlet loading conditions. For these reasons baghouses could be favored even at less stringent standards for fluidized-bed combustors. Blinding of bags by fine particulates is a potential problem on which little data are presently available to base estimates of problems in full-scale systems. 
Setting the standards would affect both systems more or less in the same manner because of the similarities in particulate control problems. Thus, the relative advantage of fluidized beds versus conventional systems will not be strongly affected by the lexel at which the particulate standard is set.

One should note that there is a correspondence between the sulfur dioxide standard and the ability of the fluidizedbed system to meet the particulate standard. particulate loading in a fluidized bed will depend markedly on the sorbent requirements. Setting a. more stringent sulfuj dioxide standaxd would increase sorbent requirements and in turn place a higher. set of requifements on the particulate control system. In that sense the cost of the sulfur dioxide standard would be reflected not only in the suifur dioxide control parts of the system, but also in increased costs for particulate control. This is not true in the case of most conventional systems where the sulfur dioxide and particulate control systems operate essentially independently.

Pressurized Eluidized-bed combustors represent a special case. For levels of standard above approximately $0.05 \mathrm{lb} / \mathrm{million}$ Btu, interial turbine requirements would be controlling rather than the standard. The gas turbine portion of the combined cycle associated with pressurized fluidizedbed designs requires very clean inlet gas. Particulate loading constraints on the inlet gas are more severe than the standard down to the level mentioned. At levels below. approximately 0.05 lb/million Btu, additional tail-end leanup systems might be required. Such additional systems have not in general been considered in cost studies for advanced pressurized fluidized-bed system concepts. The need for add-on particulate controls would increase the overall systems costs and would make pressurized systems somewhat less attractive than they presently appear. 
3.3 Cost Comparison Between Fluidized-Bed and Conventional Systems.

Perhaps the most important potential benefit of fluidizedbed systems for generating electricity is lower cost power than electricity from conventional systems. This section presents a series of cost comparisons for AFBC and PFBC systems and conventional systems with scrubbers(FGD). The analysis considers a range of coal types, a range of NSPS of varying stringency, and a range of design features ( $\mathrm{Ca} / \mathrm{s}$ ratio, disposal mode, sparing, etc.). The parametric approach used herein should facilitate comparison under the considerable uncertainty that exists presently concerning the expected performance of FBC systems in the future.

In addition to the parametric results, which do not tie a specific $\mathrm{Ca} / \mathrm{S}$ ratio to a given design or coal or sorbent type, costs are presented for a set of specific ratios developed by Westinghouse, in a companion analysis. ${ }^{3}$ Their analysis was designed to determine the most economic design for FBCs using sorbent of average characteristics.

\subsubsection{Costing Methodology}

This section presents the methodology used for estimating capital and energy costs of coal-fired conventional and fluidized-bed power plants. The first subsection is devoted to a discussion of the data sources used, and the second subsection to a discussion of the structure and assumptions of the cost models used. The details of the cost models and their development are presented in Appendix A. Sections 3.2.2 and 3.2 .3 present the results of the cost analysis and their implications. 


\section{Sources of Data}

The Energy Research and Development Administration (now DOE), in conjunction with NSF and NASA, sponsored a series of studies, published in late 1976, known as the Energy Conversion Alternatives study (ECAS). 4 ECAS was an attempt to evaluate a series of potential technological alternatives for electric power generators on a common basis. Nominal 800 MWe plants were designed and costs developed using a common set of assumptions for interest, escalation, labor, etc. Contributors included General Electric, Westinghouse, United Technology Corporation and their subcontractors. The ECAs did not include a baseline system, in our case a conventional system with FGD scrubbing. However, GE was later given separate contracts by EPA through TVA to develop such a baseline using the ECAS methodology and assumptions. TVA then prepared a report comparing and revising the ECAS results, incorporating the baseline study and the ECAS atmospheric and pressurized fluid-bed systems.

This study relies primarily on the TVA revisions to the ECAS results. In many instances, the original studies and authors had to be consulted for clarification. TVA, GE, Foster-Wheeler, and Westinghouse were contacted a number of times. Additional information was gathered in the form of published and draft reports from Westinghouse, Pedco, EPRI, FPC, and DOE. Further contacts with personnel at pedco and Westinghouse were extensive, and were invaluable for developing the cost methodology and for utilizing the available data properly.

Eigure 3-4 presents a schematic of the methodological development of the cost models. The references for the sources mentioned are presented in Table 3-1. Using a data base drawn from a composite of the several sources a computer- 


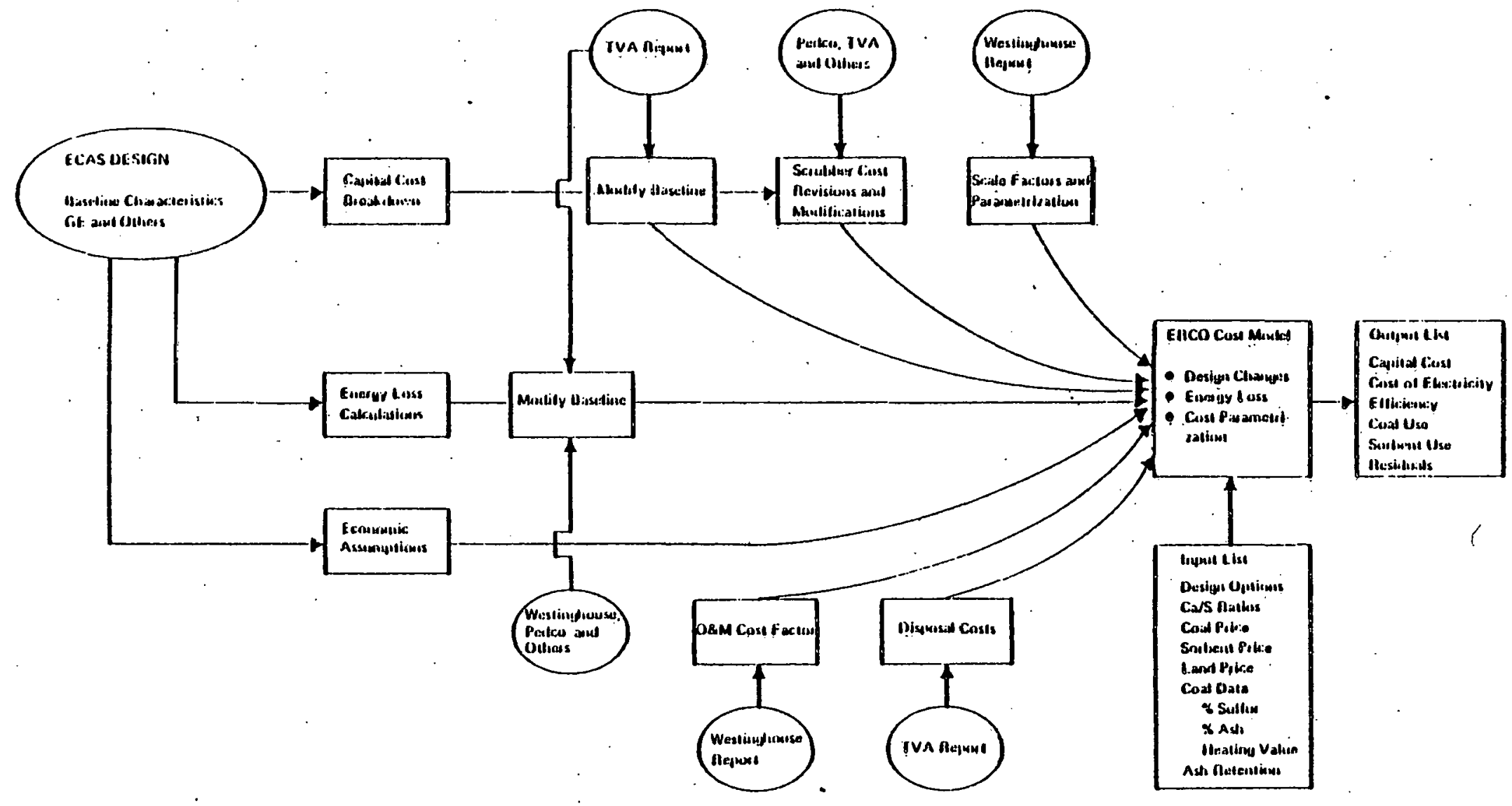

Figure 3-4. Sources for Cost Model Methodology and Assumptionș. 
TABLE 3-1

SOURCES

\section{Published Reports}

1. EPRI: Summary Evaluation of Atmospheric Pressure Fiuidized Bed Combustion Applied to Electric Utility Steam Generators, Babcock and WiTcox for EPRI, Oct. T976.

2. EPRI: Coal Fired Power Piant Capital Cost Estimates, Bechtel Corp. for EPRI, Jan. 1977.

3. EPRI: Coal and Nuclear Generating Costs: EPRI, Aprii 1977.

4. GE: Energy Conversion Altematives Study-ECAS-General Electric Phase II Final Report, GE Corp. Research and Development for NASA, ERDA, NSF, DeC. 1976.

5. GE: Conceptual Design and Implementation Assessment of a Utility Steam Plant with Conventional Furnace and Wet Lime Stack Gas Scrubbers, GE Corp. R\&D for EPA, TVA, NASA, Dec. 1976.

6. NASA: Evaluation of Phase II Conceptual Designs and Implementation Assessment Resulting from the ECAS, NASA for FRDA, NSF, ApriT 1977.

7. Exxon: Application of Fluidized-Bed Technology to Industrial Boilers, Exxon Research and Engineering for FEA, ERDA, EPA, January 1977 .

8. MITRE/METREK: Analyses of Benefits Associated with the Introduction of Advanced Generating Technologies: Description of Methodologies and Summary of Results: Final Report: Electric Utility Study, MITRE/METREK for ERDA, March 1977.

9. TRW: Electric Utilities Study: An Assessment of New Technologies from a Utility Viewpoint, TRW System and Energy for ERDA, November 1976.

10. FPC: The Status of Flue Gas Desulfurization in the United States: A Technological Assessment, Bureau of Power, FPC, JuTy 1977 .

11. POWER Magazine, Vol. $121(7): 25 ; \mathrm{Vol} .121(12): 41$.

12. Steam: Its Generation and Use, Babcock and Wilcox, 1975. 
TABLE 3-1 (Continued)

\section{Draft Reports}

13. TVA: Cost Comparison of Commercial Atmospheric and Pressurized F] uidized Bed Power Plants to Conventional Power Plants with Flue Gas Desulfurization, TVA for EPA/ORD, March 1977.

14. Westinghouse: Evaluation of the Impact of $\mathrm{SO}_{2}$ and Particulate Emission Standards on Fluidized Combustion System Energy Cost, Westinghouse R\&D for EPA/ IERL, September 1977; and submission to J. Ehrenfeld, Energy Resources Co. Inc., Westinghouse R\&D Center, December 1977; and Assessiment of the Impact of Sulfur Oxide, Particulate and Nitrous Oxide Emission Standards on FBD Power Plant Energy Costs, Westinghouse R\&D Center for EPA/IERL, January 9,1978 .

15. Pedco: Particulate and Sulfur Dioxide Emission Control Costs for Large Coal-Fired Boilers, Pedco Environmental for EPA, December 1977.

16. Gilbert/MITRE: Technical Document for Applying Tenitative New Source Performance Standards for Coal-fired Steam Generators to Fluidized-8ed Combustors, Gilbert Assoc. and MITRE/METREK for U.5. DOE, November 1977.

\section{Personal Contacts}

Foster-Wheeler: Bob Gamble, Bob Stuart GE: Dale Brown

Pedco: Larry Gibbs, Dick Gerstle, Yatendra Shah

Riley-Stoker: Burt Rawdon

TVA: Pat Kelly

Westinghouse: Dale Keairns, Dick Newby 
based estimating model was developed. The model inputs included coal characteristics, various system design parameters, coal and limestone prices, and sulfur dioxide removal requirements. In several instances errors in the original works were discovered and corrected. In addition adjustments were made to improve the consistency and the accuracy of the results. These changes and corrections are detailed in Appendix $A$.

Even with such improvements, the cost analysis ultimately rests on the ECAS engineering designs. These designs have been modified by TVA and in the current study only to a very limited degree. The results of this study, therefore, are dependent on the correctness of the original design work. This is somewhat unfortunate for three reasons. First, the ECAS studies were completed in 1976 and are based on costs for 1975. The system designs reflected best engineering knowledge in 1975; but in the ensuing years, developments have taken place, both in conventional and fluid-bed technologies, which could alter those designs. Second, the original design work and cost analysis is based on a single set of assumptions and one engineering study, and has not benefited by comparison with independently developed designs. The original ECAs work has been analyzed and compared, but quite often the basis for the comparison is a design derived from the original ECAS design and assumptions. This self-consistent characteristic of the comparative assessments of fluidized-bed and conventional technologies is not very reassuring, although it does not mean that major errors have been made. Third, only one coal (IIlinois No. 6) was used in the ECAS study. This choice limited the design work. The results, then, may represent optimum system designs for that coal, but designs for other coals may be significantly different. Illinois No. 6 coal is relatively very dirty (high ash and sulfur content), and difficult to use compared to many eastern and most western coals. 


\section{The Energy Resources Company Cost Models}

The coal used as the basis of the ECAS and TVA studies was Illinois No. 6, with a 10,788 Btu/lb. Higher Heating Value, a 3.9 percent sulfur content, and a 9.6 percent ash content. The system designs prepared for this coal are specific to it and will necessarily change for other coals. Operating parameters such as sorbent feed rate will vary as the characteristics of the coal change, thus further changing the system and its attendant costs. Given that the Illinois No. 6 coal used for the analysis is quite distinct from other important coal types, an analysis, expanded to consider alternative coals, was made to provide the borad range of results needed for the required policy analysis.

The approach adopted was similar to one utilized by Westinghouse in a draft report to the EPA. ${ }^{3}$ It involves parameterizing the base case costs to correspond to changes in the coal characteristics, specifically the sulfur, ash, and Btu contents, and to sulfur removal specifications. The detailed capital cost breakdowns of the ECAS reports were usted to develop a set of coefficients corresponding to the categories of equipment and labor costs which will change as the coal changes (See Appendix A). These coefficients are appropriately scaled according to the changes in the coal and system specifications to yield a revised capital cost. At the same time, energy losses, emission levels, solid waste output, etc., are calculated. The cost of electricity is determined according to a standard formula.

This study extended the methodology in a number of ways in order to develop more accurate and more consistent comparisons 
A cost model for a conventional system utilizing a wet scrubber was developed for comparison purposes. This model was essentially the same in format as that for the fluidized-bed systems, although many of the calculations were different. For all three cost models, conventional, atmospheric, and pressurized, the cost base developed by TVA was used. These costs included substantial revision of the solid waste disposal costs used in the ECAS and GE studies, and of other ECAS/GE costs.

Figure 3-5 depicts the process. used to develop the cost models for this project. Some of the coefficients and other calculations were not common to both conventional and fluidized-bed models, although inputs, outputs, and assumptions were as consistent as possible. The sources identified refer to the references in Table $3-1$. Figure $3-6$ presents a flow chart of the model itself. Notice that the coefficients are not calculated in the model but are inputs.

Two of the coefficients were altered from the base case as presented by TVA and GE. These two were for disposal capital costs and for disposal land costs. The changes were made in order to make the conventional and fluidized-bed costs consistent. TVA provided a detailed analysis of direct conventional system scrubber and disposal costs, and also reanalyzed the direct disposal costs for fluidized-bed systems, but unfortunately, used different cost assumptions to calculate $F B C$ and FGD total disposal costs. In this study, the assumptions used for the FGD were used to develop consistent total disposal and land costs for both systems.

For comparison purposes, two methods of disposal were included in the models for each system. The fluidized-bed altematives were onsite pond disposal, which represented 


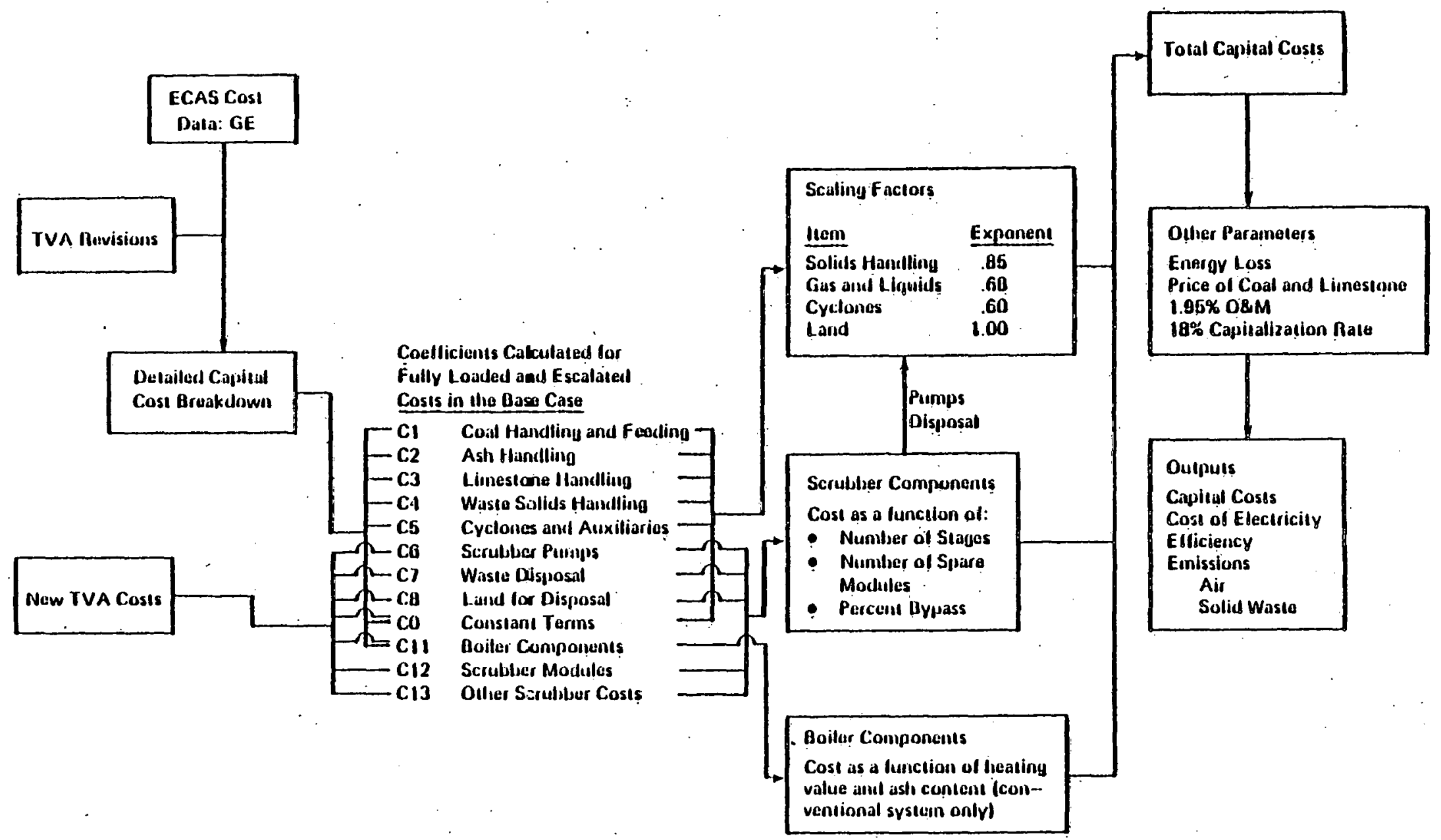

Figure 3-5. Conceptual Design of Cosı Models. 
Inputs:

Percent Rernoval

Coal: Heating Value

Sulfur Content

Ash Content

Sulfup Retention

Price

Limestone: Price

Offsite or Onsite

(Lime or Limestone)

Ca/S Ratios

(No. Spare Scrubbers)

\section{Outputs:}

Ca/S

(Spare Scrubber Modules)

Investment

(Scrubber Investment)

Net Ourput

COE

Plant Efficiency

Coal Volume

Limestone Volume

Solid Waste Volume

Sulfur Emissions

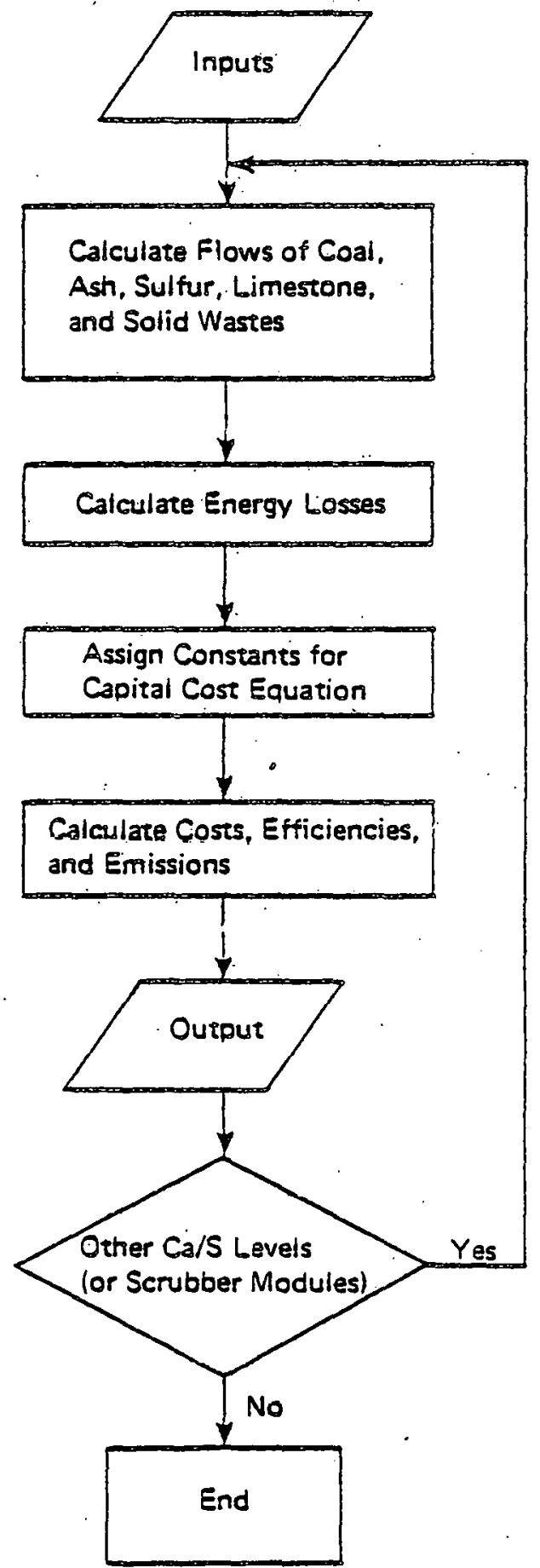

Figure 3-6. Flow chart of cost model. 
the most expensive option, and offsite fixed disposal in a diked impoundment, which represented the least expensive alternative even considering transport cost. For the conventional system, offsite disposal was more expensive because of the chemical fixation process required, and onsite pond disposal, which represents most current practice, was slightly less expensive.

For the conventional system, limestone scrubbing was assumed for the base case. However, onsite calcination of limestone and lime scrubbing was included as an option in the costing program.

The scaling factors were those used in the Westinghouse study with the addition of a factor for liquid handing, i.e., pumps and piping. These factors are consistent with general engineering cost estimating procedures and are sufficiently accurate for purposes of this study. The fluidized-bed module costs were assumed not to change significantly for the various coals and were not scaled. However, the corresponding boiler components for the conventional system are quite sensitive to changes in ash and Btu content. A formula was developed with information from Riley Stoker, Power Magazine, and in-house sources which adjusted the costs of the boiler pressure parts and other components to changes in the coal.

The scrubber component costs depend on several factors. The number of scrubber stages, a function of the percent removal, the number of spare scrubber modules, a function of the redundancy required to meet the availability criteria, and the amount of flue gas bypassing the scrubber, a function of the removal required, were included as parameters and the. costs were adjusted accordingly. The adjustments were based in large part on data from pedco. 
Energy loss calculations were included as an integral part of the model and were based on changes from the base case for gas flow, liquid flow, sorbent feed rate, etc. The net power output estimate was then used in a standard formula with the total capital investment, coal and limestone prices, and the assumptions of 18 percent per year capitalization and 1.95 percent of capital for O\&M costs, to yield a net cost of electricity.

$A$ bed depth of 4 feet (AFBC) and 10 feet (PFBC) was used in all calculations. This was the design base for ECAS.

\section{3 .2 Scenarios for Cost Comparisons}

Four distinct coals were chosen to represent a broad range of characteristics encompassing the majority of coal reserves in the united States. The coal types were intended to represent typical coals for which conventional and FBC technologies might compete. A low sulfur eastern coal was not included.

The cost comparison of fluidized-bed and conventional systems was based on a set of scenarios for NSPS standards and a set of coal types with a variety of characteristics.

Table 3-2 presents the four coals selected. Coal $A$ is the base case coal used in the ECAS studies. Coal B is a West Virginia bituminous used in an ERRI study. ${ }^{6}$ Coal $C$ was also used in the EPRI report, and is a low sulfur, western subbituminous coal capable of meeting the current $1.2 \mathrm{lb} /$ milion Btu NSPS sulfur Iimitation without pretreatment or scrubbing (compliance coal). Coal D is a typical Texas lignite. 
With respect to ISPS stipulations, a ceiling of 1.2 Ib $\mathrm{SO}_{2} /$ million Btu coal was assumed for all scenarios. The percent.

TABLE 3-2

BASIS FOR SCENARIOS

Coals

\begin{tabular}{|c|c|c|c|c|c|}
\hline Category & $\stackrel{A}{I 11 .}$ & W. $\stackrel{\text { Ba. }}{\text { Va. }}$ & $\begin{array}{c}C . \\
w_{y} y .\end{array}$ & $\begin{array}{c}D \\
\text { Tex. }\end{array}$ & $\begin{array}{c}\text { Cost } \\
\left(\$ / 10^{6} \text { Btu }\right)\end{array}$ \\
\hline $\begin{array}{l}\text { Heating } \\
\text { value (Btu/Tb) }\end{array}$ & 10,788 & 13,280 & $8 ; 020$ & 7,590 & 1 \\
\hline$\%$ sulfur & 3.9 & 3.35 & 0.48 & 0.6 & 1 \\
\hline$\%$ ash & 9.6 & 7.5 & 6.4 & 10.4 & 1 \\
\hline
\end{tabular}

removal requirement varied from 85 to 95 percent, and the

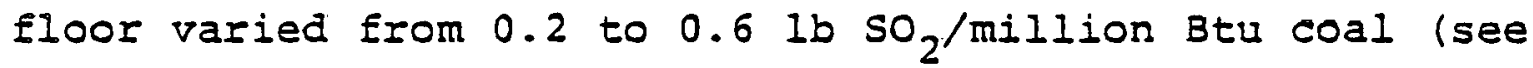
Table 3-3). The interface of the NSPS levels with the cost models is the percent removal required for a particular coal, which is input into the cost mojels. As discussed in section 3.1, the percent removal required for a particular coal can be determined from the coal, sulfur, and Btu content, and from the NSPS stipulations. Table $3-3$ also presents the percent removal required for each of the four specified coals for each of the NSPS scenarios. For high sulfur eastern coals the percent removal stipulation is most important, while for low sulfur western coals the floor stipulation is most important. 
TABLE 3-3

PEREENT REMOVAL REQUIREMENTS

\begin{tabular}{|c|c|c|c|c|c|c|}
\hline \multicolumn{3}{|c|}{ NSPS Standards } & \multicolumn{4}{|c|}{ Average \% Removal Required } \\
\hline $\begin{array}{l}\text { Floor } \\
\text { Tb/MMBtu }\end{array}$ & $\begin{array}{l}\text { Ceiling } \\
\text { lb/MMBtu }\end{array}$ & $\underset{\%}{\operatorname{Removal}}$ & Coa.] A & Coal B & Coal C & Coat 0 \\
\hline 0.2 & 1.2 & 95 & 95 & 95 & 83.3 & 87.4 \\
\hline 0.2 & 1.2 & 90 & 90 & 90 & 83.3 & 87.4 \\
\hline 0.2 & 1.2 & 85 & 85 & 85 & 83.3 & 85 \\
\hline 0.4 & 1.2 & 95 & 94.5 & 92.1 & 66.6 & 74.7 \\
\hline 0.4 & 1.2 & 90 & 90 & 90 & 66.6 & 74.7 \\
\hline 0.4 & 1.2 & 85 & 85 & 85 & 66.6 & 74.7 \\
\hline 0.6 & 1.2 & 90 & 90 & 88.1 & 49.9 & 62.1 \\
\hline
\end{tabular}

The other assumptions which were the basis of the initial set of cost model runs included the $\mathrm{Ca} / \mathrm{S}$ ratios and the disposal option selected. Offsite disposal was chosen because it represented the least cost and therefore most likely alternative for fluidized-bed systems. Offsite disposal is slightly more expensive for the conventional system due to the costs of fixation, but does not influence the cost of electricity

* The values in this table represent design targets based on average coal sulfur content. They would be adusted in practice upward to reflect overdesign needed to offset excursions from the average sulfur content and downward to reflect sulfur retention in ash (provided credit for such retention is permitted). 
significantly. The limestone scrubbing option was also selected for the conventional system.

$\mathrm{Ca} / \mathrm{S}$ ratios were varied to reflect a range of possibilities. The conventional system is much less dependent on $\mathrm{Ca} / \mathrm{S}$ ratios and, therefore, ratios of 1.3 and 1.5 were chosen, representing the high and low estimates for the conventional system assuming a moderately reactive Iimestone. The atmospheric fluidized-bed system was evaluated for Ca/s ratios of $2.0,2.5,3.0,3.5,4.0$, and 4.5 , and the pressurized fluidizedbed system was evaluated for $\mathrm{Ca} / \mathrm{s}$ ratios of $1.0,1.5,2.0$, and 2.5. These levels reflect comparable ranges of sulfur removal for these two systems. Given current understanding, higher removal efficiencies w1Il generally require higher Ca/s ratios, so that for high levels of removal, the actual $\mathrm{Ca} / \mathrm{s}$ ratios should be in the high part of the range, and for lower removal. efficiencies, the $\mathrm{Ca} / \mathrm{s}$ ratio should be in the low end of the range.

\subsubsection{Cost of Electricity Estimates}

Figures 3-7 to 3-13 present the results for the scenarios. The cost of electricity (COE) is represented on the vertical axis. Conventional, atmospheric fluidized-bed, and pressurized fluidized-bed system costs are presented as a cluster of three bars. The coal type varies along the horizontal axis. Each graph represents a different set of NSP standards and they are in order from most to least stringent. Each segment represents a different $\mathrm{Ca} / \mathrm{S}$ ratio, increasing upward. The values are those noted above and are:

1) for conventional systems- $\mathrm{Ca} / \mathrm{S}=1.3$ and 1.5 ;

2) $\mathrm{for} A F B C-\mathrm{Ca} / \mathrm{S}=2.0,2.5,3.0,3.5,4.0$ and 4.5 ;

3) for $\mathrm{PFBC}-\mathrm{Ca} / \mathrm{S}=1.0,1.5,2.0$, and 2.5 . 


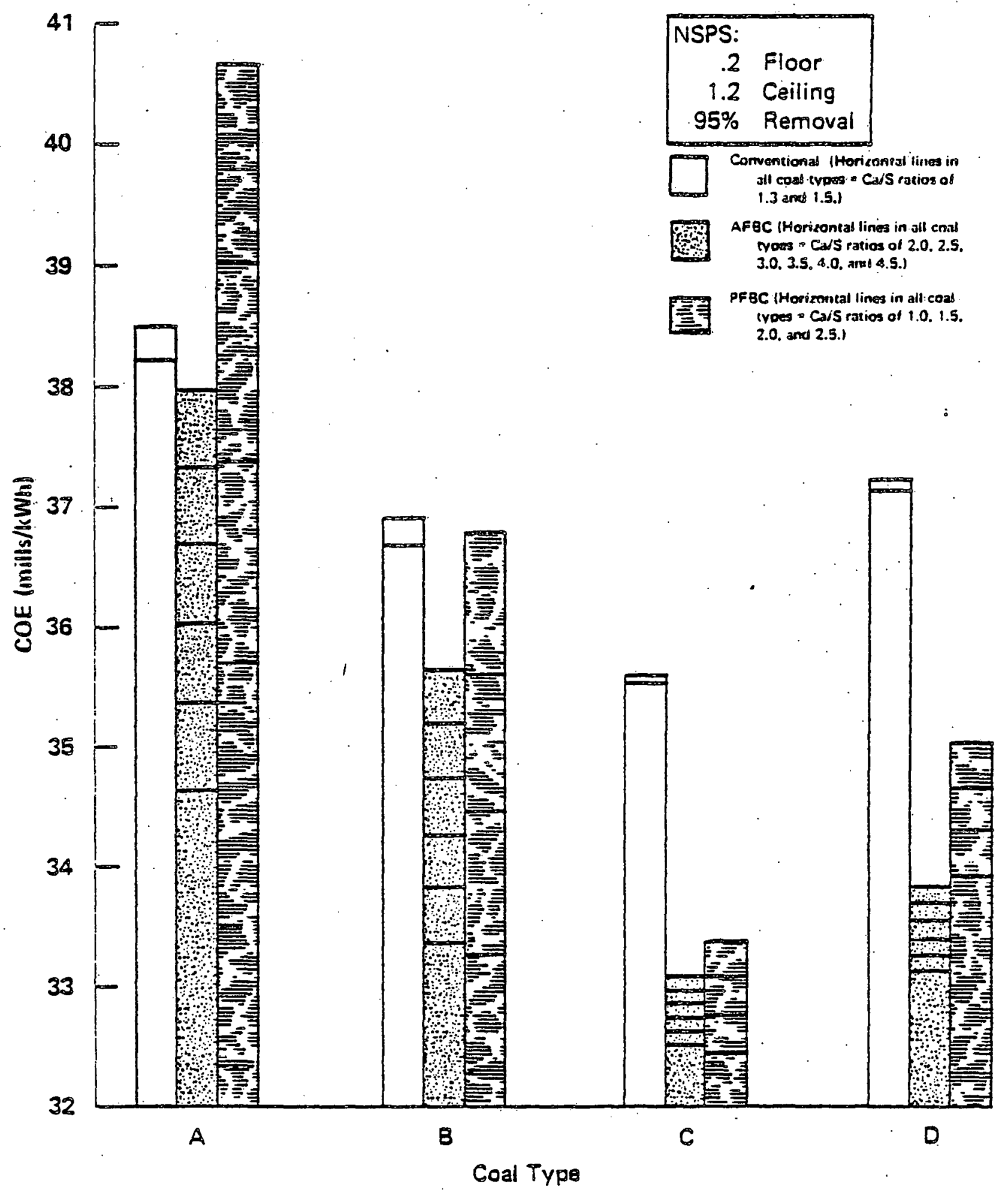

Figure 3-7. Costs of Electricity: Case 1. 


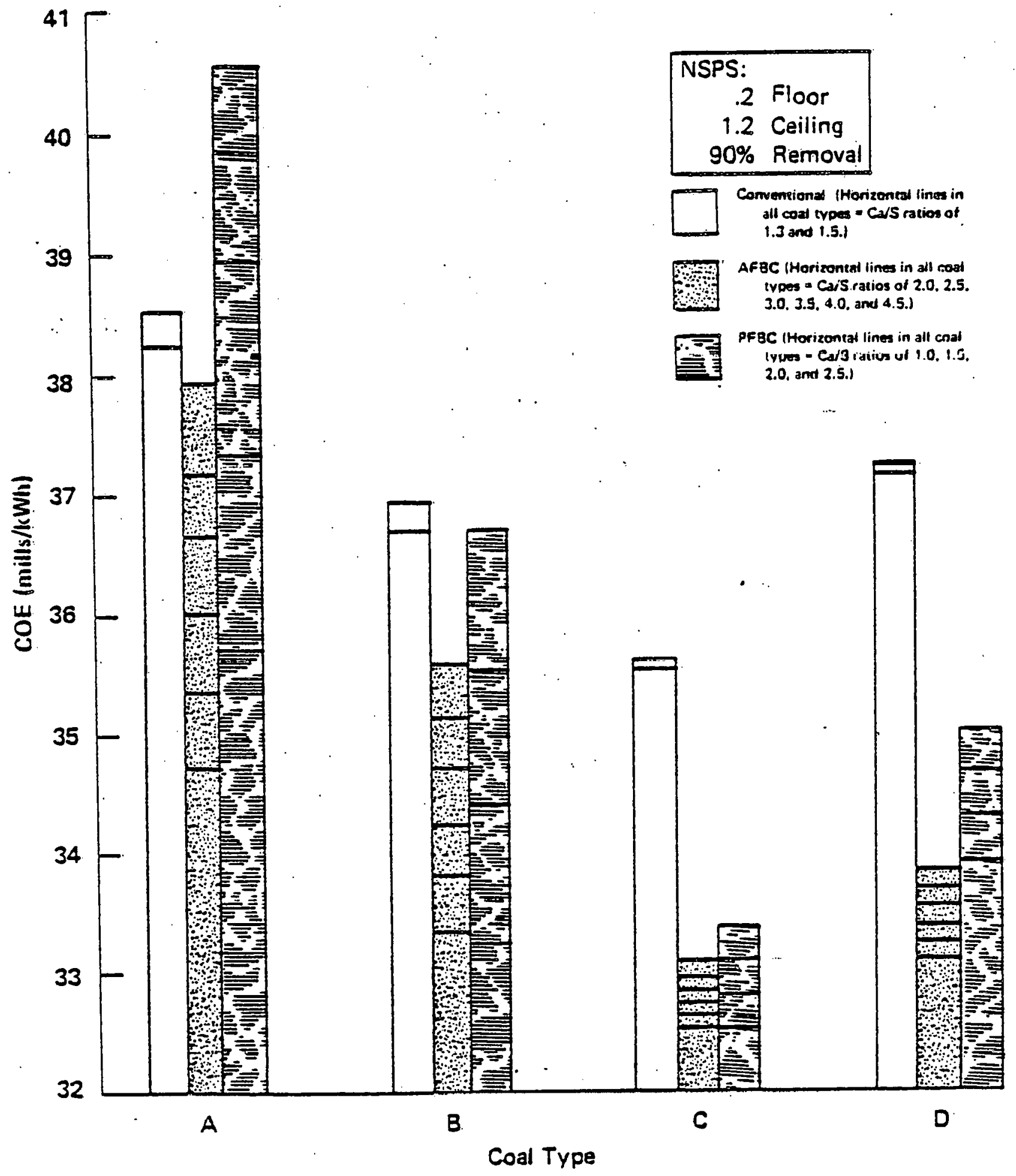

Figure 3-8. Costs of Electricity: Case 2. 


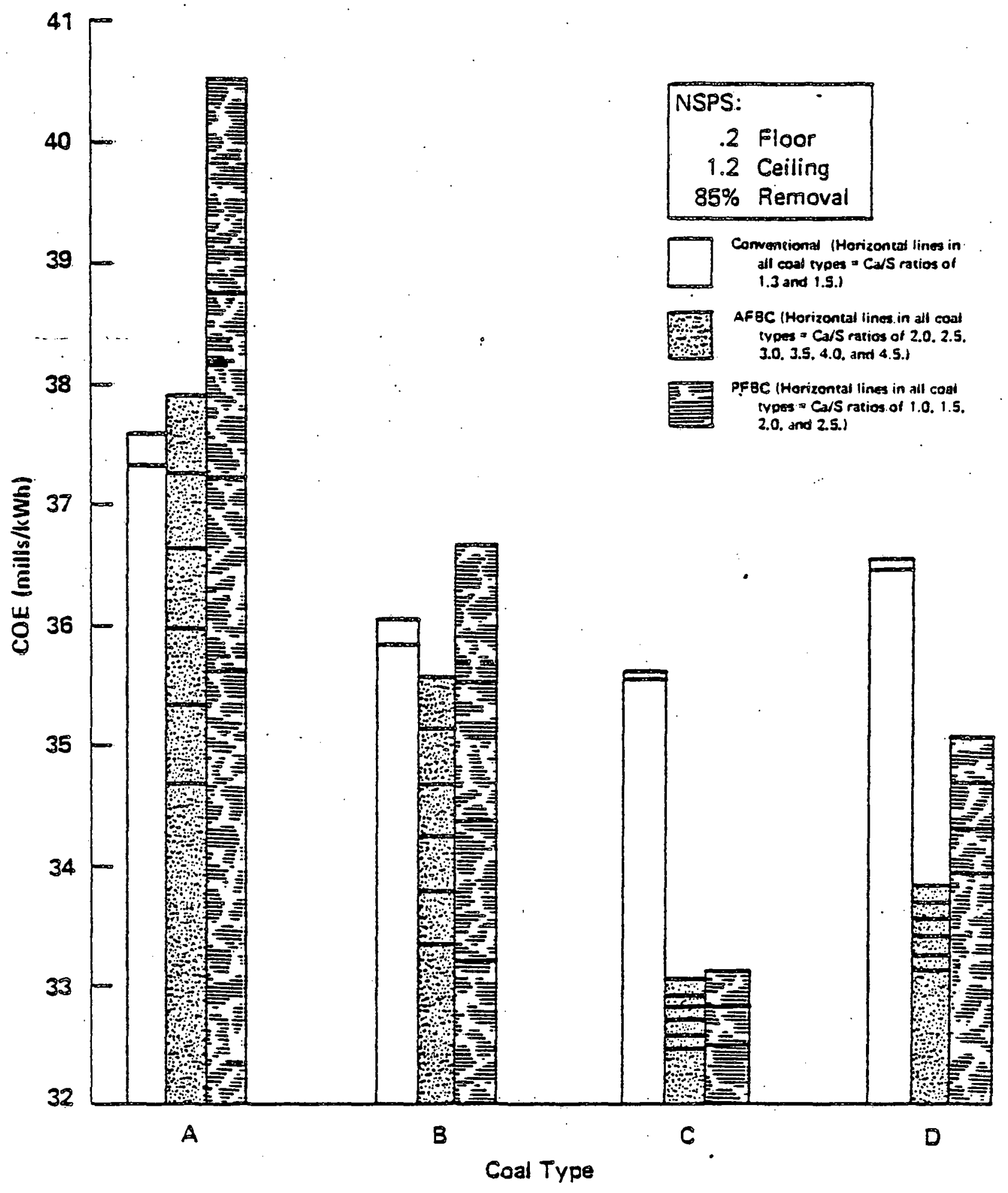

Figure 3-9. Costs of Electricity: Case 3. 


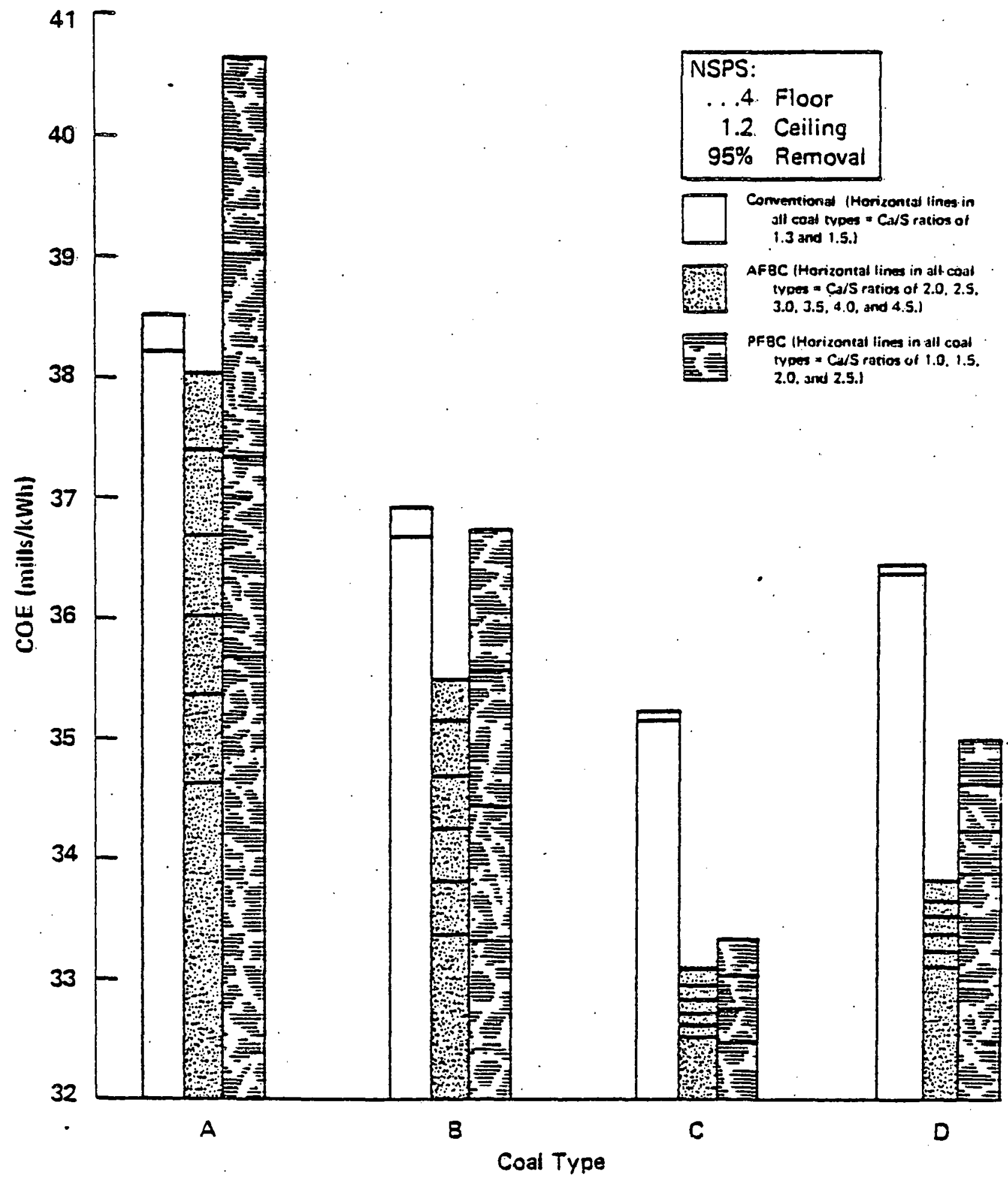

Figure 3-10. Costs of Electricity: Case 4. 


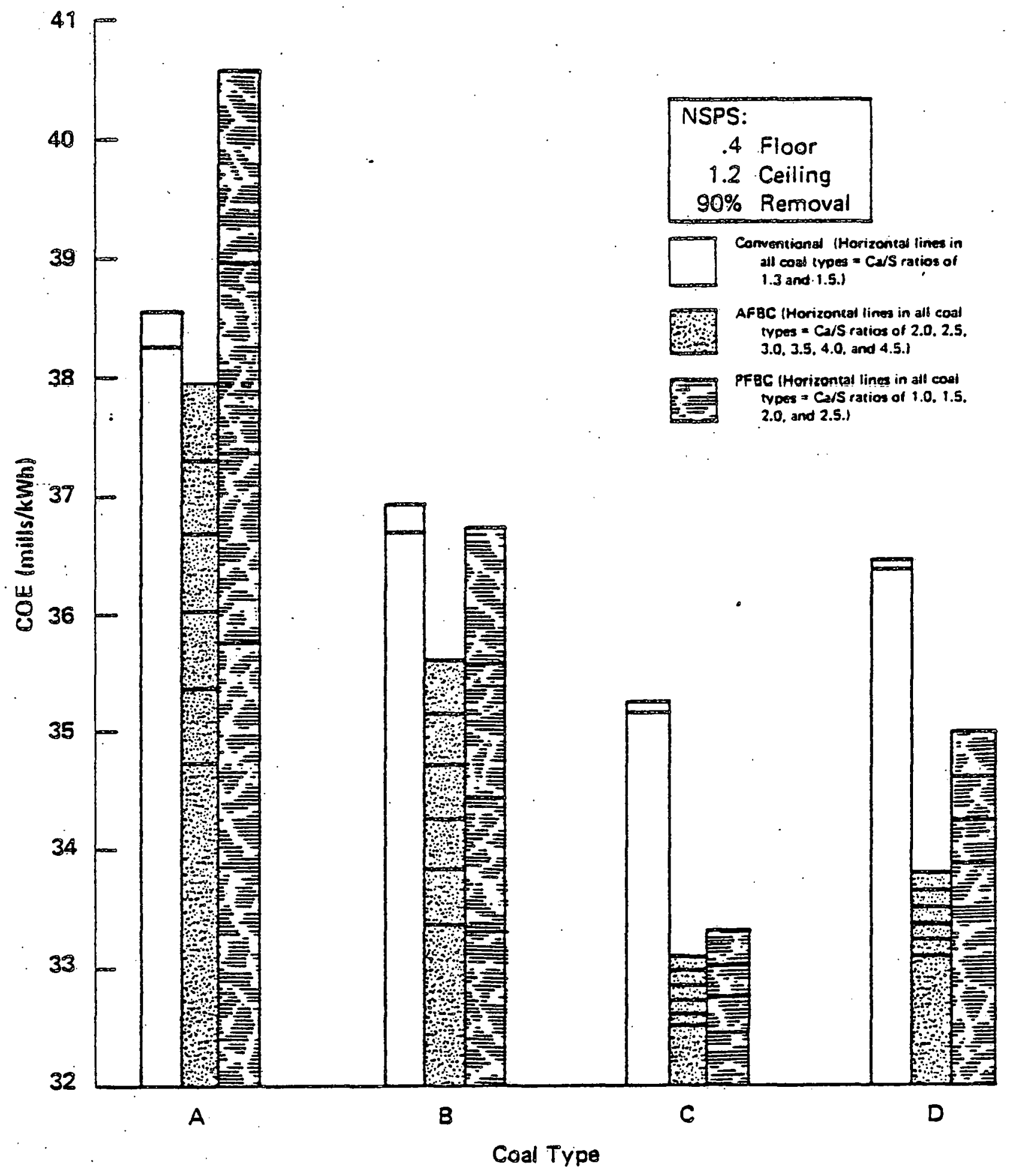

Figure 3-11. Costs of Electricity: Case 5. 


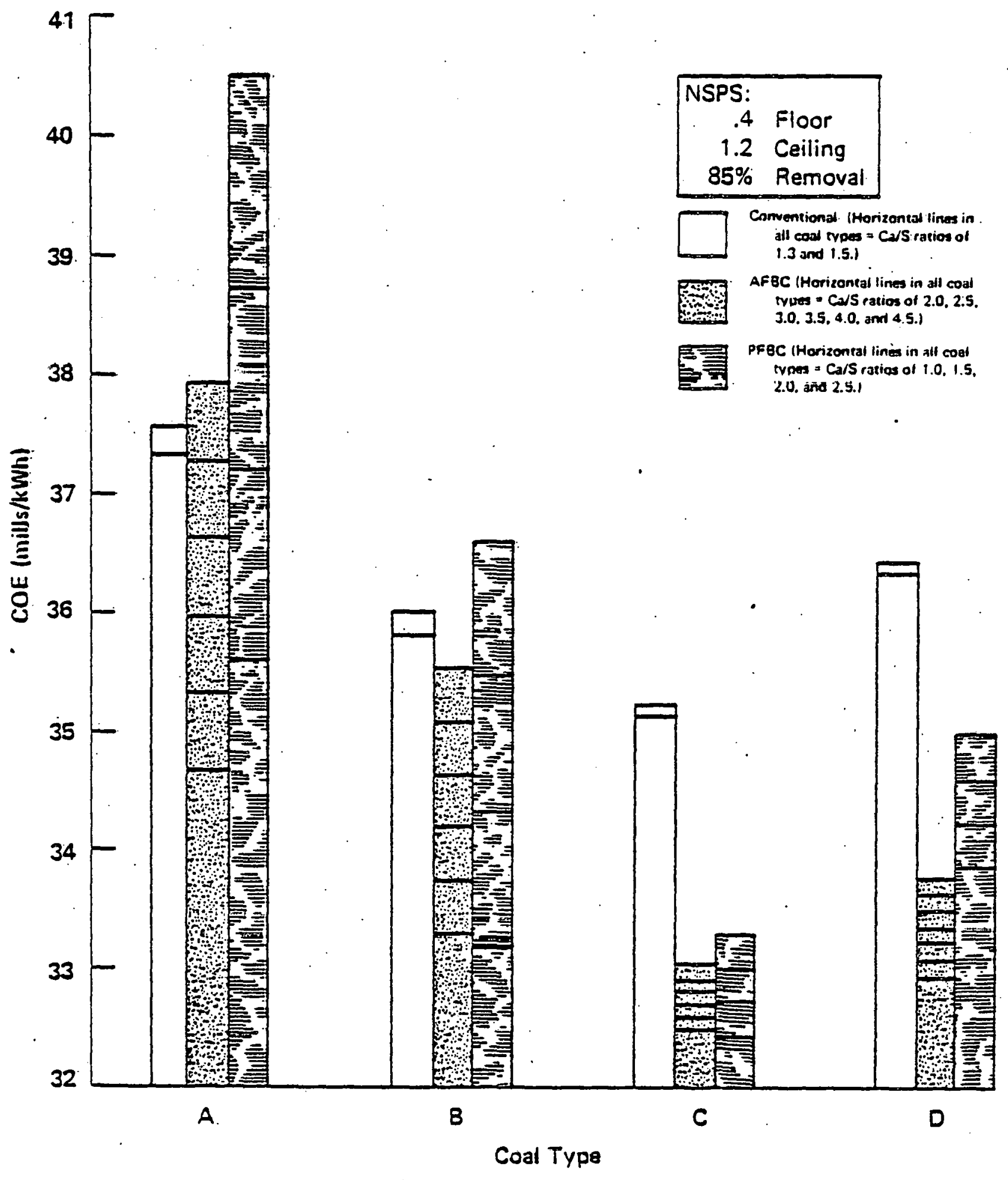

Figure 3-12. Costs of Electricity: Case 6. 


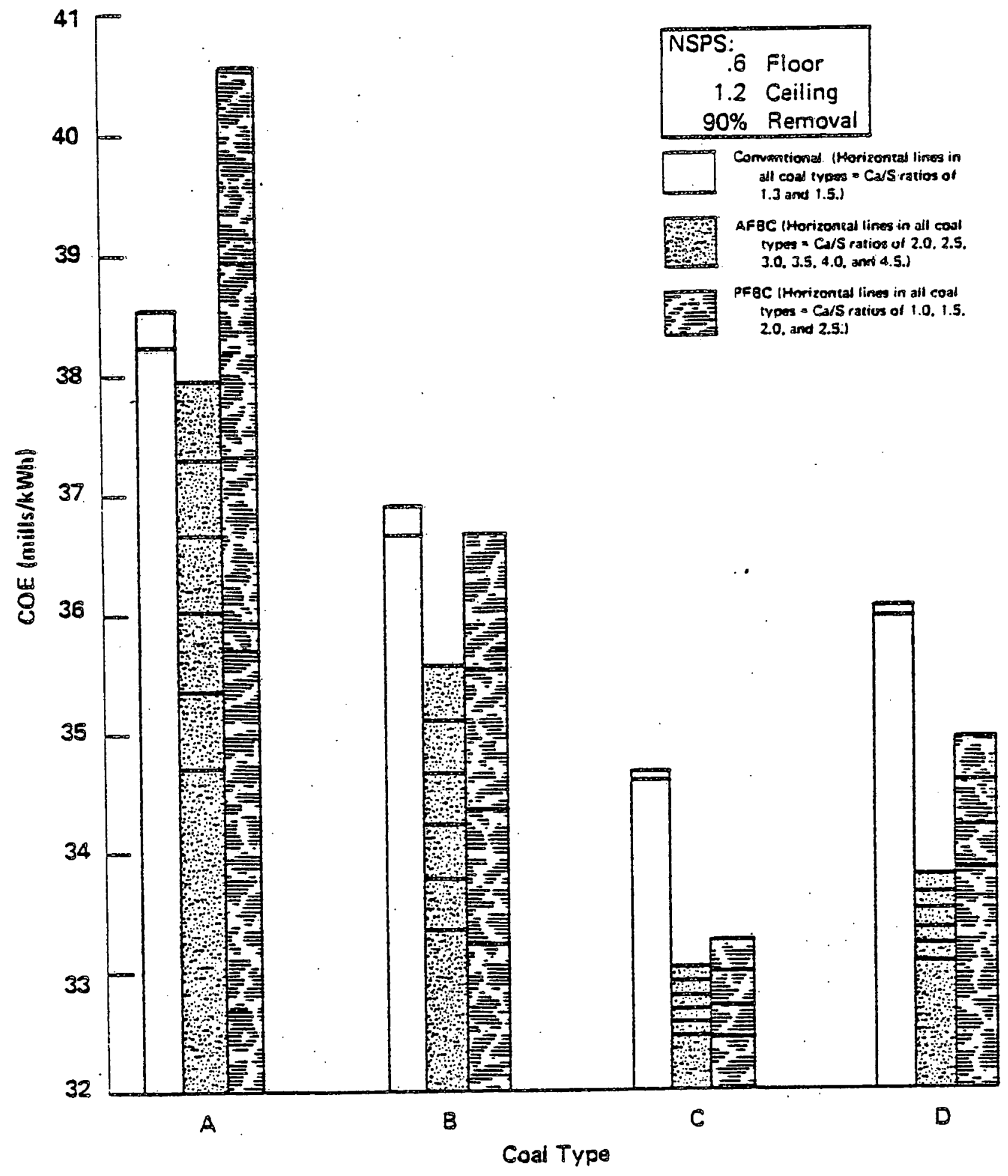

Figure 3-13. Costs of Electricity: Case 7. 
For reasonable choices of $\mathrm{Ca} / \mathrm{S}$ ratio the $\mathrm{AFBC}$ in most cases would provide the least expensive electricity. This is the case for all coals and all NSPS scenarios considered. The PFBC is generally the next most expensive system, except for the higher ranges of $\mathrm{Ca} / \mathrm{S}$ ratio for the high sulfur eastern coals. In these cases, conventional systems appear advantageous. These figures, because of their parametric character, do not provide: a concise comparison of costs in systems where $\mathrm{Ca} / \mathrm{s}$ ratio has been optimized. Such comparisons are presented below. The figures here are provided to permit comparison over the entire range of $\mathrm{Ca} / \mathrm{s}$ ratios of potential interest in FBC design.

The fluidized-bed systems exhibit a larger advantage for both western coals, especially at higher sulfur removal requirements. This result is especially important for the socalled western "compliance" subbituminous coal $C$, which will no longer be a compliance coal under new, more stringent NSPS. For this coal, the conventional system is, at the least, 1.5 mill/kWh more expensive than the fluidized-bed systems for all NSPS scenarios and for all $\mathrm{Ca} / \mathrm{S}$ ratios. This is more than a 5 percent variance, which is quite substantial considering the common basis for the analysis. The variance increases to almost 10 percent when the conventional and atmospheric systems are compared under the assumption of a $0.21 \mathrm{~b} / \mathrm{milli}$ ion Btu floor, and a $1.5 \mathrm{ca} / \mathrm{s}$ ratio.

For lignite, coal $D$, the difference between the conventional and atmospheric systems shows even larger variances, although the pressurized system loses some of its advantage. Under a 0.2 floor, the average difference between atmospheric and conventional electricity costs is $4 \mathrm{mill} / \mathrm{kWh}$ (12 percent variance), whereas conventional and pressurized are about 
$2 \mathrm{mill} / \mathrm{kWh}$ apart (about 6 percent). Under the 0.6 floor, these differences are reduced to $2.8 \mathrm{mills}(8$ percent) and 1.0 mills ( 3 percent) respectively.

For the eastern coals, the results are much more sensitive to variations in the Ca/s ratio. This is due to the substantially higher amounts of sulfur which must be removed. This implies higher sorbent feed rates, higher spent solids flow rates, and higher disposal costs even for low $\mathrm{Ca} / \mathrm{s}$ ratios. As the $\mathrm{Ca} / \mathrm{S}$ ratio increases, these costs increase proportionately. For the pressurized fluidized-bed systems the higher $\mathrm{Ca} / \mathrm{S}$ ratios result in costs quite outside of the competitive range for the base case coal.

The conventional system exhibits a jumo in costs of about $1 \mathrm{mill} / \mathrm{kWh}$ as the percent removal required goe's from 85 to 90 percent removal. This jump is due to the change in design which is necessary; a two-stage scrubber will suffice for 85 percent removal whereas three stages are needed to achieve 90 percent or better. ${ }^{7}$ other changes in the system are relatively minor, as is obvious. by the negligible cost difference between 90 and 95 percent removal.

Given their parametric nature, these figures do not clearly indicate the expected increase in the cost of electricity for FBC systems with increasing percent removal requirements. At a given $\mathrm{Ca} / \mathrm{S}$ ratio, costs vary insignificantly (less than 0.1 mill/k(wh) as removal requirements go from 84 to 9.5 percent. As will be shown below, however, higher ca/s ratios will be required to achieve higher percent removal. 
Westinghouse in a companion, coordinated analysis, developed costs for FBC systems. ${ }^{3}$ Their work followed two routes. One was similar to the approach used herein, in which costs were developed on a parametric basis. The other involved the development of specific designs based on a Westinghouse sulfur removal model using experimental data gathered on a themogravimetric analyzer. The variables in the model included $\mathrm{Ca} / \mathrm{S}$ ratio, bed depth, gas velocity, sorbent particle size, bed voidage and density, and sorbent calcination conditions. The results of applying the model agree well with FBC data for a broad range of operating conditions and large number of data. sources.

Not surprisingly, the Westinghouse sesults predict greatly improved performance (lower Ca/s ratios) at lower velocities and smaller diameters than at the condition used in the ECAS and related studies or in many experimental facilities including the Rivesville pilot plant. For the AFBC, the $\mathrm{Ca} / \mathrm{S}$ ratio to achieve 90 percent removal is estimated to be 2.9, for velocity equal to 6 feet per second, and a sorbent particle size of 500 microns, compared to a $\mathrm{Ca} / \mathrm{S}$ of 7.0 for conditions of velocity of 10 feet per second, and particle size of 1000 microns. Bed depth was assumed to be four faet in both cases. Similar improvements are estimated for PFBC systems as well.

The results of the Westinghouse analysis are shown in Figure 3-14. In this figure, the costs are based on the ERCO cost model, using these optimal $\mathrm{Ca} / \mathrm{S}$ ratios. Westinghouse also estimated the cost of electricity using a different set of cost assumptions, resulting in lower estimates for both $A F B C$ and PFBC. This difference is discussed in Appendix B. 


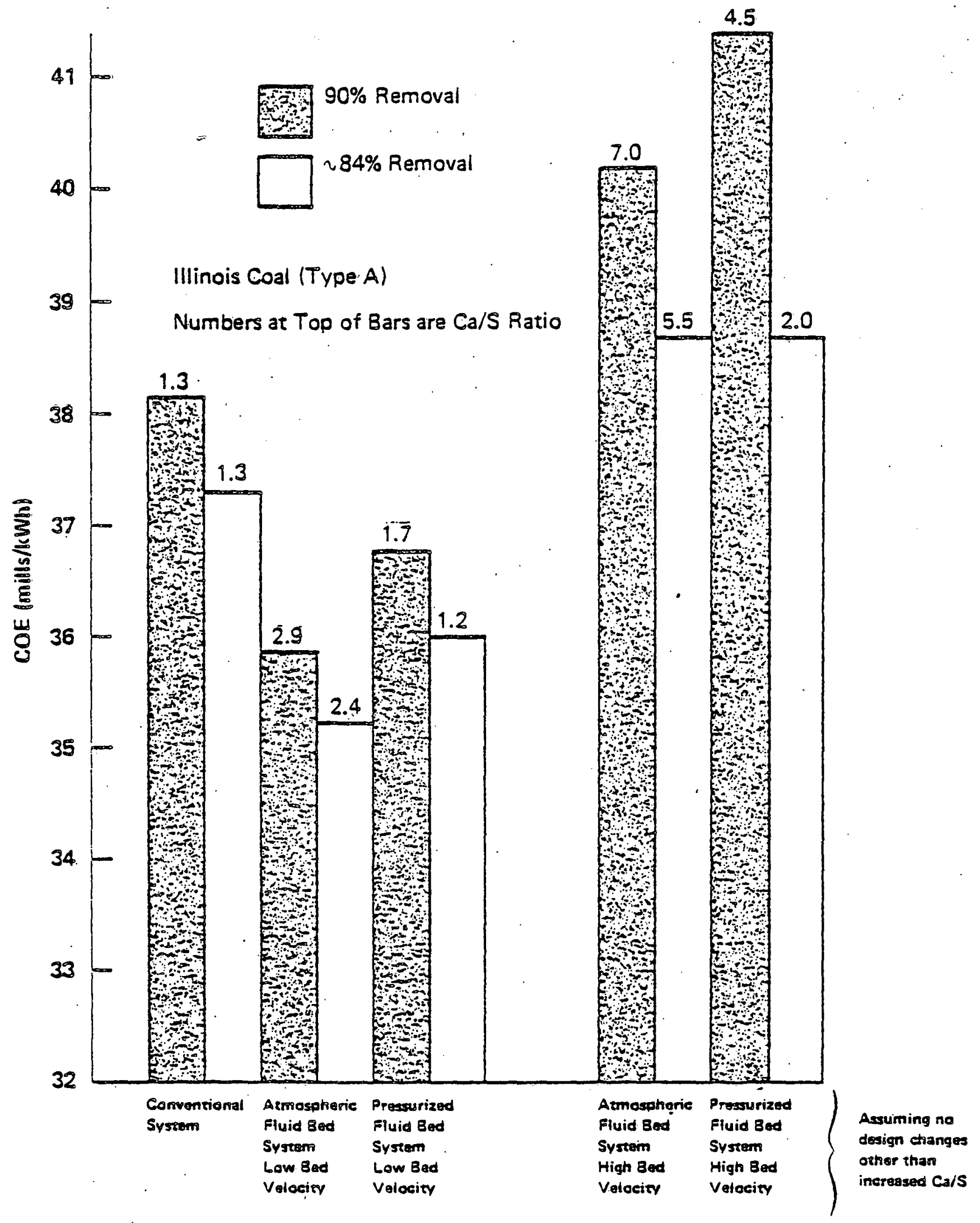

Figure 3-14. Cost Estimates Using Westinghouse Ca/S Ratios. 


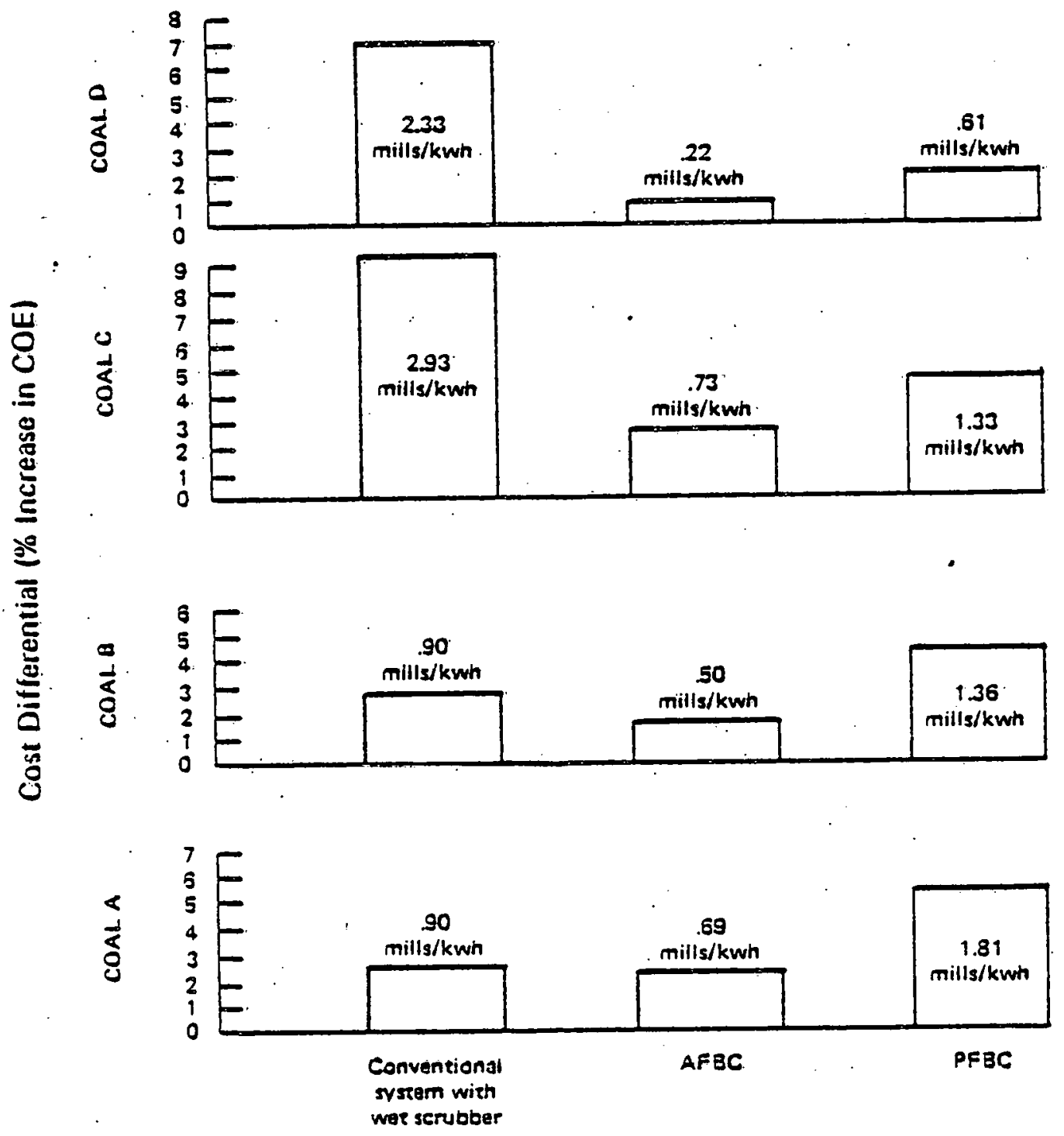

Figure 3-15. Cost differentials for current and proposed NSP standards. Percent increase in cost resulting from proposed NSPS. 
The results show, as expected, that for the low bed velocity case the pressurized fluidized-bed system is quite competitive and has a substantial edge over the conventional system. The atmospheric fluidized-bed system still has the lead, however, and is more than $2 \mathrm{mill} / \mathrm{kWh}$ cheaper tinan the conventional system for both 84 and 90 percent removal. In the high bed velocity case, however, the very high Ca/s ratios needed prove to be quite detrimental to the fluidizedbed systems.

Figure 3-15 presents cost differentials for conventional, $A F B C$, and PFBC systems under the current vs. one of the proposed NSPS cases. The current NSPS requires that emissions not exceed 1.2 Ibs $\mathrm{so}_{2} / \mathrm{million}$ Btu of coal. For this comparison, the relatively stringent case of 90 percent removal of $\mathrm{SO}_{2}$ with a floor of .2 lbs $\mathrm{so}_{2} / \mathrm{million}$ Btu of coal was used. Costs were developed at the appropriate Ca/S ratios for each case. For the current standards Ca/s ratios of $1.3,2.4$, and 1.2 were used for the conventional, AFBC and PEBC for all coal systems respectively. Under the new standards, the FBC ratios were increased to 2.9 and 1.7 for all coals. In actuality the two western coals will most likely require somewhat lower Ca/s ratios, but no specific design data were available. The differentials calculated should in any case provide a reasonable estimate of the magnitude of the change.

Figure 3-15 allows several interesting observations to be made. First, the AFBC technology actually appears to benefit, with respect to competition with PFBC and conventional technologies, from the imposition of more stringent NSPS: For all four coals, the cost difference for AFBC under current vs. proposed standards is lower than the cost differences for PFBC and the conventional system. Second, for western coals, the conventional system exhibits a large cost penalty under the proposed standards. The large penalty arises from the requirement for a full scrubber system, whereas under current standards, much or all of the flue gas could be sent directly to the 
stack without scrubbing. For the eastern coals, a high efficiency scrubber system is already necessary, and the new standards would simply require an increase in the efficiency of such a scrubber system. The fluid-bed system costs respond to changes in the sulfur removal requirements by incrementally increasing the various component costs such as limestone feeding and handing. The change in costs for the western coals is thus much less dramatic than for the conventional system.

For eastern coals, the PFBC system costs increase more than AFBC or conventional systems under the proposed standards. This is due to: the high sensitivity of the PFBC system to changes in the sorbent requirements. As the percent removal required increases, so does the Ca/s ratio, and therefore the sorbent feed rate. In Figure $3-15$, the $\mathrm{Ca} / \mathrm{S}$ ratio was increased 42 percent for the PFBC system.

\section{Sensitivity to Parameter Choice}

There are at least 10 parameters utilized in the cost models to which the results are sensitive, other than $\mathrm{Ca} / \mathrm{s}$ ratio and coal type. These include: (1) the prices for coal, limestone and sand; (2) the choice-of-disposal option; (3) the capital charge rate; (4) the plant factor; (5) the Operations and Maintenance (O\&M) factor; (6) the type of scrubber system and level of redundancy; (7) the degree of overdesign; and (8) the percent of sulfur retained in the ash after coal combustion. Each of these is discussed briefly in this section.

Figure 3-16 demonstrates the sensitivity of the cost analysis to changes in three of these parameters. The first set of bars represents a base case for the three technologies. Disposal of the wastes is offsite, the cheapest alternative available (except for the conventional system, 


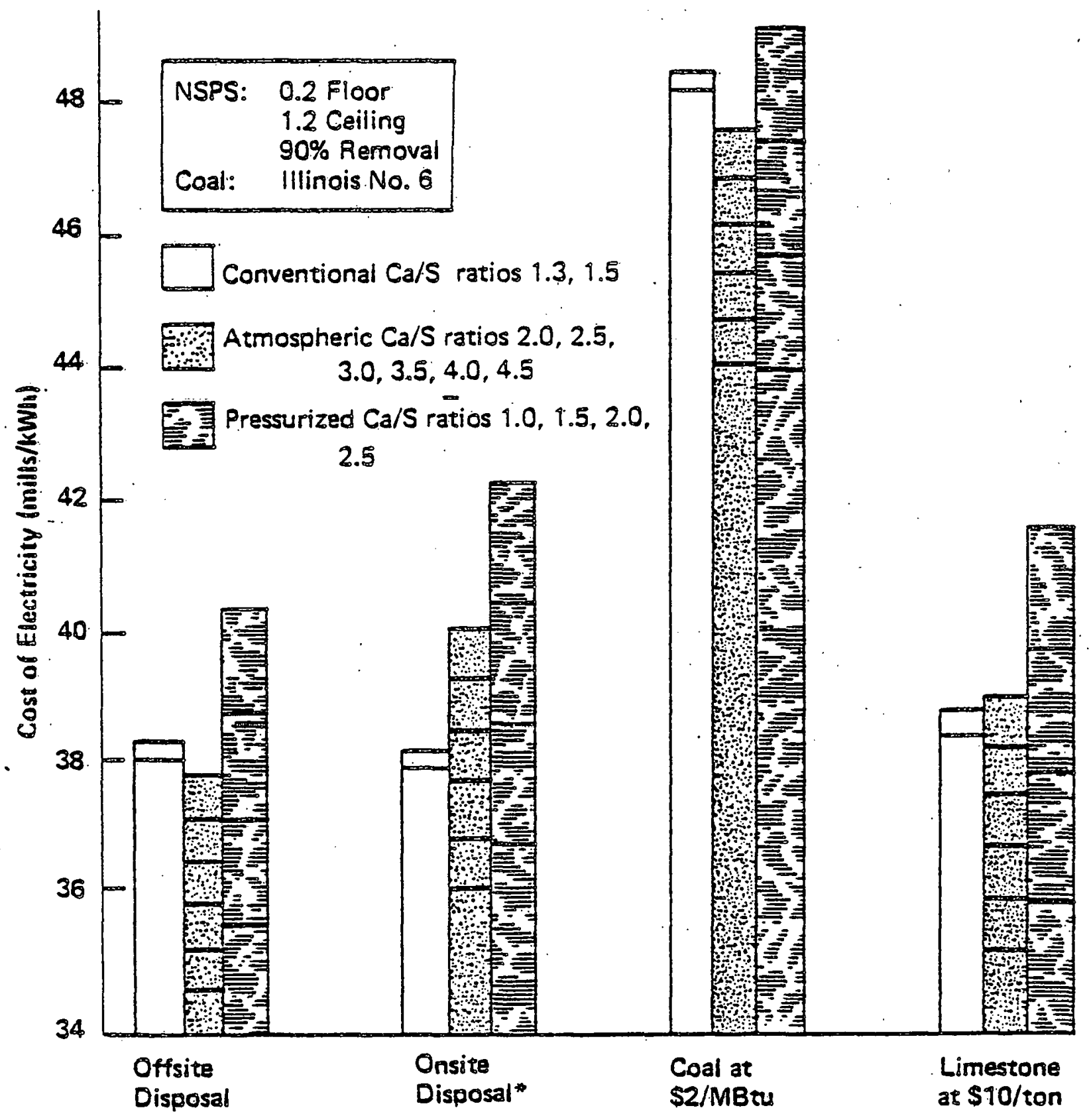

Figure 3-16. Sensitivity of costs to changing assumptions for conventional and fluidized-bed systems with base case coal.

* Most expensive alternative for FBC 
which requires the use of expensive chemicals). The NSPS for this case includes a 0.2 lb/million Btu floor, a 1.2 million Btu ceiling, and a removal requirement of 90 percent. The çoal used is Illinois No. 6 and the full 90 percent removal is required.

The second set of bars represents the case utilizing onsite disposal of the wastes. This represents a worst case for the fluidized-bed alternatives, as it assumes the solid waste will be sluiced to disposal ponds. The practice is currently the most common method of dealing with solid wastes from coal combustion, however, and in that sense it is proven. The primary reason it is so expensive is that the land costs are much higher for the ponds than for the "ravines" assumed in the other disposal (Iandfill) alternatives.

The costs for the conventional system are actually lower for onsite disposal because expensive chemical fixation will not be required. As the graph demonstrates, the competitive position of the conventional system has improved markedly and now is more favorable than pressurized FBC for almost all calcium-to-sulfur ratios, and competitive with atmospheric fluidized bed in the middle range of calcium-to-sulfur ratios. This result points out the sensitivity of the costs to the disposal costs. If the claims for ease of spent solids disposal for fluidized-bed systems fail to materialize, the technology will be less atrractive on a cost basis than it currently appears. Current understanding of waste characteristics and disposal options would indicate that offsite disposal of fluidized-bed wastes and onsite disposal of conventional scrubber wastes are the optimal choices. This comparison would resemble that of the "offsite disposal" item in Figure $3-16$ as the conventional system costs for on- and offsite disposal are quite similar. However, our understanding may change quickly if fluidized-bed wastes are found to be hazardous or otherwise problematic, or if regenerable 
technologies for scrubber applications are developed. Such regenerable technologies are likely to be quite expensive initially. However, if these technologies become practical, and especially if the costs for land and disposal continue to rise, then the fluidized-bed cost advantage will again disappear unless, of course, regenerable fluidized-bed processes are also developed.

The third set of bars assumes that disposal is offsite but that the cost of coal doubles to $\$ 2 /$ million Btu. The competitive positions of the FBC systems improves slightly as a result of their higher fuel efficiencies, but the effect is very small in comparison with the increase in costs for all systems. Such a result is likely to affect the overall rate of coal resource development but is likely to have little effect on the development of fluidized beds as opposed to conventional systems.

The fourth set of bars assumes that coal is $\$ 1 /$ million Btu but that the price of limestone has doubled to $\$ 10 /$ ton. All systems show an increase in cost, with the conventional system showing a better competitive position. This is due to the lower sorbent requirements in the conventional system. Under this assumption, the conventional system is more attractive than pressurized FBC for higher Ca/s ratios. Atmospheric FBC is still the least expensive, although it has lost much of its advantage over the conventional system. This result may limit the use of $F B C$ systems in areas where high quality limestone is quite scarce. In this case transportation costs would increase limestone costs significantly.

Two of the parameters listed at the beginning of this section are applicable only to the conventional system with wet scrubber. The two parameters are the degree of redundancy and the type of scrubber system. TVA examined four alternative scrubber systems. One, the lime scrubbing with onsite calcination, was the alternative specified in the original ECAS-based 
report by $G E$. The others were lime scrubbing (purchased lime), limestone scrubbing, and regenerable magnesium-oxide scrubbing. Onsite calcination is not currently being considered anywhere in the United states. ${ }^{7}$ The magnesiumoxide process is not yet available on a commercial utility scale. Of the remaining two, this study utilized limestone scrubbing in order that sorbent pricing could be consistent. I imestone scrubbing is also quite common. In addition to these options, other scrubbers are available on the market which are based on different types of scrubber towers. A detailed comparison is not possible here, and it must be assumed that the original design was more or less optimal for the system. Between the lime and limestone systems, the cost results are relatively insensitive. TVA estimates for the two options vary by $0.01 \mathrm{mil1} / \mathrm{kwh} .5$

The degree of redundancy raises a number of questions which are considerably more important in the current discussion. The operation of the boiler in a conventional system is not dependent on the FGD system. However, if emission standards are interpreted strictly; the operation of the boiler may be legally tied to the proper functioning of the scrubber system. Certain exceptions, such as for startup and emergencies, may be allowed but it can be assumed that lengthy operation with a nonfunctional scrubber will be illegal. Therefore, the question of scrubber availability becomes a direct concern related to overall system reliability. Reliability can be reasonably assured only by scrubbers with very high reliability or by system redundancy, i.e., functional spare scrubber modules. For the base case, we have assumed that the individual scrubber modules have an availability of 90 percent. To meet a criteria of 90 percent overall system availability, one spare scrubber module would be required for the four-module system. If scrubber modules could be provided with high enough availability (at a cost, of course), only four would be required. Also, if a utility would be willing 
to accept a lower reliability, the extra module could be avoided. The cost of electricity would be about $0.4-0.5$ mill/kWh lower in this case (representing the cost of the spare scrubber module not required).

The degree of overdesign for the sulfur removal system is very important. As presented earlier in Eigure 3-3, the percent sulfur in coal from the same mine can vary significantly from hour to hour and day to day. This fact can pose significant problems for a new coal-fired plant which must meet stringent emission limitation: In particular, a 90 percent removal requirement, averaged on a 2.4 hour basiș, will require that the variations of coal. sulfur content be considered in the design of the plant. Other factors which influence the operation of the $\mathrm{SO}_{2}$ removal systems may also vary, thus complicating the problem of compliance. For instance, limestone reactivity may vary a great deal, although very little data are available.

One possible means discussed above of assuring compliance in the face of such uncertainties is to overdesign the sulfur removal system so that the highest coal sulfur values and lowest limestone reactivity values can be accommodated without causing emission standard violations. Overdesign of these systems will have cost penalties, however, which can alter the attractiveness of one technology over another. Figure 3-17 presents a detailed comparison of conventional, AFBC and PFBC system costs for various levels of $\mathrm{SO}_{2}$ removal system overdesign for each of the four coal types used in this study. The conventional system with limestone scrubber exhibits the smallest sensitivity to overdesign, whereas the PFBC system exhibits the greatest sensitivity. This observation can be explained by the fact that the sorbent requirements for PFBC and $A F B C$ systems increase quite rapidly as the system overdesign increases. The sorbent flow rate is the sensitive parameter in this case and drives up the costs for AFBC and PFBC: Although the conventional system costs also escalate, the $\mathrm{Ca} / \mathrm{s}$ ratio is much lower and therefore the costs escalate at a slower rate. As could be expected, the cases where western coal is utilized exhibit much smaller penalties for 


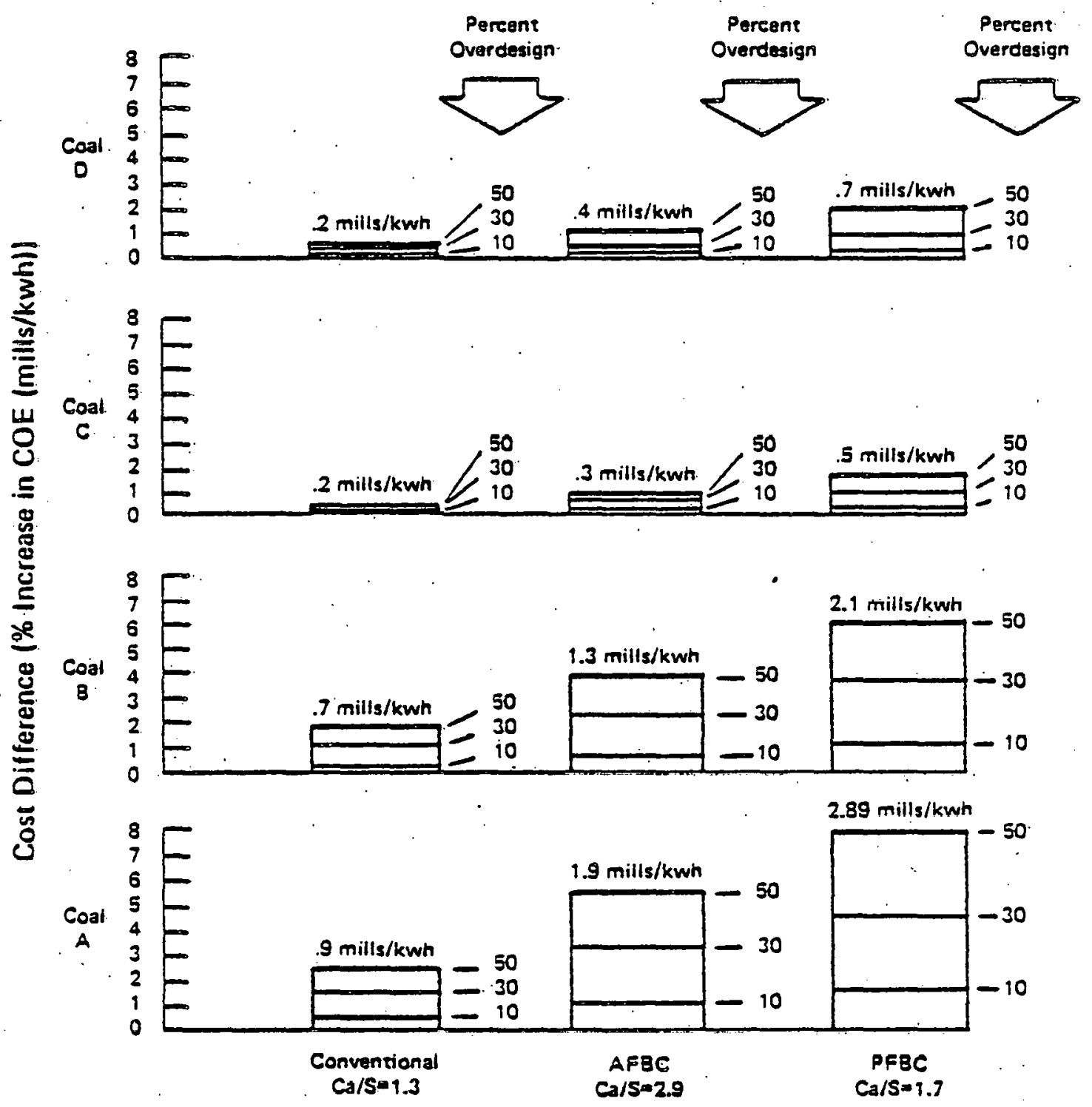

Figure 3-17. Cost penalty for overdesign in the $\mathrm{SO}_{2}$ removal system (assuming new NSPS). 
overdesign for all systems. This fact results from the much smaller quantities of sulfur that flow through the system.

For the 3.9 percent sulfur IIlinois coal (coal A), the penalty for 50 percent overdesign amounts to 2 percent of the COE for conventional systems and almost 6 percent of AFBC. Such overdesign would decrease the cost advantage of AFBC over conventiunal by about $1 \mathrm{mill} / \mathrm{k}$ ivh .

The effects of a higher price for land on FBC and conventional system costs will be reflected as an increase in the disposal costs. If the comparison of conventional with fluidized-bed systems assumes that both utilize the same disposal alternatives, the conventional system will always look more attractive than fluidized bed as the price of land goes up. The conventional. system produces less volume of solid wastes. However, if the comparison is between a conventional system with onsite disposal and a fluidized-bed system with offsite disposal, that tendency will be reversed because of the larger land area required for ponding as opposed to impoundment. Land cost in the base case was assumed to be $\$ 3,000$ per acre.

One variable with potential influence on sorbent and scrubber costs is the percent of sulfur in the coal which is retained in the ash. As discussed above, there are data indicating that in western coals, up to almost half of the sulfur can become combined with the ash. Wet scrubbing with fly ash is now an accepted alternative to lime or limestone scrubbing for some coals and is based on this principle. ${ }^{7}$ As the percent sulfur retained in the ash increases, the percent sulfur dioxide removal required goes down, provided the retention can be credited against the total requirement. 
The costs presented above show that as the percent removal required for the western coals decreases, the competitive position of fluidized-bed systems becomes weaker. This result may be important for some or all of the western coals, depending on the extent to which they exhibit sulfur retention. The result tends to offset the natural advantage the fluidized-bed systems have for combusting western coal.

Thus, for western coals, the policy on sulfur retention adopted can play a significant role in determining the future market for fluidized beds. A liberal policy will weaken their potential market. A no-credit policy could swing the pendulum considerably in the other direction. No credit for sulfur retention, depending on the compliance monitoring mechanism, could affect conventional systems and fluidized beds differentiy.

Since sulfur removal is an in situ process in FBC systems. it is virtually impossible (and immaterial) to determine whether the sulfur is captured by the ash or added sorbent. Compliance would have to be measured by comparison of inlet coal sulfur content (appropriately averaged) and system outlet emissions. In essence, then, it would be very difficult to account for ash retention.

Compliance in a conventional system could be determined by direct measurement of efficiency across the scrubbers, avoiding the above problem. In this case, it would be quite simple to require high percent removals, independent of sulfur retention. Such a dual policy, reflecting different monitoring approaches, would severely penalize conventional systems burning coals with high potential ash retention. Such coals include a substantial quantity of the lignites and subbituminous coals of the Northern Great Plains. 
The assumptions concerning the capital charge, the OsM cost factor, and the plant factor are important for determining the cost of electricity but have no influence over the capital costs. The effects of changes in these assumptions are limited due to the fairly narrow range of acceptable. values: for the parameters.

The O\&M factor, 1.95 percent of total capital costs per year, essentially penalizes the higher capital cost systems by assessing a higher O\&M charge. This effect may be important for pressurized fluidized beds in particular due to their high capital costs. The overall effect is small, however. More important is the possibility that the O\&M costs vary widely from that indicated by the o\&M factor. Although there is fairly close agreement with TVA O\&M estimates, other sources estimate much higher O\&M costs. For instance, Pedco ${ }^{8}$ presents estimates for the O\&M costs of scrubbers alone which exceed the TVA O\&M estimates for the entire conventional system. The Pedco estimates are also much higher than 1.95 percent of total capital costs. If Pedco is correct, the conventional system would prove much less attractive on a cost basis. On the other hand problems and difficulties associated with the design and operation of coal and limestone feeding equipment in FBC systems have not been solved. Such problems may persist for some time in plants and may increase the O\&M expenses considerably. There is a good possibility that o\&M costs for fluidized-bed systems will be higher than initially estimated, at least until the technology becomes familiar.

The 18 percent capital charge factor is broady accepted, although other values have also been used. ${ }^{8}, 9$ Increases in this factor would also tend to penalize the more expensive systems, such as pressurized FBC. Eowever, the effect is small, and will generally not change from system to system. 
The plant factor determines the power that a plant. produces over the course of a year. Although 65 percent is not terribly high, it is often used. For new, large, coal-fired plants. If the plant factor is higher, the cost of electricity for all plants would be reduced. Only base-load plants were considered in this analysis. Cycling applications, where plant factor would be less than 0.5 , were not examined.

The cost of electricity from FBCs will be sensitive to other design choices not included in this analysis. Most significantly, bed depth was kept constant in all of the calculations, even the several Westinghouse cases. Changes in bed depth would affect the $\mathrm{Ca} / \mathrm{S}$ ratio required to achieve a given level of sulfur removal and the fan size. Increased bed depth should reduce $\mathrm{Ca} / \mathrm{S}$ ratio but increase fan power requirements.

The data generated in this report are based on data and assumptions from a number of other studies, but with some changes. A comparison of the results with these studies is. presented in Appendix B. 


\section{3.: Energy Penalty Effects}

In this section, potential energy penalties, expressed as decrements in plant efficiency, are discussed. The effects of a revised NSPS compared to the existing standard and the effects of varying degrees of stringency in the revisions are included. Figure $3-1.8$ presents the data on which this analysis in based. Plant efficiency is plotted against Ca/s ratio for the several different coal types and systems.

A revised NSPS with 90 percent removal and a 0.2 floor was used as a basis of comparison with the existing NSPS. The percent removals for these cases for each coal type is indicated in Figure 3-18.

For high sulfur coals (types $A$ and $B$ ) in conventional systems, the energy penalty in moving to a cevised NSPS will be insignificant, as the removal required currently is close to that which may be required under a revised NSPS. For low sulfur coals the change is just the opposite; a dramatic increase will result.

For the compliance coal (coal $\mathrm{C}$ ), the penalty would be severe, amounting to nearly one percentage point or a decrease of about three percent in plant output. This arises as a result of requiring scrubbers where none had been needed under the old NSPS. The energy penalty is due to fan power needed to overcome scrubber pressure drop, 


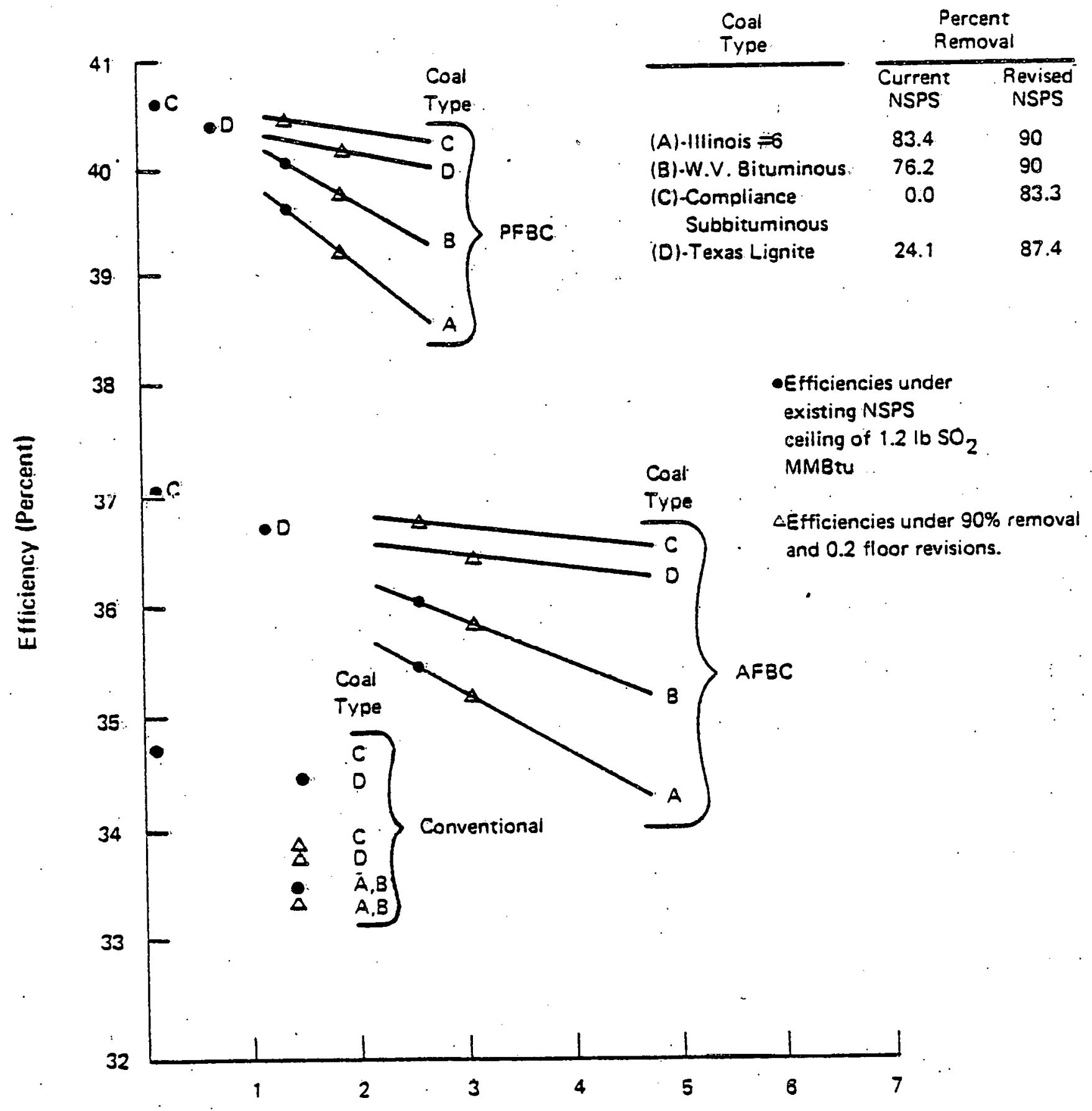

$\mathrm{Ca} / \mathrm{S}$ Ratio

Figure 3-18. Plant efficiencies. 
liquid pumping, and plume reheat. In the lignite, the penalty is not quite so severe, as even under the existing NSPS, some scrubbing (about 25 percent) was required.

The energy penalty in conventional systems is quite insensitive to the degree of sulfur removal required. The major source of energy penalty, plume reheat is not affected by percent removal once the level is sufficientily high to preclude bypass of part of the flue gas.

The efficiencies of AFBC and PFBC, on the other hand, depend guite significantly on the numerical values of the standard. The major sources of energy loss in FBC systems are sorbent calcination, sorbent grinding and feeding, and pressure drop. The major item in this list is sorbent calcination loss which is a direct function of $\mathrm{Ca} / \mathrm{s}$ ratio, as implied by the curves in Figure $3-18$.

To estimate the energy penalty, it is assumed, as in the cost analysis, that the present standard could be achieved (for high sulfur coals), at Ca/s ratios of 2.4 and 1.2 for the AFBC and PFBC respectively, and that under the 90 percent removal revised scenario, these would increase to 2.9 and 1.7 , respectively.

The results (compare the dots to triangles in Figure 3-18) for the high sulfur coals are a decrease of about 0.2 to 0.3 percentage points for $\mathrm{AFBC}$ and about 0.3 to 0.4 percentage points for BFBC. For lignite (coal D), it was assumed that the small degree of removal under current isSPS could be obtained at lower $\mathrm{Ca} / \mathrm{s}$ than required for the high sulfur coals. Assuming lower $\mathrm{Ca} / \mathrm{S}$ ratios as indicated by the dots for coald, efficiency loss would be quite small in both $A F B C$ and $P F B C$, about 0.2 percentage points. 
The case for compliance coal (coal C) is quite different. Under the existing NSPS, no sulfur removal would be required. No sorbent would be required. An inert fluidizing medium would be used instead. Such inert systems were the original basis for FBC development. At present, however, no active developments of such systems are known to be under way in this country. Foreign vendors are now offering up to industrial scale inert $F B C$ systems for sale. In order to develop a comparison, performance of an inert FBC was estimated by using a $\mathrm{Ca} / \mathrm{S}$ ratio of zero in the model. The result indicates a sull energy ponalty of about 0.2 percentage points for both systems.

Energy penalties for varying degress of stringency, as sulfur removal percent, can be estimated by comparing values at the appropriate $\mathrm{Ca} / \mathrm{s}$ ratios. In general, the efficiency in both AFBC and PFBC systems shows a strong dependence on Ca/s ratio for high sulfur coals. Thus, there will be a significant loss in going from 85 percent, say, to 90 percent or more.

The figure shows the general ranking of efficiencies for the three systems. PFBC is the most efficient, being based on a combined cycle. Much of the difference in AFBC and conventional system efficiency is due to plume reheat requirements. 


\subsection{Solid Waste Aspects}

The solid waste implications of the revised New Source Performance Standards must be considered in assessing overall environmental consequences. At current levels of combustor and pollution control technology development, tighter air emission standaras mean an exacerbation of already difficult solid waste disposal and leachate prevention problems. The tremendous quantities of solid waste from both FBC and scrubber systems pose, per se, a large potential impact, made more complex by the presence of toxic substances. Given the rather sparse data now extant a thorough assessment is difficult. The following analysis attempts to highlight the nature of the problems for both $F G D$ and FBC systems.

\subsubsection{Sludge Composition}

In a conventional pulverized coal-fired system with FGD, the principal components of the solid waste stream are coal ash and FGD sludge. Coal ash can be divided into two components-fiy ash and bottom ash. Fly ash is the major ash product in pulverized coal systems and is a natural pozzolan." For both fly and bottom ash, the types and

A pozzolar is a siliceous material having no inherent cementitious properties, but which, in finely divided form and in the presence of moisture, chemically reacts with alkaline earth hydroxides to form a cementitious compound. Fly ash may be mixed with FGD sludge prior to disposal in a pond or lagoon. 
amounts of trace elements present will depend upon boiler operating features and coal characteristics. FGD wastes are a liquid-solid mixture containing four principal crystalline phases: (1) calcium sulfite, (2) calcium sulfate, (3) fly ash, and (4) unreacted lime or limestone appearing as calcium carbonate. The relative amounts of each of the solid crystalline phases is dependent upon several system design parameters, including whether lime or limestone is used as the alkaline additive, coal sulfur content, scrubber efficiency, fly ash amounts and removal efficiency, molar ratio of calcium. to sulfur, absorbent utilization efficiency, and extent of sulfur product oxidation.

Sludge liquors have been found to consistently exceed drinking water standards for total dissolved solids, and to have high concentrations of calcium, sulfate, and chloride (and, in some cases, magnesium and sodium). In addition, excessive concentrations of several trace metals have been noted, to which fly ash has been shown to be a major contributor. 10 Representative values for the chemical compositions of coal ash and FGD sludge are shown in Table 3-4.

Also presented in Table 3-4 are typical chemical compositions for FBC solid wastes. In an FBC system, the solid wastes consist of coal ash and spent sorbent from the fluidized bed as well as a mixture of sorbent and fly ash that is collected in the particulate control system. The final composition of the FBC wastes is determined by the input coal characteristics, the combustor operating conditions, and the composition of the limestone (atmospheric) or dolomite (pressurized) sulfur absorbing 


\section{TABLE 3-4}

IYPICAL CHEMICAL COMPOSITIONS OF COAL ASH, FGD SLUDGE, AND FBC SOLID WASTES

(wt. percent of dry solids)

\begin{tabular}{|c|c|c|c|c|c|c|c|c|}
\hline \multicolumn{3}{|c|}{ COAL ASH ${ }^{10}$} & \multicolumn{3}{|c|}{$F G D^{5}$} & \multicolumn{3}{|c|}{$F B r^{5}$} \\
\hline & Bottom Ash & Fly Ash & & Limestone & Lime & $\therefore$ & $\begin{array}{l}\text { Atmo- } \\
\text { spheric }\end{array}$ & Pressurized \\
\hline $\mathrm{SiO}_{2}$ & $20-60$ & $28-60$ & $\mathrm{CaSO}_{3} \cdot \mathrm{H} / 2 \mathrm{H}_{2} \mathrm{O}$ & 46 & 76 & $\mathrm{CaSO}_{4}$ & 42 & 26 \\
\hline $\mathrm{Al}_{2} \mathrm{O}_{3}$ & $10-35$ & $12-36$ & $\mathrm{CaSO}_{4} \cdot 2 \mathrm{H}_{2} \mathrm{O}$ & 26 & 18 & $\mathrm{CaO}$ & 24 & 13 \\
\hline $\mathrm{Fe}_{2} \mathrm{O}_{3}$ & $5-35$ & $14-40$ & $\mathrm{CaCO}_{3}$ & 26 & -- & $\mathrm{MgO}$ & 0 & 16 \\
\hline $\mathrm{CaO}$ & $1-20$ & $1-85$ & $\mathrm{CaO}$ & -- & 5 & Ash & 31 & 42 \\
\hline MgO & $.3-4$ & $0-5$ & Insolubles & 2 & 1 & C & 3 & 4 \\
\hline $\mathrm{Na}_{2} \mathrm{O}$ & $1-4$ & $0-2$ & & . & & & & \\
\hline $\mathrm{K}_{2} 0$ & $1-4$ & $0-2$ & . & & & & & \\
\hline $\mathrm{SO}_{3}$ & -- & $0-4$ & & & & & & \\
\hline
\end{tabular}


agent. * In general, FBC wastes will consist of unburned coal or carbon, coal ash, urieacted lime (or Cao.Mgo for pressurized systems), calcite (or $\mathrm{CaCO}_{3} \cdot$ Mgo for pressurized), calcium sulfate, and perhaps small fractions of calcium sulfite and Cas. Calcium sulfate and calcite are the most stable of these compounds and are therefore most suitable for direct disposal without further processing. Calcium oxide will hydrate to form calcium hydroxide in an exothermic reaction upon contact with water and so is undesirable in a landfill. Magnesium oxide does not hydrate at atmospheric pressure.

Although somewhat similar in chemical composition, $F G D$ sludge and $F B C$ solid waste are not at all similar in physical characteristics. The physical properties of FGD sludge vary considerably from system to system. However, FGD sludge is a thixotropic, partially oxidized slurry that settles to about 40-50 percent solids content by weight. since the thixotropic slurry tends to liquefy easily, it is very difficult to handle and secondary dewatering techniques such as centrifuging and vacuum filtering do not reliably yield the $70-75$ percent solids needed prior to landfilling.

A number of approaches to enhancing physical stability have been developed, including stabilization through underdrainage and compaction, production of gypsum, and chemical

* In general, limestone consists of more than 80 percent calcium carbonate, while dolomite consists of approximately equal molar fractions of calcium and magnesium carbonates. In a pressurized system, due to inhibited calcination of. $\mathrm{CaCO}_{3}$ at super-atmospheric pressures, dolomite is a more effective absorbing agent for $\mathrm{SO}_{2}$. 
treatment ("fixation") for landfill. The latter approach appears to be most promising (and most costly), resulting in improved structural properties as well as major reductions in solubility and permeability. Much testing remains to be done, however, and, at present, most FGD sludges are not disposed in ponds lined with an impermeable membrane to prevent adverse groundwater impacts. In contrast, FBC waste is a dry, pebbly, whitish brown, almost fully oxidized solid. Thus, the primary environmental concern with FBC waste is its leachate characteristics once it has been disposed. At this time only very limited experimental leaching data, collected in the laboratory, are available and so the environmental impacts of largescale FBC waste disposal cannot be adequately characterized. It is clear, however, that if direct landfill is environmentally acceptable, then the land impacts. (and the costs) of FBC waste disposal should be less than those of FGD sludge disposal.

\section{5 .2 Quantities of Solid Waste}

Many factors determine the quantities of ash, sludge, and other wastes generated when coal is used as the primary fuel in electric power production, including:

1. Boiler design

- rated capacity

- efficiency

2. Coal quality

- heating value

- ash and sulfur content 
3. Percent sulfur removal required in FGD system and in fluidized-bed combustor

4. FGD system design
- alkaline acditive used
- once-through or regenerable

5. FBC sorbent

- calcium carbonate molar fraction

(i.e., reactivity)

- inert material content

In the case of FBC systems, for given coals and sorbents, the percent sulfur reduction required of the system determines the molar ratio of calcium to sulfur that must be maintained in the combustor. A prime complicating factor is the variability that is known to exist in both coal and sorbent chemical composition and properties. ${ }^{1}$

The solid waste generation rate in FBC systems is directly related to the rate of sorbent feed and., in general, the quantities of solid waste produced will be of the same order of magnitude as that produced in conventional systems. With the same range of $\mathrm{Ca} / \mathrm{s}$ ratios used throughout, a. comparison is provided in Table 3-5 for nominally sized 800 Mwe (net) power plants. The basic equation used to compute solid'waste generation, according to the assumptions shown with Table $3-5$, was as follows:

$$
\begin{aligned}
& F S S=\frac{F C^{*} P A}{100}+\frac{P S}{32 * 100}\left[\left(P R^{*} \frac{M_{W S}}{100}\right)+\left(C S-\frac{P R}{100}\right) M W S_{2}\right] F C \\
& \text { where } F S S=\text { flow rate of solid wastes }(1 \mathrm{~b} / \mathrm{hr}) \\
& F C=\text { coal feed rate }(1 \mathrm{~b} / \mathrm{hr}) \\
& \mathrm{PA}=\text { percent ash in coal }\left(\frac{s}{2}\right)
\end{aligned}
$$


TABLE $3-5$

COMPARISON OF SOLID WASTE GENERATION IN CONVENTIONAL SYSTEMS WITH LIMESTONE FGD AND FLUIDIZED-BED SYSTEMS

\begin{tabular}{|c|c|c|c|c|c|c|c|}
\hline \multirow[b]{2}{*}{$\begin{array}{c}\text { Conventional } \\
\text { Systems }\end{array}$} & \multirow{2}{*}{$\begin{array}{l}\text { Design } \\
\text { Molar } \\
\text { Ratio } \\
\text { Ca/S } \\
\end{array}$} & \multirow{2}{*}{$\begin{array}{c}\text { Percent } \\
\text { Calcium } \\
\text { Utiliza- } \\
\text { tion } \\
\end{array}$} & \multirow{2}{*}{$\begin{array}{l}\text { Percent } \\
\text { Solids } \\
\text { in } \\
\text { Waste } \\
\end{array}$} & \multicolumn{4}{|c|}{ Sol id Waste (1000 Tons Per Year) } \\
\hline & & & & $\begin{array}{c}\text { Coal A } \\
(10788,3.9,9.6)^{3} \\
\end{array}$ & $\begin{array}{c}\text { Coal B } \\
(13280,3.35,7.5) \\
\end{array}$ & $\begin{array}{c}\text { Coa) } C^{\prime} \\
(8020, .48,6.4)\end{array}$ & $\begin{array}{c}\text { Coal } 0^{2} \\
(7590, .6,10.4)\end{array}$ \\
\hline $\begin{array}{l}\text { Atmospheric FBC } \\
\text { (Limestone) }\end{array}$ & $\begin{array}{l}2 \\
3 \\
4\end{array}$ & $\begin{array}{l}45 \\
30 \\
23\end{array}$ & $\begin{array}{l}100 \\
100 \\
100\end{array}$ & $\begin{array}{l}645 \\
782 \\
920\end{array}$ & $\begin{array}{l}437 \\
534 \\
630\end{array}$ & $\begin{array}{l}246 \\
268 \\
292\end{array}$ & $\begin{array}{l}395 \\
426 \\
455\end{array}$ \\
\hline $\begin{array}{l}\text { Pressurized FBC } \\
\text { (Dolomite) }\end{array}$ & $\begin{array}{l}1.5 \\
2 \\
3\end{array}$ & $\begin{array}{l}60 \\
45 \\
30\end{array}$ & $\begin{array}{l}100 \\
100 \\
100\end{array}$ & $\begin{array}{l}660 \\
768 \\
876\end{array}$ & $\begin{array}{l}450 \\
525 \\
600\end{array}$ & $\begin{array}{l}236 \\
254 \\
272\end{array}$ & $\begin{array}{l}377 \\
400 \\
424\end{array}$ \\
\hline $\begin{array}{l}\text { Conventional FGD } \\
\text { (Limestone) }\end{array}$ & $\begin{array}{l}1.3 \\
1.3\end{array}$ & $\begin{array}{l}75 \\
75\end{array}$ & $\begin{array}{l}50 \\
70\end{array}$ & $\begin{array}{r}1032 \\
797\end{array}$ & $\begin{array}{l}707 \\
543\end{array}$ & $\begin{array}{l}321 \\
282\end{array}$ & $\begin{array}{l}498 \\
447\end{array}$ \\
\hline
\end{tabular}

\footnotetext{
Assumptions: (1) Dry coal ash added to FGD sludge for disposal.

(2) Waste compositions are as shown in Table 3-4.

(3) Limestone is 100 percent $\mathrm{CaCO}_{3}$; dolomite is 100 percent $\mathrm{CaCO}_{3} \cdot \mathrm{HgCO}_{3}$.

(4) Plant capacity is 800 MWe (net): plant load factor is .65 (5674 $\mathrm{hr} / \mathrm{yr}$ ).

(5) Plant efficiencies are .36 for AFBC, .40 for PFBC, and .33 for conventional with FGD.

(6) Regulatory Case 2: $\mathrm{SO}_{2}$ standards are .2 floor, 1.2 ceiling, and 90 percent removal.

Notes: $\quad$ 1. For Coal $\mathrm{C}$, the $\mathrm{SO}_{2}$ standards are met with 83.3 percent removal.

2. For Coal $D$, the $S 0_{2}^{2}$ standards are met with 87.4 percent removal.

3. Numbers in parentheses are: coal heating value in Btu/lb, sulfur content, ash content.
} 


$$
\begin{aligned}
& \text { PS }= \text { percent sulfur in coal }\left(\frac{q}{)}\right) \\
& \text { PR }= \text { percent sulfur removal required to } \\
& \text { comply with so } 2 \text { emission limitations } \\
& \text { CS }=\text { molar ratio of calcium to sulfur used } \\
& \text { in sulfur removal system } \\
& \text { MWS }_{1}=\text { molecular weight of reacted sorbent } \\
& \mathrm{MWS}_{2}=\text { molecular weight of unreacted sorbent }
\end{aligned}
$$

\subsubsection{Disposal Considerations}

Currently, there are no Federal regulations governing the disposal of FGD sludge. The Resource Conservation and Recovery Act of 1976 (RCRA), however, provides for Federal regulations for hazardous waste disposal and Federal guidelines (to be used by the states) for non-hazardous solid waste disposal. The RCRA specifically identifies solid wastes and sludges, including those generated by air pollution control devices, as being covered by the Act. At present it appears that FGD sludge will be classified as non-hazardous, with disposal guidelines to be issued in two to three years. ${ }^{12}$ The question of RCRA applicability to wastes from $F B C$ has not yet been addressed, but it seems likely that a similar position would be taken.

Unlike FGD wastes, FBC wastes are dry, oxidized solids that may be suitable for landfill. However, as in the case of FGD sludges, the greatest pollution potential is that posed by water percolating through the wastes and subsoil into the groundwater system. Surface water degradation due to runoff from landilis is also of concern. Although there are little or no data available with which to characterize the leaching potential of FBC wastes, 11,13 , the 
disposal problem for FBC wastes can be brought into perspective by considering current disposal practices for conventional system coal ash and FGD wastes.

The environmental impact of FGD sludge disposal is determined by the properties of the sludge in conjunction with the geological and hydrological features of the disposal sites. The so-called "environmental acceptability" of the sludge is a consideration secondary to the primary problem of controlling the behavior of the sludge under the disposal method applied. The feasible disposal alternatives for a given plant will be constrained by sitespecific conditions such as distance to disposal site, topography, weather, soil characteristics, water table depth, and ground water characteristics. Furthermore, each disposal method has associated features of complexity, cost, pollution potential, land requirements, reclaimability, and stage of technical development. ${ }^{14}$

Regardless of the disposal method utilized, the leaching potential of FGD (and FBC) wastes must be reduced or eliminated. Basically, there are two types of environmentally sound disposal methods for FGD wastes: (1) ponding of untreated waste, and (2) landfilling with chemically treated or physically conditioned waste. The various disposal options can be described as some combination of the following: 14

1. Type of Disposal

- Ponding - the waste slurry is sluiced to a disposal site and supernate recycled to the scrubber system.

- Basin Disposal - disposal in a closed site wherein runoff is contained and underdrainage provided to recycle excess waters to the scrubber system. 
- Landfill - an oper site wherein runoff is not contained.

2. Condition of Waste

- Untreated - as received from primary or secondary dewatering.

- Chemically Fixed - treated chemically to alter permeability and leachability characteristics, thereby rendering the wastes suitable for landfill.

- Conditioned - treated by techniques other than chemical fixation, such as by oxidation to gypsum and dewatering by mixing with dry fly ash, to allow the material to be handled like a soil.

These general categories for FGD sludge disposal and associated environmental control requirements are indicated in Table 3-6. The ponding method of sludge disposal represents an extension of state-of-the-art methods of fIY ash disposal. The environmental impact of pond disposal is primarily dependent upon the ability to prevent leachate contamination of groundwater. This is a problem in any sludge disposal scheme. Runoff is a potential source of pollution for landfill sites, which, by definition, are open and do not generally recycle water to the scrubber. Iand reclamation is most feasible in the case of landfill disposal, but techniques for reclamation (i.e., drying, grading, vegetating) of ash and sludge ponds have been successfully applied on an experimental basis.

Control of leachate and resultant groundwater contamination can be accomplished either by: (I) lining the pond or landfill with clay, impermeable soil cements, or synthetic materials, or (2) chemically treating the sludge to reduce permeability and solubility. Note that basin disposal, a major variation on the ponding method of disposal, involves leachate recycling via an underdrainage system and does not require a disposal basin liner. 
TABLE 3-6

DISPOSAL OPTIONS AND ENVIRONMENTAL EFFECTS

\begin{tabular}{|c|c|c|c|c|c|}
\hline \multirow{2}{*}{$\begin{array}{l}\text { Type of } \\
\text { Disposal }\end{array}$} & \multirow{2}{*}{$\begin{array}{l}\text { Condition } \\
\text { of Waste }\end{array}$} & \multirow{2}{*}{$\begin{array}{l}\text { Primary } \\
\text { Orainage }\end{array}$} & \multicolumn{3}{|c|}{ Environmental Effects } \\
\hline & & & Seepage & Runoff & Reclamation \\
\hline \multirow[t]{2}{*}{ Ponding } & Untreated & Supernate & Yes & No & No \\
\hline & $\begin{array}{l}\text { Chenically } \\
\text { Fixed }\end{array}$ & Supernate & Yes & No & Yes. \\
\hline \multirow[t]{3}{*}{ Basin } & Untreated & $\begin{array}{l}\text { Under. } \\
\text { drainage }\end{array}$ & Yes & No & No \\
\hline & $-\infty-\infty+\infty+\infty+\infty=\infty-\infty$ & $-\infty-\infty-\infty-\infty-\infty-\infty$ & & & \\
\hline & Conditioned & $\begin{array}{l}\text { Under- } \\
\text { drainage }\end{array}$ & Yes & No & No \\
\hline \multirow[t]{2}{*}{ Landfill } & Conditioned & Rungff & Yes & Yes & Yes \\
\hline & $\begin{array}{l}\text { Chemically } \\
\text { Fixed }\end{array}$ & Runoff & Yes & Yes & Yes \\
\hline
\end{tabular}

Source: Reference 14. 
Several commercial processes are available for chemically treating FGD sludges to improve their environmental acceptability. Although the chemistry is complicated, the general scheme for fixation is to alter the crystalline structure of the sludge through oxidation of sulfite to sulfate, adding a pozzolanic material such as fly ash, or bonding the water in a hydrated form through addition of lime or calcium sulfate. In general, the soluble salt content in the leachate from treated sludge is typically one-half or less than that of untreated sludge. Also, the permeability of treated sludge is typically at least one order of magnitude less. Therefore, the expected dissolved salts leaching from treated sludge are considerably less than from untreated sludge. The environmental impact of treated sludge should be less than that of untreated sludge under most. disposal methods. ${ }^{14}$ This conclusion has not been proven, however, on a large scale over a long time period.

\section{Summary}

The major differences between FGD wastes and FBC wastes are listed below:

1. FBC wastes are dry whereas FGD waste is a thixotropic slurry. Thus, FBC wastes are physically suitable for direct disposal in a landfill while FGD sludge must be dewatered and chemically stabilized prior to landfilling.

2. FBC wastes are more highly oxidized than $F G D$ wastes and this added chemical stability should provide resistance to leaching. However, leachate formation and control is a case-specific problem and 
few leachate experiments, for both FGD and FBC wastes, under actual landfill conditions have been conducted.

3. FBC wastes contain higher concentrations of trace elements than FGD wastes. This is primarily due to lower FBC operating temperatures. However, since FBC wastes are more stable and usually more alkaline, the trace elements may be less likely to leach. Final conclusions cannot be made at this time.

4. FBC wastes are generally more alkaline than Fri. sludges, which may result in inhibited metal salt leaching. However, this again will depend on the landfill conditions and cannot be confirmed until FBC waste is studied under these conditions.

First, in the presence of water, calcium oxide ( $\mathrm{CaO}$ ) will hydrate readily to form calcium hydroxide, $\mathrm{Ca}(\mathrm{OH}){ }_{2}$. This reaction is exothermic and high heat release rates are not desired in landfills. Second, calcium and sulfate concentrations in experimental FBC waste leachate tests exceed water quality criteria. This may be a significant problem in lightof the large quantities of waste generated by the FBC. Leaching of chlorides, sulfates and calcium may cause drinking water to have high mineral content ("hard" water) if they leach into the water supply. This latter problem is common to both FBC and $\mathrm{FGD}$ wastes.

The environmental implications of FGD and FBC solid wastes are significant because the quantities of material to 
be disposed of are so great. On a $1 b$ per $1 b$ basis, the ratio of spent solids (excluding ash) to coal input for FBC systems will be in the range from 0.3 to 0.5 for 4 percent sulfur eastern coal, while the ratio of spent solids to coal ash will range from 2 to 8 . For a conventional FGD system, the ratio of FGD sludge (50 percent solids) to coal input $(1 b / 1 b)$ is about 0.4 for 4 percent sulfur eastern $\operatorname{coal}^{3}$ 


\section{REFERENCES TO CHAPTER THREE}

${ }^{\text {I}}$ Pessonal communication, R. Statnick, EPA, to John Ehrenfeld, ERCO (January 1978).

${ }^{2}$ Eaison Electric Institute Equipment Availability, Composite Unit Sumary Report 1974, Fossil Units 1964-1974, 600 MW and above. The outage rate for the boiler includes failures in both EPS and EGD systems.

${ }^{3}$ Westinghouse R\&D Center, Evaluation of the Impact of SO, and Particulate Emission Standards on Fluidized-Bed Combustion System Energy Cost, EPA/IERL (September 1977); Westinghouse R\&D Center; Submission to John Ehrenfeld, ERCO (December 1977); and Westinghouse R\&D Center. Assessment of the Impact of Sulfur Dioxide, Particulate and Nitrous Oxide Emission standards on FBC System Design and Energy Costs, EPA/IERI (January 9, 1978).

4. General Electric, Energy Conversion Alternatives Study (ECAS): Phase II, Einal Report, NASA, ERDA, and NSF (December 1976)。

5Tennessee Valley Authority, Cost Comparison of Commercial Atmospheric and Pressurized Fluidized-Bed Power Plants to Conventional Power Plants with Flue Gas Desulfurization, EPA R\&D (March 1977).

${ }^{6}$ Bechtel Corp., Coal-Fired Power plant Capital cost Estimates, EPRI (January 1977).

7 Personal communication, Larry Gibbs, Pedco Environmental, to George Gantz, ERCO (December 1977).

${ }^{8}$ Pedco Environmental, Particulate and Sulfur Dioxide Emission Control Costs for Large Coal-Fired Boilers, EPA (December 1977).

9 MITRE Corporation/METRER Division, Analyses of Benefits Associated with the Introduction of Advanced Generating Technologies: Description of Methodologies and Summary of Results Einal Report: Electric Utility Study, ERDA (March 1977).

${ }^{10}$ Energy Resources Company Inc., Utility Analysis of Coal Transportation Availability, Task 2: Transportation and Disposal of Coal Ash and FGD Sludge for the New England ESECA Candidates, EEA (February 1977). 


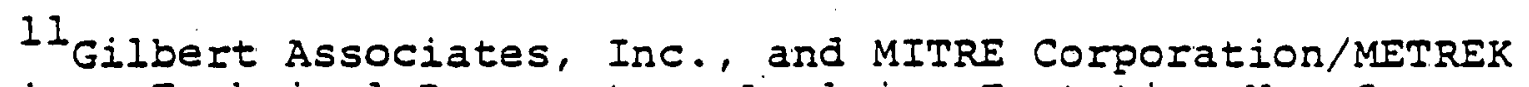
Division, Technical Document on Applying Tentative New Source Performance Standards for Coal-Fired Steam Generators to Fluidized-Bed Combustors, DOE draft (November .1977).

12 Jones, J.W. et al., "Environmental Management of Effluents and Solid Wastes from Steam Electric Generating. Plants," Energy/Environment II, Second National Conference on the Interagency R\&D Program, sponsored by EPA Office of Energy, Minerals and Industry (Washington, D.C., June 6-7, $1.977)$.

${ }^{13} \mathrm{GCA}$ Corp. , Preliminary Environmental Assessment of Coal-Fired Fluidized-Bed Combustion Systems, EPA (May 1977).

${ }^{14}$ Rossoff, J. et al., The Aerospace Corporation, Disposal of By-Products from Nonregenerable Flue Gas Desulfurization Systems: Second Progress Report (May 1977). 
CHAPTER FOUR

POLICY IMPLICATIONS CONCERNING NEW SOURCE PERFORMANCE STANDARDS FOR STEAM-ELECTRIC GENERATORS

\subsection{Introduction.}

The Clean Air Amendments of 1977. (PI 95-95) require the Administrator of the Environmental Protection Agency to revise the New Source Performance Standards at regular intervals not to exceed four years. The first such revision will be proposed early in 1978 and will be the standard for steam-electric generators. The amendments directed the Administrator to incorporate requirements for a continuous percent reduction in the standards for energy sources as well as emission limitations characteristic of the previous set of standaras.

At the same time that this new approach to stancard setting is to be taken with regard to conventional power plants, a sumber of new technological approaches to power generation are in various stages of development. The development of these technologies, particularly those promoting the use of coal relative to oil or gas, are very important in dealing with our energy requirements in the future.

Although there appear to be environmentally satisfactory coal-using technologies emerging, coal is inevitably a more environmentally damaging fuel than either gas or oil. This is true not only in the end use of the product but in almost every stage of its use, from mining through transportation, and in the processing of coal prior to end use. 
This conflict adds to the difficult task of setting standards for emerging technologies. The New Source Performance Standards, reflecting the BACT provisions of the Act, are designed to be technology forcing, in the sense of recognizing the best available technology for control of a particular process. New technologies implicitly should be able to meet the environmental performance levels of existing or best available technology, unless there are compelling reasons based on economic, energy, or environmental benefits other than those which would be obtained by setting standards for atmospheric emissions at least as stringent as those for present available technology.

The problem of setting standards for emerging energy technology is confounded also by the paucity of environmental. data characteristic of development projects. The principal objectives during early development are not environmental goals but more directly reflect productive use goals for the technology. In the case of energy technologies, the goals are principally economy and efficiency. In the quest of these goals, it is often difficult to incorporate a comprehensive view of the upper limits of environmental performance available through the optimization of the overall technological process.

Although the timing of the setting of standards is very complicated with respect to its effect on the development and the commercialization process, two alternatives, more or less, characterize the process. If the standard is set early on the basis of data available at laboratory or pilot stage or if the standard is set reflecting the performance of existing technology, then it is possible that the developers 
of the new energy technology will become discouraged and abandion the project. Presuming that the new process would provide benefits, even environmental benefits, significantly greater than existing technologies, then this consequence could preempt a substantial social benefit.

On the other hand, if the EPA waits until late in the development stage, then there may be insufficient technology forcing as Congress intended.: Process development occurring in a more or less unregulated manner should maximize the objectives viewed as important by the developers (such as efficiency, reliability, etc.). It is unlikely, however, that they would emphasize the development of environmental controls to the same degree. As a result of these two potential and contradictory alternatives, it is important that the EPA find the appropriate point at which to set a standard in order not to forego ani potential social benefits but at the same time to push the developing technology toward an environmentally satisfying conclusion.

The discussion following looks at this process with particular regard to fluidized-bed combustion technology. Fluidized-bed combustion technology is now at the stage of development that the next proposed large-scale development project, a demonstration plant, would be large enough to fall under the requirements of a NSPS for steam-electric generators providing electricity to the public. Specifically, the discussion will examine three questions:

1. What options does the EPA have in setting a New Source Performance Standard, and what are the consequences of these options with regard to fluidized-bed combustion development? 
2. What are the benefits of fluidized-bed combustion relative to conventional systems that might be foregone (or obtained) under the weight of standard setting?

3. If no standards are set at present for $F B C$, what research and development targets vis-à-vis environmental. goals should be sought by EPA?

\subsection{Policy Options in Setting New Source Performance Standards and Possible Consequences}

Although the full impact of the new amendments to the Clean Air Act is as yet still not completely understood, and no standards have as yet been formally proposed, several regulatory options available to EPA at this time can be discussed. In Table 4-1 such a set of options is listed. It is possible that, under judicial review and further legal interpretation, other options will arise. The consequences of those options are summarized in the table along with some comments These are further elucidated in the discussion following.

Four principal options appear to be available:

A. Set a NSPS, bașed on conventional system performance, applicable to all technologies including fluidized-bed combustion.

B. Set a NSPS as above for all technologies, but announce the EPA's intention to waive the requirements for demonstration plants under the innovative technology waiver provisions.

c. Set NSPS for conventional systems only, excluding fluidized-bed combustors.

D. Set a separate standard for fluidized-bed combustion demonstration projects. 


\section{Option}

\section{Degree of}

Technology

Forcing

\section{Comments}

A. Set NSPS based on conventional system performance, apply to FBC demonstrations

B. Set NSPS, give advance notice of intention to waive requirements for demonstration plants

C. Exclude FBCs in current revisjons

D. Set separate standard for FBC demonstration projects
$\mathrm{High}$

Developers may become discouraged and shut down or delay programs; given the apparent advantages of FBC and apparent ability to meet MSPS at all levels being considered, this is an unlikely consequence; advances in the stateof-the-art for conventional and FBC systems will create pressure for further revisions of the ISSPS.

High* * Restrictions limit use of the waiver, for emerging energy technology projects, can provide only limited relief in multi-objective projects; cannot permit easing standards or excusing compitiance in order to meet general project goals-reliability, efficlency, etc.: wajuer process complex and requires state as well as EPA approval; not substantially different, even with advance rotice, from Option $A$.

Low

Provides substantial (perhaps excessive) relief from environmental constraints during development. Maximum flexibility in dealing with trade-offs on multi-objective projects (FBC demonstrations, for example) between air emissions and energy, economic and other environmental benefits; requires very close 1 iajson with EPA; step toward separate standard at next stage.

Moderate

Treat demonstration of emerging technologies on caseby-case basis; could lead to separate standard for commercial FBC; acconimodate trade-offs as above.

* Wajuer cannot be granted unless system promises at least as great a degree of continuous emission reduction as is currently available through demonstrated technology. 
Before proceeding to discuss these options, note that it is assumed that the NSPS would incorporate provisions for a ceiling, a floor, and a percent reduction pertinent to $\mathrm{SO}_{2}$ removal; an emission limitation for nitrogen oxide; and an emission limitation for particulate. It is also assumed that appropriate credit for precombustion treatment would be provided in the standard and that equivalent credit for sulfur removal would be given to the fluidized-bed combustor. In addition, it is assumed the standards will establish appropriate averaging times and will provide for noncompliance during periods of startup or malfunction.

In particular, the discussion and the analysis in the rest of this report assume that scrubbers will not be required on fluidized-bed combustion systems. If the opposite viewpoint were, in fact, taken by the EPA; that is, scrubbers would be required on every tail-gas stream including $F B C$ exhausts; then many of the conclusions made here would no longer be valid. Under the scrubber-everywhere scenario, fluidized-bed. systems would lose their economic edge and many of the other beneficial features.

A discussion of these four options follows.

\subsubsection{Set NSPS Based Essentially on Conventional System Performance (Option $A$ )}

In this approach, in which electric-generating technologies based on common fuels are viewed more or less uniformly (a so-called black box approach), fluidized-bed technologies, as well as perhaps other future technologies, would have to meet at least as stringent a set of standards 
as in the conventional case. This approach to standard setting is closest to the technology-forcing characteristics intended by Congress in both the 1977 Amendments to the Clean Ais Act and the 1970 Amendments as well.

Two consequences appear possible as a result of this option. The first is that the current developers (both the Department of Energy and private industry) could become discouraged and would shut down or delay their development programs. The second option is that the same developers, working with the EPA, would accept the NSPS as enviromental targets.

A.lthough there has been much public and private discussion of the first possibility, that is, that the developers would abandon or delay fluidized-bed development, it is difficult to understand the concern, given the conclusions as to the competitiveness and state of development of rBCs reached in the earlier portions of this study. Assuming that no scrubbers would be required, Eluidized-bed combustion performance on economic, energy; or environmental grounds appears, at least, comparable or even superior to that of conventional systems with scrubbers at all levels of NSPS being considered currently. Further, based on performance to date, it appears possible to design the next stage plant, that is., a demonstration project, to meet existing or proposed standards. To what degree meeting this requirement would lead to sacrifice of other project objectives is unknown.

There has been concern amongst various of the development groups that requiring the next FBC project to meet an NSPS would delay the program, if the standards required significant departure from the present design experience. As noted 
in the paragraph above, even under such circumstance, there appear to be firms willing to bid for the design of such a plant. Although present experience at the pilot stage is limited to that at the Rivesville project (plus some data from the installation at Renfrew, England), firms are willing to introduce other configurations and design conditions into their work. TVA, for example, has received several serious proposals for a 200 MWe demonstration project.

Experience with the pilot facility at Rivesville, although Iimited at present, indicates that the major problems that must be solved are more fundamental to overall system reliability, coal feeding, etc., than to environmental objectives. of course, more stringent environmental standards may place greater demands on overall system performance. However, factors other than environmental constraints are likely to be the critical ones in setting the pace of FBC development. Progress in moving from 30 MWe to 200 MWe may be slowed down by the failure of tine Rivesville plant to solve fundamental operational problems.

The issue as to the impact of standard setting is somewhat clouded in the case of the atmospheric fluidized bed. There are being raised currently, in several quarters, a number of questions as to whether the performance of FBCs relative to conventional systems is indeed sufficiently beneficial to justify the degree of public investment now being provided. Uncertainty about NSPS may be contributory to the hesitancy in the minds of the decisionmakers, but, based on technical considerations alone, the establishment of NSPS as being contemplated by the EPA currently should not 
interfere with the development of the atmospheric fluidizedbed combustion system.

In the second case, that is, that the developers accept the NSPS as a target, the technology-forcing aspects of the Clean Air Act will be sealized. But at the same time, the developers should realize that current NSPS levels do not represent a fixed target for environmental performance. Continuing R\&D supported by Federal and private prograims may have goals even more stringent than current NSPS and, if successful, would force tighter revisions in the future. For example, current programs within the office of Research and Development of EPA are aimed at reducing $\mathrm{NO}_{x}$ emissions from pulverized coal burning to about half of the level from the best controlled current equipment. Similar programs are aimed at developing inproved scrubbers providing higher levels of removal and higher reliability at lower cost.

Thus, presuming a continuing program, the acceptance: of existing NSPS (Or the imminent revisions) as the ultimate target for environmental performance of FBCs may raise future problems. This possibility requires very close liaison between the EPA and the technology developers during the next stages of development in order that the most bereficial environmental goals possible are incorporated in the continuing development program.

At some time in the future, assuming continuing acceptance of fluidized-bed combustion as an alternative to conventional systems, FBCS would be considered, at the time of a NSPS revision, on their own merits, in any case. If they show benefits relative to other technologies such matters would 
be considered in setting an independent standard. On the other side of the coin, current technology must keep pace. with new developments or future standards may limit its applicability. This latter consequence is the most direct goal of the technology-forcing nature of the NSPS portions of the Clean Air Act.

One of the concerns of the developers is that it is desirable in a demonstration project to examine performance of the system under a wide variety of conditions, some of which. will, in all likelihood, lead to failure to comply with a standard based on best operating conditions. This raises a problem regarding the enforcement of the NSPS.

Section 111 does not contain any express exemptions for malfunctioning new sources or for sources operated exclusively Ior purposes of research and demonstration. Nevertheless, the court in portland Cement v. Ruckelshaus ${ }^{1}$ provided a rationale for excepting periods of startup, shutdown or unavoidable malfunction from the application of general standards. Specifically, in that opinion, Judge Leventhal noted that justified exceptions to $\$ 111$ standards are likely to impart "a construction of 'reasonableness' to the standards as a whole." Accordingly, EPA regulations issued under $\$ 111$ prior to the passage of the 1977 amendments made it clear that NSPS need not be achieved during periods of abnormal operation. ${ }^{2}$

The court's reasoning in portland Cement would perhaps also support limited exemptions from NSPS for pilot and. demo FBCs, since operations at such facilities may be carried out over a range of intentionally varied conditions and using largely undemonstrated control technoques. It may 
be unreasonably rigid to require such plants to adhere to particular numerical NSPS under all operational conditions.

For several emerging technologies, other than EBCs, the ability to meet all provisions of an NSPS, set on the basis of conventional systems, appears unlikely, yet such a process. may provide such economic, energy or other environmental benefits that a trade-off is merited. For example, it appears unfeasible on either cost or technical grounds to achieve a 90 percent removal in systems employing solvent refined coal (SRC-1). Imposition of scrubbers would render the overall process economically unatractive. Forcing such technology to conform, at the demonstration stage, to a NSPS reflecting existing technology would hamper the trade-off process or even close it off completely. This, however, does not appear to be the case with. FBC systems which, as noted above, should be able to achieve the same level of controls as can conventional systems.

\subsubsection{Set New Source Performance Standards But Promise to Waive Fluidized-Bed Combustion Demonstration plants (Option B)}

Section 109 of the 1977 amendments (PL-95-95) as a new provision to the Act sets forth a waiver procedure for new sources which are developing innovative technological systems of continuous emission reductions. Waivers awarded through this procedure are subject to time limitations and other restrictions spelled out in the amendments. Application for such a waiver can be made upon request by any person proposing to own or operate a new source (in this case, an FBC demonstration plant). 
It is the advance notice aspect of this option that distinguishes it from option $A$, as even under that option, the operator may. request a waiver. The following discussion focuses on the consequence of such promise of waiver consideration but also points out several limitations with respect to this option.

A waiver may be granted only if the (EPA) Administrator determines, among other things, that

1) the proposed system has not been adequately demonstrated

2) the proposed system will operate effectively and that there is a substantial likelihood that such system or systems will achieve greater continuous emission reduction than that required under the standards of performance which would otherwise apply or achieve at least an equivalent reduction at lower cost in. terms of energy, economic or nonair quality environmental impact.

The latter restriction will not permit the granting of a waiver for the purpose of demonstrating performance of a complex technological process other than that associated with the continuous reduction part. A waiver of any part of the NSPS to accomodate other development objectives, for example, reliability or energy efficiency, would not be allowable. This limits severely the utility of this approach for emerging energy technology demonstration projects which have multiple objectives, particularly where environmental gains are secondary to other project objectives.

Other terms limit the waiver to that portion on which the innovation system is used. Thus, a waiver of the 
particulate portion of the NSPS probably would not be permitted since the FBC does not meet item (2) above with respect to particulate emission reduction potential. Requests for waiver from the $\mathrm{NO}_{\mathrm{x}}$ portion might be consistent with the above provisions, but according to perfomance projections, FBC systems should exceed the proposed standard. substantially. As a conseguence, this part of the standard is not the critical factor in developmental decisions.

- The $\mathrm{SO}_{2}$ removal process would appear to fit the criteria set forth in the amendments. Note that fluidizedbed systems are specifically mentioned as an example of innovative technology in the House report on PL-95-95.

Assuming that the next FBC project, a 200 MWe or other large demonstration plant, can qualify for a.waiver, providing advance notice that an application would be favorably examined by the Administrator should establish a positive climate for current decisions to proceed with plans for such a project. Such request based on the present AFBC developmental timetable (see section 4.4 below). would probably be made in the four-year period following the forthcoming NSPS revision. The temporal restrictions on a waiver (seven years from the granting date, or four years from commencement of operations, whichever is earlier) are consistent with the planned project schedule.

In the absence of such advance warning (and implicit favorable viewpoint), the developers may be discouraged by the many restrictive aspects of the waiver process and abandon the project (but note the small probability of this occurrence under option A). This option would require a very clear understanding and cooperation, perhaps even 
stipulations * as to the environmental objectives of the program between the EPA and the developer. This situation reflects one of the basic conflicts discussed in the introduction, that is, between the technological objectives in energy process development and environmental objectives.

Although the EPA may intend to waive requirements for NSPS, the waiver requires public hearing and local acceptance (consent of the governor of the state in which the source is to be located). It is not certain that such acceptance would be forthcoming. In this case the EPA's intent to ease the development process may in fact make the developer's job all that more difficult.

4.2.3 Exclude Fluidized-Bed Combustion Technology in

Under this option, the EPA would not include fluidizedbed combustors in the standards by use of appropriate language in the regulations or by some outside vehicle. In this case, setting the NSPS would not directly affect the next generation of EBC development projects. This option requires further investigation to determine its permissiveness under the Act. Interpretation of the adequateness of the demonstrated capability of FBC to meet standards will be important in consideration of this option. Even if EPA chooses this option, there remains the possibility of suit by environmental intervenors to force the inclusion of the fluidized-bed combustor (the AFBC version, currently) in the standard.

\footnotetext{
*The Clean Air Act; Section III $(k)(I)(B)$ as amended provides for terms and conditions for granting waivers to be treated as standards of performance.
} 
This option risks the most of all four options discussed here in terms of inadequate attention to environmental goals in the development process. For this reason, the developers would in all likelihood proceed to the next stage.

This approach is not without constraints. The NSPS for conventional systems represents an explicit goal that will have to be met at some future time; in the AFBC case, four or perhaps, if development proceeds slowly, eight years hence. The current R\&D objectives of the EPA or other environmental control development programs represent an implicit set of targets. To make such a set of objectives a meaningful target for FBC development, the EPA would have to provide a clear indication of this objective to the developers through a statement at the time of the standards promulgation or, in the case of another Federal agency, through a memorandum of understanding setting forth such goals. Such a memorandum could deal with trade-offs among several air emissions by recognizing, in a preliminary way, the potential for significant savings in energy or economic costs or other environmental impacts.

If this option were chosen, particularly if a memorandum of understanding were developed, it would in essence represent the first step toward a separate standard for the technology. Given the apparent ability of FBC systems to meet all parts of the forthcoming revised NSPS for conventional systems (at least for sulfur removal requirements less than about 90 percent), such a separate standard in the future would not be necessary. In the case of solventrefined coal, as mentioned above, such a separate and distinct standard might be justified. Of course, the case for significant and offsetting berefits in the energy, 
economy or other environmental impact categories must be clearly established in order to move in this direction.

This option would probably make the siting of a demonstration project simpler than under the waiver option (Option B). The hearing and procedural aspects of that option are quite complex. The proposed project would still be subject to all of the review requirements of the State Implementation Plans (SIP), and non-attainment or PSD policies (if applicable).

\subsubsection{Set Separate Standards for Fluidized-Bed Combustor Demonstration Projects (Option D)}

The option would be to set a separate standard for fluidized-bed demonstration projects. The standard could explicitly be restricted to demonstration projects or, even in the absence of explicit reference, could be implicitly limited to such projects since no commercial ventures are anticipated in the near future (prior to the next planned round of NSPS revisions). The standard could take the form of lower numerical standards or design or equipment standards. In the case of FBCs lower numerical standards would not be justified as they would represent less stringent targets than can be realized. Design or equipment standards could perhaps better reflect the overall characteristics of an energy technology demonstration project.

Experiments aimed at optimizing the sulfur capture process may overload a particulate control system, but only at limited times. Specifying use of'a state-of-the-art ESP with minimum specific collector area or a baghouse, with a maximum air-to-cloth ratio would provide reasonable levels 
of control under such excursions and compliance levels under other conditions. Setting minimum $\mathrm{Ca} / \mathrm{S}$ ratios, based on pilot plant data, could similarly limit the maximum emission levels of $\mathrm{SO}_{2}$, but would accommodate a range of experimental conditions.

This approach would facilitate experimentation on the non-environmental aspects of the system. It is, however, not strongly technology-forcing, since it avoids incorporation. of specific environmental objectives in the project. As a consequence, it would require extremely close liaison and cooperation between EPA and the developing agency to maximize environmental benefits along with the developer's goals.

The legislative basis for involing this option is not clear to this situation. Design or equipment'standards may be used when no satisfactory measurement techniques are avaliable, or in cases where the pollutant is emitted in a fugitive manner. INeither of these aspects is valid in the case of the fluidized-bed combustion system. Technically, FBC systems are as amenable to the setting of numerical standards as are conventional systems.

This option and option $C$ above provide opportunities to develop an appropriate and sufficient data base on which to set an NSPS during or at the conclusion of the demonstration phase of a project.

\subsection{Future Actions}

The above discussion reflects options available to EPA in the current revision process. Several of the options will require further action in the future. 
Under Option A, fluidized-bed systems will not require special treatment in the future. That is not to say, however, that no action will be taken. Future revisions, as noted in the above discussion, will reflect gains in environmental control technology from continuing R\&D or from improved. designs or operating practices in the field. FBC systems, conventional systems with scrubber, and any other coal-based process for generating electricity will have to keep pace with such other development or fall by the wayside under the technology-forcing pressures of the regulatory process.

On the other hand, Options B, C, and D, as discussed above, leave the question of a New Source Performance Standard for fluidized-bed combustion technology unsettled, even at present. In the event that demonstration projects show that the plants can indeed meet the same standards as conventional systems, then this question will become moot. EPA can ada fluidized-bed combustion technology at the next NSPS rovision sequence by whatever manner is appropriate.

A more interesting question arises if a demonstration project operating under terms of either the waiver (Option B) or no standard (Option C) fails to meet the isSPS for conventional technology. In this case, EPA can grant an additional waiver or continue to avoid setting a numerical standard. There would have to be a compelling reason for continuing to follow this route in the future. The berefits of the fluidized-bed combustion technology relative to conventional systems must be made very clear and must be significantly greater at that point in time.

On the other hand, under options $C$ or $D$, based on data derived from the demonstration project, EPA can set a New Source Performance Standard at the next or most appropriate revision 
period separate and different from conventional system standards. Such standards could be either more or less severe depending on the performance of the demonstration project. A more stringent standard would not require any justification. If envizonomental performance is poorer in any case than con ventional systems, then the developer must be prepared to make a very clear case for a less stringent standard, based on economic, energy, or total environmental grounds.

\subsection{Effects of FBC Development Timetabie}

No matter what regulatory approach dealing with emergo ing techniques is chosen in the current revisions to the stanlaxds, only AEBC demonstration projects will be affected in the next four-year period prior to subseọuent NSPS review. As noted in the discussions of the individual options, the actions taken now will have important future ramifications. It is important to make the proper selection at present as the environmental control capabilities of the first-generation comercial versions of the emerging technology depend greaty on the degee to which environmental goals are stressed in the development process.

siore specifically, EPA must examine the temporal sequence projected for the development of fluidized-bed systems to asrive at a proper decision. In Figure 4-1, time-lines for the development, based on Federal programs, of atmospheric and pressurized fluidized-bed combustors are depicted.

This figure represents the present DOE understanding of the development process at this time. The timetable is highly dependent on funding, technical progress on a variety of current and planned R\&D projects, and on current priorities among alternate routes for the development of energy supply technologies. 


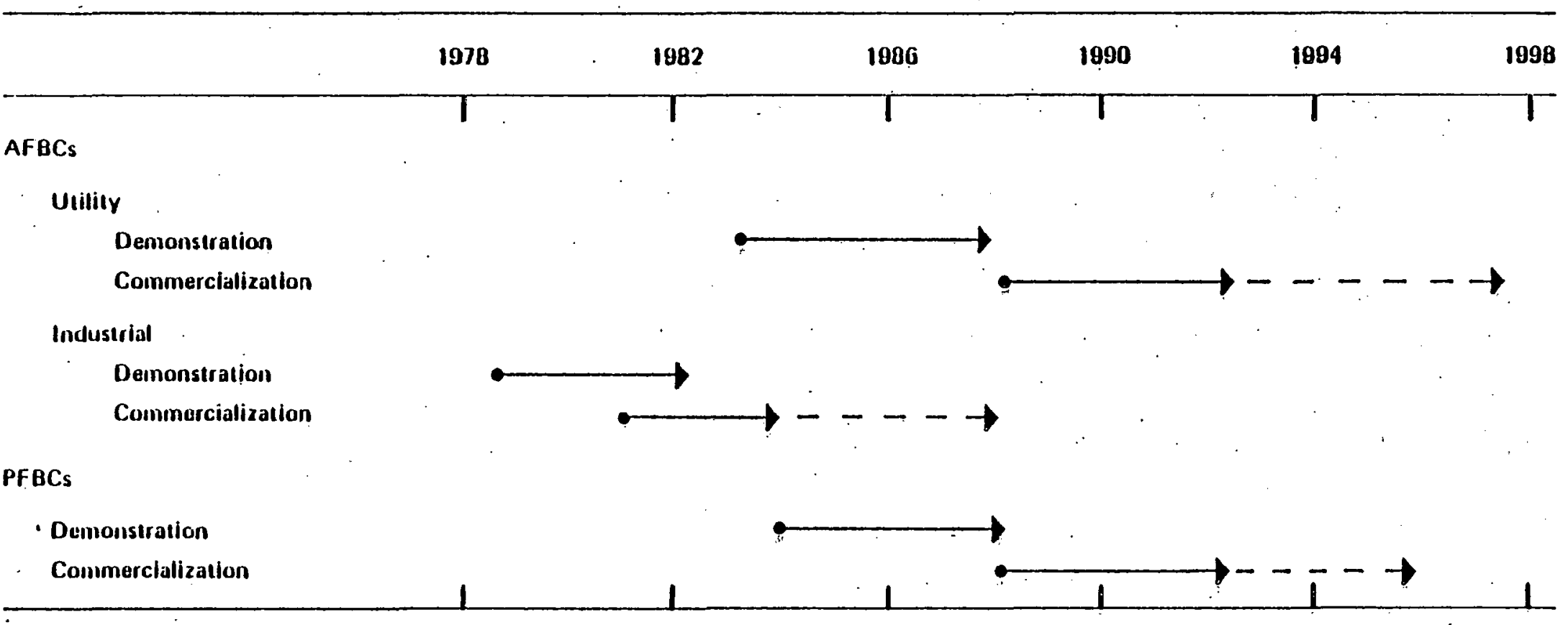

Figure 4-1. Time line for development of FBCs. (Source: DOE) 
Although no activities at utility scale are indicated for the 1978-82 period, the projects that may commence operation during the next four-year interval (1982-86) require current attention in the current regulatory process. With. respect to AFBC development a 30 MWe pilot project is currently in prom gress. This project is just at the lower limit of system size for which the New Source Performance standards have been and will continue to be applicable. Although no final decisions have been made concerning a demonstration project by the government, the TVA, other institutions, or private companies (American Electric Power, for example), such a project may get under way as early as 1982. Given approval, the planning and permitting process for that project would begin during the next 4 years. For this reason, it is important to treat atmospheric fluidized-bed systems in the current revisions. Failure to do this now will leave the EPA unprepared to deal with applications for demonstration plants expected within the next 4 years and to handle the technologyforcing issues discussed herein.

With respect to PFBC systems, American Electric Power Company (AEP) has been developing plans to construct a 170 MW PFBC plant at the Ohio location scheduled to commence operations in the 1982-84 time frame. The decision to proceed will depend on a number of private criteria, not available to the public. Gas turbine reliability, under realistic conditions, is at present, an area of critical concern. DOE is sponsoring a test program at Leatherhead, England, in which a single turbine cascade is to be run for an extended period ( 1000 hours). It seems likely that the results of this test will strongly influence the direction of AEP's decision. If positive, then the permitting process will begin, perhaps, even before 1982. Under these circumstances, it will be necessary to take some action (including a decision to do nothing) in the present standards revisions. 
If EPA selects one of the options (Option $C$ or D) that does not establish a definitive standard for fluidized-bed systems, then further action will be required in 1982 (assuming that is the date of the next major revision of the NSPS for steam/electric generating systems). If current estimates of development and commercialization hold up, then the first units to become available on a comercial basis are expected during the late 1980 's. In order to properly regulate emis sions from these. units, the EPA must have NSFS finalized well ahead of the advent of the first application for such a system.

In fact, given the very long lead time for utility decision making, a NSPS in 1982 may not provide sufficient lead time for utilities to make full advantage of tochnological progress in the atmospeheric fluidized-bed program. This aspect of utility planning suggests that, although there appears to be a substantial resistance throughout the energy development and utility community to setting a issps for fluidized-bed systems, failure to set a standard presently may, in. the long run, slow down the utilization of this technology ratizer than the converse, as is claimed by the opponents.

4.5 Social Benefits of Fluidized-Bed Combustors

\subsubsection{Beneficial Technical Characteristics}

Before discussing the potential social benefits of the application of fluidized-bed combustors to electric power generation, it is important to describe those technical characteristics of the systems which in turn lead to the social benefits. Table 4-2 contains a number of the more important systems characteristics and develops a ranking system showing their relative performance. In general, tinis table shows that both atmospheric and pressurized versions 
TABLE $4-2$

IMPORTANT TECHNICAL CHARACTERISTICS OF FEUIDIZED-DED COMBUSTORS RELATIVE TO CONVENTIONAL COAL BOILERS WITH SCRUBBERS

\begin{tabular}{|c|c|c|c|}
\hline \multirow{2}{*}{ Characteristics } & \multicolumn{2}{|c|}{-.--Relative Rating -.- } & \multirow[b]{2}{*}{ Comments } \\
\hline & $A F B C$ & PFBC & \\
\hline Cost of Electricity & Lower & See Conments & $\begin{array}{l}\text { PFBC costs range from higher to lower } \\
\text { as function of } \mathrm{Ca} / \mathrm{s} \text { ratio and coal type; }\end{array}$ \\
\hline System Reliablifty & Higher & Unknown & $\begin{array}{l}\text { Conventional systems now limited by } \\
\text { current scrubber technology, improved } \\
\text { scrubber availability may offset cur- } \\
\text { rently projected difference; }\end{array}$ \\
\hline Fuel Flexiblity & Greater & Greater & $\begin{array}{l}\text { FBC can burn almost all fuels, in- } \\
\text { cluding gas or oil, wastes and others; } \\
\text { turbine constraints could limit use } \\
\text { of high ash fuels for PFBC's; }\end{array}$ \\
\hline $\begin{array}{l}\text { Thermal (Cycle) } \\
\text { Effictency }\end{array}$ & $\begin{array}{l}\text { Higher } \\
(4-8 \%)\end{array}$ & $\begin{array}{l}\text { Higher } \\
(15-21 \%)\end{array}$ & $\begin{array}{l}\text { Advanced scrubbers not needing reheat } \\
\text { could el fiminate advantage relative to } \\
\text { AFBC: }\end{array}$ \\
\hline${ }^{N 0}$ Emissions & Lower & Lower & $\begin{array}{l}\text { Improventents in conventional systems } \\
\text { from current R\&D on low } N 0_{x} \text { burners } \\
\text { could reduce or el iminate advantage; } \\
\text { emissions from full-scale AFBC with } \\
\text { carbon burnout cell could approach } \\
\text { that of conventional systemi no data } \\
\text { presently available: }\end{array}$ \\
\hline $\begin{array}{l}\text { Solid Waste Quantity } \\
\text { (Dry) }\end{array}$ & Greater & Greater & \\
\hline
\end{tabular}


TABLE 4-? (CONT.)

\begin{tabular}{llll}
\hline Characteristics & $\begin{array}{l}\text {-.. Relative Rating } \cdots \\
\text { PFBC }\end{array}$ & Comments \\
\hline Solid Waste quality & Better & Better & $\begin{array}{l}\text { Dry output easter to dispose of than } \\
\text { slurry; advanced dry or regenerable } \\
\text { scrubber systems could reverse } \\
\text { advantage. }\end{array}$ \\
\hline
\end{tabular}


of fluidized beds have superior characteristics to conventional coal systems.

The cost of electricity relative to future applications of conventional systems with scrubbers, based on the assumptions made in this study and in other recent or current studies, is projected to be lower for atmospheric fluidized beds. PFBC costs may be higher or lower depending on coal and on value of $\mathrm{Ca} / \mathrm{s}$ ratio assumed. Not all combinations of coal and limestone may provide such economies. For certain sites, reactivity of local limestone may be quite low.. In such a case, the necessity of transporting more reactive iimestone at high cost or the use of large quantities of the local stone could offset the cost advantage of fluidized beds.

Pressurized fluidized beds (in certain cases, as noted), may not appear to offer as great economies. Their major advantage, as shown below in the table, is the significantly higher thermal efficiency projected.

Atmospheric fluidized beds show potential for providing a greater degree of system reliability than do conventional systems equipped with scrubbers. Pressurized systems are not sufficiently developed to make estimates of reliability. The increased complexity of the pressurized system with its combination of gas turbine and steam cycle would probably make it less reliable than its atmospheric cousin.

The prediction of greater reliability is largely based on the limiting aspect of scrubbers in conventional systems. The fluidized-bed combustor will, in all likelihood, be about as reliable as the coal-burning portion of the present-day systems. If new scrubbers come along as is expected in the 
light of current development programs, then this reliability edge may disappear as the new scrubbers, particularly those using dry sorbents, should be more reliable.

Both atmospheric and pressurized fluidized beds should have significantly greater fuel flexibility than conventional systems. This is both true in their general design, in that beds can be designed to meet a great variety of fuels, but also in the sense that, once having been built, a given fluidized bed can accept coals (or even other fuels) of quite different quality far beyond the range permissible in a given conventional system. The severe requirements for particular control internal to the pressurized system might limit their use to fuels of a low to moderate ash content. Both systems could work on wastes or a combination of waste fuels and conventional fossil fuels.

Thermal or cycle efficiency in both atmospheric and pressurized fluidized beds should be greater than that of conventional systems. Pressurized beds show a significantly higher efficiency, some 15 to perhaps more than 20 percent higher than conventional systems (around 39 percent compared to 32-34 percent). This would lead to large savings in the amount of fuel required, and would significantly reduce, as will be shown in the next section, the total quantity of emissions per unit of electricity produced. The advantage of atmospheric systems over conventional could disappear in the future with the advent of more advanced scrubber systems. One of the major losses of efficiency in a conventional system with scrubbers according to current design is the requirement for reheating the plume subsequent to its passage through 
the scrubbers. This step requires as much as 2 or 3 percent. of the total output of the plant. Advanced scrubbers operating at higher temperatures could eliminate the need for reheat.

Looking at several environmental aspects, both atmospheric and pressurized fluidized beds are expected to have lower nitrogen oxide emissions than current conventional systems. This is principally a consequence of lower operating temperatures in the combustion sections of fluidized-bed systems. This advantage is less certain than some of the others. Improvements in conventional systems based on current R\&D programs could tum around the situation. EPA is now seeking. to develop burners with nitrogen oxide emissions as low a.s. 0.2 lb/milizion Btu.

Low emissions from Eluidized-bed combustors observed in small laboratory systems may not be realized in largescale systems. It is possible that emissions from fillscale atmospheric fluidized beds equipped with carbon burnout celis could even approach those of conventional systems. Inadequate data are at present available on which to base this comparison.

Finally, the solid waste characteristics of fluidized beds are quite different. from conventional coal boilers. The guantity of solid waste on the dry basis is larger from both atmospheric and pressurized fluidized beds. This conclusion is based on current calcium-to-sulfur ratios being considered for utility-scale systems. Future advances which would reduce this ratio could offset the current disadvantage of fluidized-bed.systems. On a wet basis, conventionaj. systems even now have a larger total quantity of waste output, compared to the dry output of a FBC. 
Fluidized-bed systems, on the other hand, generate a more easily handled solid waste. The waste is produced in a dry state instead of the slurry characteristic of lime and limestone systems. It is easier to dispose of the dry output. Fixation of solid waste from scrubbers can offset the disadvantage, but the overall handling process is still more complex and difficult. Advanced scrubber systems based on dry outputs or utilizing regenerable concepts could reverse the current advantage of fluidized-bed systems.

Each of these technical characteristics of fluidized beds, either singly or in combination with others, leads to a set of potential social benefits to be gained by using fluidized beds in place of conventional coal-burning plants for the generation of electricity. The next section of this report discusses the nature of those benefits.

\subsubsection{Social Benefits}

The following discussion examines a number of potential social benefits that could accrue from the substitution of fluidized-bed systems for conventional coal-burning plants and utility systems. Three types of benefits are discussed dealing with (1) economic development and economic efficiency; (2) potential environmental benefits or, in some cases, disbenefits; and (3) otherwise unclassified benefits. No attempt is made to quantify the benefits in this analysis. Except for those directly involved with national economic development and efficiency, it is very difficult in any case to place monetary values on the beriefits. Table 4-3 presents a summary of the benefits, their bases, and the discussion that follows. 


\section{TABLE $4-3$}

POTENTIAL SOCIAL BENEFTTS OF FLUIOIZED BEDS RELATIVE TO CONVENTIONAL COAL BURNING PLANTS WITH SCRUBBERS

\begin{tabular}{|c|c|c|}
\hline Benefit. Type & Basis & Comments \\
\hline \multirow[t]{3}{*}{ 1. $\frac{\text { National Economic }}{\text { Development/ }}$} & $\begin{array}{l}\text { Lower cost of electricity with } \\
\text { FBC increases consumer surplus-- } \\
\text { on a per plant basis }\end{array}$ & $\begin{array}{l}\text { Lower costs may not be passed through } \\
\text { due to regulatory lag--equity issues } \\
\text { involved: }\end{array}$ \\
\hline & $\begin{array}{l}\text { Higher reliability may lead to } \\
\text { speedy capture of market }\end{array}$ & $\begin{array}{l}\text { Temporai behavior of benefits impor- } \\
\text { tant from public investment point of } \\
\text { ytew }\end{array}$ \\
\hline & $\begin{array}{l}\text { Less system redundancy due to } \\
\text { wigher FBC reliability }\end{array}$ & $\begin{array}{l}\text { Operational reliability of full-scale } \\
\text { FBC's unknown }\end{array}$ \\
\hline \multicolumn{3}{|l|}{ 2. Environmental } \\
\hline${ }^{110} x$ & $\begin{array}{l}\text { Lower NO enissions--continuous } \\
\text { better flel flextbility }\end{array}$ & $\begin{array}{l}\text { May not maintain edge considering } \\
\text { research goals/program for low NO } \\
\text { "convent onal" burners. May be } \\
\text { limited to selected fuels, e.g., lig- } \\
\text { nite }\end{array}$ \\
\hline $\mathrm{SO}_{2}$ & $\begin{array}{l}\text { Lower } \mathrm{SO}_{2} \text { emissions-annual } \\
\text { basis }\end{array}$ & $\begin{array}{l}\text { Bypass of scrubbers leads to standards } \\
\text { being exceeded }\end{array}$ \\
\hline Toxics in TSP & $\begin{array}{l}\text { Lower toxic components in } \\
\text { particular emissions }\end{array}$ & $\begin{array}{l}\text { Conjectural--linited data--importance } \\
\text { unknown }\end{array}$ \\
\hline
\end{tabular}


TABLE $4-3$ (CONT.)

Benefit Type Basis $\quad$ Comments

\section{Environmental (cont.)}

TSP

About even TSP

Total Atmospheric

Emissions

Solid Waste
Output

Occupational

Health

3. Other

Dependence on 0 il/Gas
Less overall atmospheric emisstons/klth; lligher energy efficiency

Higher quantity dry solids; Dry (FBC) vs. slurry (FGD)

Sinaller land area--landfill

(FBC) vs. ponding (FGD)

Less coal mining transporting injuries/deaths;

Higher energy efficiency

Reduce dependence by accelerating coal conversion process
FBC may be more difficult to control with varlable liniestone or dolomite properties; baghouses should produce essentially equivalent performance; Baghouses would probably be used at TSP standards of $0.051 \mathrm{~b} / 10^{6} \mathrm{Btu}$ or lower

Scrubbers not requịing relieat could essentially eliminate advantage of FBC

Future scrubber developments may eliminate slurry output; fixation makes land use difference disappear

Advanced scrubbers could essentially el iminate advantage of $A F B C$

More advantageous operating characteristics of FBC (reliability, dry) may overcome reluctance to shift from $011 / g a s$ in industrial MFBI cases 
TABLE 4-3 (COHT.)

Benefit Type

Basis

Comments

3. Other (cont.)

Total Environmental/0ccupational Effects

Increase total impact due to acceleration of coal conversion process

$0 i 1 / g a s$ use is less environinentally and occupationally damaging

Extended Ltfe

Higher energy effictency

$\mathrm{CO}_{2}$ emisstons from coal greater than from ofl/gas per kWh; Much greater ISP and solld waste

for Coal Reserves

May be pasitive or negative depending on future value of coal as energy source or hydrocarbon feedstock

Shorten Limestone/ Larger Ca/S ratio Dolomite Reserves

Utillze "Waste" Energy Sources

Fuel flexibiltity of FBC's 
National Economic Development and (Economic) Efficiency

Fluidized-bed systems, at least atmospheric fluidizedbed combustors, appear to offer some benefit in terms of efficiency in the economic sense. This is a direct consequence of the projected lower costs of electricity for these systems. Atmospheric fluidized beds appear to be able to produce, based on current design considerations, electricity from 2 to 5 mills less expensive than electricity from conven-. tional systems. It is much more difficult to project costs for power from pressurized systems as this technology is less developed currently than that of the atmospheric version. The PFBC estimates developed herein show costs comparable with conventional system costs. Other, more extensive, analyses show advantages.

Improvement in efficiency may be offset by distributional issues rising out of the nature of the highly regulated electric utility industry. Immediate cost savings arising from bringing fluidized-bed combustion plants on line may not reach the users of power for several years.

The efficiency gains possible with fluidized beds will be limited in some cases where specific economics based on location, coal, limestone, or dolomite availability may favor conventional systems. Future developments. in scrubbers and more efficient conventional systems, as noted in the above section, could reverse or eliminate the fluidized bed's advantage.

The higher reliability promise of fluidized beds may also lead to benefits in this category. A higher level of reliability in a given unit would permit utilities to reduce the overall capital requirements within a large system by requiring 
less redudancy (or reserve margin). This feature would lower the cost of electricity beyond that shown in this analysis. The above discussion examined only the relative economy on a plant-by-plant basis, not on a system-wide basis.

Higher reliability might lead to an earlier capture of the utility market by this technology, vis-à-vis conventional systems. This has importance in assessing the merits of public investment in the development of FBC technology. More rapid application of fluidized beds would more easily justify current investments in its development, provided that there are ret positive social benefits.

Environmental Benefits

Table 4-3 lists a series of environmental benefits. Both atmospheric and pressurized beds show the potential of lower emissions of nitrogen oxide, as discussed above. The social benerit accruing from this technical superiority would be manifest in lower health costs, better visibility due to the reduction of particulate nitrates, and similar environmental effects. As noted earlier, this benefit may disappear or be diminished by future developments in the conventional combustion arena.

Even considering such developments, there appear to be certain applications of fluidized beds that will continue to offer such advantages in terms of nitrogen oxide effects. Lignites, for example, appear to be burnable in fluidized beds without any disadvantage in tems of emissions. In conventional systems, lignites must generally be burned in cyclonetype combustors. This combustor produced significantly higher levels of nitrogen oxide than do the more conventional 
forms of pulverized coal burners. This is reflected in the format of the proposed NSPS which will probably provide for a higher emission limitation for lignite-burning cyclone units.

Although the sulfur dioxide emissions would be presumably the same on a per-million-Btu basis for fluid beds and conventional systems, emissions on an annual basis from fluidized beds would be less for two reasons. The first is that the bypass/malfunction characteristic of the standard could permit a sulfur dioxide emission in excess of the standard at some times. Since, in a fluidized bed, combustion and sulfur dioxide removal are intimately connected, it is virtually impossible for the system to produce sulfur dioxide but not to control it. (Although not always at the required percent removal level.) The second ' reason for this benefit is mentioned later, but arises out of the overall energy efficiency advantage of fluidized beds, which leads to a lower number of Btu's required per unit output of electricity.

There appears to be some basis, examining limited data available today, that particulates emitted from fluidized beds will have lower concentrations of the more toxic components than do emissions from conventional coal-burning plants. This conclusion is largely. conjectural, based on the assumption that, at the lower operating temperatures in the fluidized-bed systems, less of the more volatile and often more toxic elements will be vaporized and then condensed into the very small and difficult-to-control particle size fraction. This observation is based on very limited data.

Since matter must be conserved, then these toxic materials would end up in the solid waste output of fluidized beds. Because of matrix binding effects, these more toxic materials might be rendered ineffective, and, although present 
in larger quantities, would lend no more toxic possibilities to solid wastes from fluidized beds than from conventional systems.

The emission of particulates from both fluidized beds and conventional systems appears to be about equal. Particulate control may, however, be more difficult to accomplish in fluidizedbed systems, at least for electrostatic precipitators. The amount of particulate produced depends on the nature of the coal and on the stone used. Given variations in the properties of both these feedstocks, it may be harder to keep emissions within the standard for fluidized beds than for conventional systems. The use of baghouses as a particulate control device should, however, given the above caveat, lead to essentially comparable performance. Baghouses are relatively insensitive to variations in inlet loading conditions. Presuming a standard of about 0.05 lb particulate/million Btu or lower, baghouses would almost certainly be required on all coal-burning facilities.

As noted above, lower atmospheric emissions from fluidized beds on an annual basis or on a per kWh basis would be obtained. This follows directly from the higher energy efficiency of the units and the way in which the standard is defined. For the atmospheric fluidized beds, this benefit might amount to only a few percent, where it could be quite significant for pressurized systems, ranging from 15 to perhaps greater than 20 percent. Advanced scrubbers, as noted earlier, which offset the potential inefficiency disadvantage of current systems, could eliminate largely this advantage for atmospheric fluidized-bed systems. 
The potential benefits or disbenefits associated with solid wastes are more difficult to define. Fluidized beds, as noted earlier, produce a larger quantity of solids on a dry basis. This is manifest, as noted below, in a larger requirement for limestone or dolomite relative to conventional systems. Even given the larger dry solid output, fluidized beds appear to be more beneficial than conventional systems, considering the amount of land required for sludge disposal. When the disposal of wet sludge is compared to dry, then it. appears that a larger land area is required for conventional systems. Fixation of sludges from wet scrubbing conventional systems would permit the use of landfill both for fluidized beds and for flue gas desulfurization systems, and may reduce this benefit to a negligible quantity. Also, leaching properties of FBC versus FGD residues may differ; but data are not available on which to base any firm conclusions. Future scrubber developments providing dry outputs or marketable products could reverse the relative benefits. Conversely, however, regenerative systems for fluidized beds would increase the relative benefit substantially.

Finally, as the last of the environmental benefits, fluidized beds offer some benefit in terms of occupational health and safety. This arises directly out of the higher energy efficiency of the systems. Less coal utilization per unit energy output means less mining, transport, etc., and less injuries and deaths associated with these aspects of coal utilization.

\subsubsection{Other Benefits}

Fluidized beds have the potential of reducing dependence on oil and gas to a greater extent, perhaps, than do conventional coal-burning plants. This possibility would 
arise should industry and utilities reduce dependence on oil and coal by accelerating the coal conversion process. To the extent that the coal conversion process is indeed accelerated, then fluidized beds would offer some advantage relative to conventional coal-buning plants. Acceleration in use of coal might result as a consequence of increased reliability of fluidized-bed systems and lower operating costs than those associated with conventional systems. Reliability is a very important and much desired feature in boilers. Promise of improved reliability may offset some of the natural distrust of new technologies and hasten the acceptance of fluidized beds.

For the same reasons that fluidized beds could provide benefits in terms of decreasing dependence on oil and gas, they would provide equivalent disbenefits with regard to overall occupational and environmental effects, because oil and gas tend to be environmentally and occupationally less damaging than coal. Health-related injuries involved in oil and gas production, transportation, and use are far less than those resulting from coal. Wuch higher particulate and solid waste outputs would result from the use of coal. In another vein, looking at long-term environmental effects, carbon dioxide emissions are greater on a per-kwh or -Btu basis from coal than from the other fossil fuels. Considering current concern about long-term global effects of $\mathrm{CO}_{2}$ increases, this could be viewed as a large potential disbenefit.

Fluidized beds could offer a benefit in terms of extending the life of total fossil resource of the country through their ability to use waste fuels more conveniently than conventional systems. This potential is beneficial, 
both by reducing dependency on domestic or imported fossil fuel stocks, and also in mitigating the environmental impact now created by the disposal of these wastes.

The last benefit or disbenefit to be discussed involves the effects on resources of both coal and limestone or dolomite. Fluidized-bed systems, because of their higher energy efficiency, would lead to extended life for the coal reserves. This may or may not be considered a benefit. The direction of the social benefit depends on the future value of coal as the energy source or as a hydrocarbon feedstock. Given today's situation, it would appear that this would be a benefit. If other technologies come along to reduce the need for mining coal either as a feedstock or as an energy source, then extending the life of the resource might be a negative benefit.

Conversely, because of the higher requirements for sorbents in fluidized beds, the life of limestone and dolomite reserves would be reduced relative to use of scrubbers.

4.6 Unsatisfied Environmental Research and Development Heeds

It was noted above, in discussing a number of the possible regulatory options available to EPA, that several require close cooperation and liaison between EPA and the developing agencies to ensure that the technology-forcing basis for the Clean Air Act is introduced in the development process. In the absence of numerical standards which set the targets for new technology to achieve or exceed, it is necessary to carry out a range of R\&D activities which can point to the optimal environmental possibilities in a developing technology 
beyond those suggested by the limited data developed during the development process.

Such research and development needs include two kinds of studies: system or design studies and a large variety of experimental studies. An illustrative set of such R\&D needs is given in Table 4-4. This list is not meant to be exhaustive, but suggests a number of areas which would lead to a broader understanding. of the environmental possibilities for fluidizedbed combustion systems.

\section{Design Studies}

Much of the development of fluidized beds to date has focused on a limited number of basic design concepts. Given the limited budget available early in the program, much of the experimental and development work was done by a single contractor. Current culmination of that process is represented by the current DOE pilot project at Rivesville. This is a 30 MWe system based on designs developed by Pope, Evans, and Robbins, a firm who have been responsible for much of the development of fluid-bed combustor concepts in the united States. Their design is centered on a multiple-combustor module concept and incorporates a carbon burnout cell to deal with the high emissions of unburned carbons in the overheads from the basic combustion cells.

In the past several years, there have been a number of major design studies examining and projecting the performance of large electric power stations. The first of these studies was the so-called ECAS study, a comparative analysis of a variety of advanced technology approaches to. power generation. It was sponsored by ERDA, NSF, and NASA. A common set of system 
TABLE 4-4

ENVIRONMENTAL OBJECTIVES FOR FBC R\&D PROGRAM

\section{Design Studies}

Alternative system designs - cost and performance analysis

Low fluidization velocity

Deep beds.

Fiy ash reinjection vs. carbon burnup cell

$\mathrm{NO}_{x}$ formation model-scale up

$\mathrm{SO}_{2}$. capture models

Regenerative system studies

\section{Experimental Studies}

$\mathrm{SO}_{2}$ Capture

Reactivity characterization of limestones/dolomites

$\mathrm{SO}_{2}$ capture kinetic model development

$\mathrm{SO}_{2}$ release in carbon burnout cell

$\mathrm{Ca} / \mathrm{S}$ ratio for 90-95 percent removal as function of coal, stone, operating conditions

Behavior at partial load conditions

Use of limestone in PFBC

Sorbent regeneration studies

Statistical nature of $\mathrm{SO}_{2}$ removal on a continuous basis

Particulate

Particulate load and size distribution as function of stone, operating conditions

Fly ash characterization before and after carbon burnup cell

$$
\text { ESP - resistivity; composition, size }
$$

Filter - hygroscopicity, abrasiveness, electric properties

Characterize stone friability, etc. 
TABLE $4-4$ (cont.)

Experimental Studies (cont.)

Behavior at partial load conditions

Loss of cyclone efficiency

Organic composition of fly ash - PNAs, etc.

Toxic metal composition

$\stackrel{\text { NO }}{x}$

Effect of carbon burnup cell (temperature/dwell time)

Effect of $\mathrm{Ca} / \mathrm{S}$ ratio on $\mathrm{NO}_{x}$ formation

Behavior at partial load conditions

$\mathrm{NO}_{x}$ control options

Solid. Waste

Leachability

Composition 
performance parameters was used in order to develop a means of intercomparison. The concept used for the atmospheric fluidizedbed system in the ECAS study was essentially that employed in the Rivesville plant. A series of modifications and improvements on the ECAS studies have followed, but all are based on that general design.

The multiple-cell approach employing an additional carbon burnout cell appears to offer some significant advantages in terms of system performance relative to alternate designs. There are, however, a number of unfavorable environmental aspects to this approach. It is very important to examine other system configurations very carefully at this time in order to determine the limits of this technology vis-a-vis environmental features, and to estimate what economic or performance disbenefits might arise in tradeoffs for higher environmental performance specifications.

Full exploration of alternatives requires both a set of theoretical design. studies, and also a variety of experimental programs, as further detailed below. The design studies should examine systems concepts other than that incorporated in current analyses. Such designs should look at lower fluidi-: zation velocity and deeper beds, both of which would provide increased gas residence time, possibly lowering the required calcium-to-sulfur ratio for a given: sulfur capture. Iower velocity might make fly ash reinjection more practical than in the existing designs. This would perhaps eliminate the need for a carbon burnout cell which in turn could produce lower $\mathrm{NO}_{\mathrm{x}}$ emission levels and greater overall sulfur dioxide capture.

Other pencil-and-paper studies are needed, in addition, to clarify specific operational specifics. Models describing 
the mechanisms of $\mathrm{SO}_{2}$ capture have been developed, but much improvement is needed. Similarly, rather rudimentary models predicting nitrogen oxide formation have been developed, but fall far short of predicting performance under most practical conditions. This latter aspect is very critical, as nitrogen oxide generation is in all likelihood quite sensitive to system size. Experience in conventional systems has shown that nitrogen oxide output increases with increasing combustor size. Since one of the beneficial features of fluidized-bed combustors is their low nitrogen oxide emission characteristics, it is very important to understand the degree to which this benefit will be affected by scale-up toward systems of practical size.

Sorbent regeneration can, if economically and technically feasible, significantly increase the potentiai benefits of fluidized-bed combustion systems. At high $\mathrm{Ca} / \mathrm{s}$ ratios, sorbent cost adds about one mill per kWh to the cost of electricity. A favorable trade-off against increased capital costs and somewhat lower efficiency (endothermic regeneration cycles) could reduce the projected cost of electricity. Even if no significant economic gains were obtained, large environmental improvements would result. The solid waste disposal problems associated with large volume spent sorbent output would essentially disappear. There still would probably be a small stream of exhausted materials to dispose of. Closeness to an appropriate local source of sorbent stone would not be economically limiting, so that a major potential siting constraint (particularly for pressurized systems) would disappear. Finalily stone resources would be conserved. 
Experimental Studies

$$
\mathrm{SO}_{2} \text { Capture }
$$

The most important environmental feature of fluidizedbed combustors is their in situ sulfur capture process. Iittle is known about this process beyond that empirical knowledge generated in the R\&D phase to date. It is difficult to extrapolate to projected operating scale systems. As a result, experimental activities are needed to broaden understanding of this important part of the fluidized-bed combustion process.

Studies to this end should include characterization of the reactivity of a wide range of limestone and dolomites, the development of data on which to base a sulfur dioxide capture model, study of the potential rerelease of sulfur dioxide at the higher temperatures characteristics of carbon burnout cells, examination of the behavior at partial load conditions, and the determination of the appropriate calcium-to-sulfur ratio as a function of a wide variety of conditions.

In particular it is important to examine low-sulfur coals in fluidized-bed systems. Historically such coals were not broady included in fluidized-bed combustion studies since, under the previous New Source Performance standards, such coals would not have required sulfur dioxide controls. Theoretical data useful for predicting behavior of low sulfur. coals show conflicting consequences. If the system behaves in a first-order manner, as has been stated by a number of investigators, then the percent reduction should be independent of the sulfur content in the coal. Existing data at high sulfur 
conditions are insufficient to establish firmly the validity of this mechanism, however.

It is very important to examine perfomance as a function of load. Base load utility systems, al though, in general, they operate at full load or not at all, are at times utilized at partial load conditions. Under these circunstances the dynamics of the sulfur control process could be substantially altered. It is important to determine whether a fluidizedbed combustor can comply with standards under these circumstances.

Finally, looking ahead to the development of pressurized fluidized-bed combustors, it is important to examine the extent to which limestone can be used in the systems in place of dolomite. Although dolomite has been generally used in pressurized systems, in some cases it is possible to use limestone. If limestone could be used more generally, then the cost of electricity from a pressurized system might be lower than projected and systems would not be restricted geographically to locations near dolomite deposits.

Laboratory and pilot scale data on regenerative sorbent cycles are needed to support studies of this approach.

\section{Particulate}

Little is known about the particulate emission characteristics of fluidized beds. Although many current studies predict that fluidized-bed combustion systems will be able to meet existing or more stringent New Source performance Standards, these statements have been generated in the absence of a broad data base. The primary uncontrolled particulate emissions from fluidized beds are substantial, generally larger than those 
from the combustion section of a conventional boiler. Some advantage is claimed due to the larger mean particle diameter in fluidized-bed systems, which characteristicly leads to more efficacious control in mechanical collectors. It is important to characterize the particle load and size distribution as a function of stone, operating conditions, and system configuration.. The particulate should be characterized both before and after the carbon burnout cell in the present designs in order to provide information for alternative systems.

Anticipating that both electrostatic precipitators and fabric filters might be used to control particulates from fluidized-bed systems, data characterizing the fly-ash with respect to both of these technologies are needed. In the case of the electrostatic precipitator, data concerning resistivity, the chemical composition, particle size distribution, etc., should be obtained. For fabric filters, data on hygroscopicity, abrasiveness and electrical properties are required.

Again as in the case of $\mathrm{SO}_{2}$ capture, examination of performance at partial load conditions is needed. Particulate formation will be affected by changing conditions in the combustor. Also, the mechanical collector (cyclone) section may lose efficiency at reduced throughputs, in turn affecting the ESP or baghouse.

Characteristies of different limestones and dolomites with regard to particulate formation should be studied, including examination of the friability of different stones and their tendency to decrepitate. Finally, a great deal of data is required on the composition of particulates in fluidized-bed combustor. Many claims of lower toxicity than conventional fly ash have been made, although on the basis of little data. 
Heavy metals composition data are required. Given that fluidized-bed combustors may provide less overall carbon utilization than do conventional systems, it is very important to study the organic constituents in fly ash. In particular, the presence of polynuclear aromatic compounds should be examined.

\section{Nitrogen Oxides}

It is very important to establish the degree of benefits available through low nitrogen-oxide emission characteristics of fluidizedobed combustion systems. Potential low emissions represent one of the major advantages claimed for fluidizedbed combustion systems. As noted in the introduction to this section, it is difficult to predict with confidence whether this advantage will actually accrue to full-scale systems.

Data are needed on the effect of the carbon burnout cell on nitrogen oxide formation. This part of the system provides an opportunity for reaction at higher temperatures than exist in the combustion section. Additional residence time for reaction is also provided. Some of the data from laboratory and pilot studies indicate that the nitrogen oxide levels depend. on the calcium-to-sulfur ratio. More data on this effect is needed in order to optimize the overall system performance. And, as in the above cases, behavior of nitrogen oxide formation at less than full load conditions is required.

\section{Solid Waste}

Data on the characteristics of solid ash and spent sorbent are also required. The leachability, that is, the solution of 
components in the solid waste in water passing through, should be better characterized. Overall measurements of the composition of solid waste are also required. These data should be collected for a variety of coal and sorbent types in order to develop estimates of the full range of potential environmental hazards posed by the disposal of solid waste from fluidized-bed combustion systems. 


\section{REFERENCES TO CHAPTER FOUR}

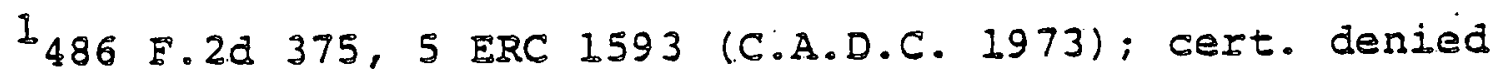
417 U.S. 921.

${ }^{2}$ see $40 \mathrm{CFR} \$ 60.8$ and $\$ 60.11(c),(d)$. 


\section{THIS PAGE \\ WAS INTENTIONALLY \\ LEFT BLANK}




\section{DETAILS OF COST MODELS}

\section{A. 1 Conventional system with FGD}

This section presents the details of the cost model for a conventional coal-fired power plant with lime or limestone flue gas scrubbing. It is divided into six subsections corresponding to the following topics:
A.1.1 Cost components
A.1.2 Scrubber and Boiler Adjustments
A.1.3 Capital Cost Formula
A.1.4 Energy Loss Formula
A.1.5 Energy Cost Formula
A. 1.6 Other Model Outputs

\section{A.1.1 Cost Components}

TVAl presented the detailed breakdown of capital costs for a conventional system developed in the $G E^{2}$ study. In addition, they made certain changes, particularly for the scrubber and solid waste disposal portions of the costs. The detailed breakdown, with revisions as suggested by. TVA, was used to group the components into the various categories corresponding to the coefficients in the capital cost equation. These categories were: 
- Coal handing

- Ash handiing

- Limestone handling

- Solid waste handing

- Solid waste disposal

- Scrubber pumps and piping

- Land for disposal

- Scrubber modules and equipment

- Scrubber constants

- Sensitive boiler components

- Constant terms

The capital costs for the plant were broken down into component and balance of plant costs. The components included the steam generator, steam turbine and the electrostatic precipitator. The BOP costs were divided into direct labor, indirect labor, which is assumed equal to 90 percent of the direct labor, and materials. Plant costs are determined by applying A\&E to the materials, direct labor and indirect labor costs, adding the component costs and applying a contingency margin. Total costs were then calculated by adding an escalation factor of 54.8 percent. For the scrubber and disposal costs presented in the TVA study, the accounting procedure was somewhat different. For these, a 25 percent factor for indirect costs is applied to the direct investment cost, which includes materials. $A \& E$, contingency and escalation are added in the same manner, except for the land costs for disposal. No A\&E charges are assessed to the land.

Table A-I presents the item-by-1tem cost breakdown as well as the parameters and scaling factors discussed in the following two sections. 
TABLE A-1

CAPITAL COST FORMULA COMPONENTS FOR CONYENTIONAL SYSTEM

\begin{tabular}{|c|c|c|c|c|c|c|c|}
\hline Component & Items Included & Label & & $\begin{array}{l}\text { Base Case } \\
\text { Cost }(14)\end{array}$ & $\begin{array}{l}\text { Parameters } \\
\text { Changes III: }\end{array}$ & Scalling Factor & \\
\hline Coal llaudling & Pulverizers and coal handling equitument & $\mathrm{Cl}_{\mathrm{B}}$ & & $22 \times 522$ & $\begin{array}{l}\text { Cool feed Rate } \\
\text { (FC) }\end{array}$ & .85 & \\
\hline Asli llandling & Asth handling systeas & C2. & & 10.5569 & Asth flow Hate (FA) & .85 & \\
\hline $\begin{array}{l}\text { finestone } \\
\text { ilandl fing }\end{array}$ & $\begin{array}{l}\text { Liwestone handsing and preparation } \\
\text { systew } \\
\text { Calciner for lifue scrubber }\end{array}$ & c3: & & $\begin{array}{l}9.34472 \\
\text { (1 imestone) } \\
23.13548 \\
\text { (1 ime) }\end{array}$ & $\begin{array}{l}\text { Q inestone Feed Rate } \\
\text { (IS) }\end{array}$ & .85 & \\
\hline $\begin{array}{l}\text { Solid Haste } \\
\text { Disposal }\end{array}$ & $\begin{array}{l}\text { Disposal pond or tapounduent. } \\
\text { Iner. Canks and puaps }\end{array}$ & c4" & & 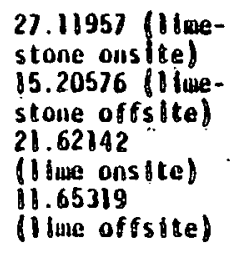 & $\begin{array}{l}\text { Soltd Waste flow Rate } \\
\text { (fSS) }\end{array}$ & .85 & · \\
\hline $\begin{array}{l}\text { Scrubber Pumps } \\
\text { and Pipling }\end{array}$ & $\begin{array}{l}\text { Punps, plping. olst el fusinalors } \\
\text { for scrubber's }\end{array}$ & C5 & & 12.20327 & $\begin{array}{l}\text { Linustone feed Rate } \\
\text { (FS) }\end{array}$ & $\begin{array}{l}.68 \\
\text { (Also: adjusted } \\
\text { to conforul } \\
\text { with scrubber } \\
\text { systen des ton) }\end{array}$ & \\
\hline $\begin{array}{l}\text { Land for } \\
\text { Dispusal }\end{array}$ & $\begin{array}{l}\text { Land for disposal (plus chemicals } \\
\text { for offsite disposai) }\end{array}$ & $\operatorname{co*}$ & & 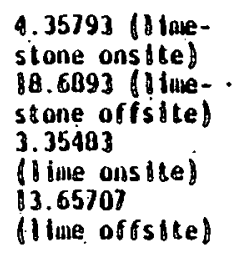 & $\begin{array}{l}\text { Solid Haste flow Rate } \\
\text { (FSS) }\end{array}$ & 1.0 & \\
\hline $\begin{array}{l}\text { Scrublier Hodules } \\
\text { and Equi peneste }\end{array}$ & $\begin{array}{l}\text { Scrubber towers and gas handling } \\
\text { equlfunent }\end{array}$ & Cll* & & $\begin{array}{l}30.66305 \\
\text { (I imestone } \\
29.86196 \\
\text { (li ine }\end{array}$ & $\begin{array}{l}\text { Muniber of Stages } \\
\text { Number of Modules } \\
\text { Percent of Dypass }\end{array}$ & $\begin{array}{l}\text { Adjusted to con- } \\
\text { forw witli systews } \\
\text { des bgn }\end{array}$ & \\
\hline $\begin{array}{l}\text { Scrubtier } \\
\text { Constants }\end{array}$ & $\begin{array}{l}\text { Stack gas reheaters, ut flities. } \\
\text { and facloities }\end{array}$ & $\mathrm{Cl} \cdot 2^{*}$ & $\cdot$ & 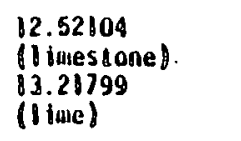 & Mane & & \\
\hline $\begin{array}{l}\text { Sensittue Codler } \\
\text { Couponents. }\end{array}$ & $\begin{array}{l}\text { Pressure parts of the boiler electro- } \\
\text { static precipitator. and insiallation }\end{array}$ & $\mathrm{Cr}_{3}$ & & 74.89545 & $\begin{array}{l}\text { Ash flow Rate (fil) } \\
\text { Coal Hedting Value } \\
\text { (Iuiv) }\end{array}$ & $\begin{array}{l}\text { Adjusted to account } \\
\text { for percent ast } \\
\text { and lutu }\end{array}$ & . \\
\hline Constant Jerws & $\begin{array}{l}\text { Stean turblne, poller coimponents, } \\
\text { structural steel, puinps, piplug. ex- } \\
\text { changes. condensers, cooling. towers. } \\
\text { stack cranes, electrical equipuent, } \\
\text { cluld structulal, piping s instru- } \\
\text { mentation, yardwork o milscellaneous }\end{array}$ & co & & 411.36585 & Mone & & \\
\hline rotne domestone & site & & & 615.6 & & & \\
\hline
\end{tabular}

- Four scrutbong and atsposal alternatlyes were included in the snodel for purposes of comparlson. These alternatives included linestone ys. B twe scrubbing and onsite vs. of fsite disposal. 


\section{A.1.2 Scrubber and Boiler Adjustments}

The function of the cost model is to adjust the base case costs for the various components to reflect changes in the coal and in other assumptions. Most of the cost components could be simply scaled according to changes in one parameter. For instance, coal handing equipment was scaled according to the feed rate of the coal. However, for some of the scrubber costs and the sensitive boiler costs, several parameters had to be accounted for.

The scrubber system design suggested by TVA specified three contact stages in the absorber. Three stages are generally required only for 90 percent removal or above, 3 and therefore the TVA system is overdesigned for the 83 percent removal required. The ERCO model adjusts the scrubber modules and the scrubber pumps and piping to conform with two-stage design at removal efficiencies below 85 percent, and with three-stage design for removal efficiencies above 85 percent. The costs for these,items increase by one-third for the three-stage system. All other costs were assumed constant. Total scrubber cost increases by 15 percent for a three-stage system compared to a two-stage system. This increase is consistent with data from Pedco. 4

The TVA system does not include any redundant modules to insure a high scrubber reliability. The ERCO model is based on the assumptions that each module has an availability of 90 percent, and that utilities will require a scrubber system reliability of 90 percent. ${ }^{3}$ Thus, one redundant module is required for a system requiring 80 percent removal or higher, and will provide a system reliability of approximately 92 percent. The cost increase for the extra module is equal to one-fourth of the cost for the four basic modules 
and related equipment, and pumps and piping. All other scrubber components are assumed constant.

The ERCO model also includes a provision for bypassing a portion of the flue gas if the removal requirement is below 80 percent. The adjustments are made to the number of modules required in the syster, for 90 percent reliability, to the costs of the scrubber facilities and other "constant" scrubber costs, and to the energy lost through stack gas reheat. The bypass calculations do not provide for temporary violations of NSPS. The assumption is that the standards will always be met and that the inherent design includes enough redundancy to account for variations in the coal sulfur content. Bypass is allowed only when the system can bypass a portion of the flue gas without violating the standards.

For the boiler portion of the plant, it was felt that some adjustments should be made to account for the quality of the coals being used. The heating value and the ash content of the coal are the most important parameters, as they determine the feed rate and the amount of slag and particulate matter that has to be handed. Consideration of other important factors, such as grindability, moisture content, slagging temperature, etc., was excluded due to the complexities involved. In order to scale the boiler components, $a$ breakdown of the costs was obtained from Foster wheeler. 5 The boiler components most sensitive to changes in ash and heating value are the pressure parts and the electrostatic precipitator. These items were grouped into the "Sensitive Boiler Components" category of Table A-I. 
The coefficients for the cost equation for these items were assumed to be constant, thus yielding a linear cost equation of two variables, ash content and heating value. Numerical values were developed in the following manner. It: was assumed that the cost of these items was relatively proportional to their weight. It was also assumed that the weight of these components was relatively proportional to the surface area of the boiler. 6 . Three data points were identified ${ }^{7}$ that corresponded relatively well with three of the four coals chosen for the analysis in this study. A simple regression was used to determine the coefficients, based on the coal characteristics of the base case coal. The equation which resulted is:

Cost $(C l 3)=$ Baseline Cost $(C 13) \cdot\left[1+\frac{(P A-9.6)}{125}+\frac{10788-\mathrm{HV}}{30,000}\right]$

where

$$
\begin{aligned}
& \mathrm{PA}=\text { percent ash } \\
& \mathrm{HV}=\text { heating value }
\end{aligned}
$$

This formula implies that the cost of the sensitive boiler components will increase 10 percent if the ash content increases 12.5 percent, and 10 percent if the heating value decreases 3,000 Btu/Ib.

\section{A.1.3 Capital Cost Formula}

The equations for the capital costs of the system in millions of dollars result as follows:*

* See Table A-1 for definition of terms. 


$$
\begin{aligned}
& \text { Scrubber Capital }=C 11+C 12+C 3\left(\frac{F S}{120018}\right)^{.85}+ \\
& C 4\left(\frac{\text { FSS }}{215727}\right)^{.85}+C 5\left(\frac{F S}{120018}\right)^{.68}+C 7\left(\frac{\text { FSS }}{215727}\right)^{1.0}
\end{aligned}
$$

Total Capital = Scrubber Capital $+\mathrm{CO}+\mathrm{Cl} 3+\mathrm{Cl} \cdot$

$$
\left(\frac{F C}{757508}\right)^{.85}+.62\left(\frac{F A}{72721}\right)^{.85}
$$

This value is converted to dollars per kilowatt by converting to dollars and dividing by the net power output in. kilowatts, which is calculated as described in the following section.

\section{A. 1.4 Energy Loss Formula}

Energy losses in the conventional system arise from several sources: stack gas reheat, scrubber pumps, fans for gas flow, high flue gas temperature due to sulfur content, and miscellaneous sources. The model calculations are based on the design specified by TVA/GE and the energy losses specified by TVA. I The basic design in the TVA case assumed $300^{\circ} \mathrm{F}$ flue gas temperature, three-stage wet scrubber, and a $50^{\circ}$ F reheat of 100 percent of the flue gas. The energy losses in the model are calculated by determining the differences between the coal characteristics and other parameters' input and the base case. This is accomplished by the following five formulas:

Energy Change in Gas Flow (ECHGF) =

$$
(3-\mathrm{NST}) \cdot 1.15+\text { BYPS } \cdot 2.3
$$

where

$$
\begin{aligned}
& \text { NST = number of stages } \\
& \text { BYPS = percent flue gas bypassed }
\end{aligned}
$$


Energy Change in Liquid Flow (ECHIF) =

$$
(3-\mathrm{NST}) \cdot 1.12+\text { BYPS } \cdot 4.48
$$

Energy Change in Flue Gas Temperature (ECMFGT) =

$$
(1.3765-.353 \text { PS }) \cdot \frac{868.6}{100}
$$

Energy Change in Reheat (ECHRHT) = BYPS 14.6

Net Power Output $=798.1 \mathrm{H}$

$$
E C H G F+E C H L F+E C H F G T+E C H R H T
$$

Formula $(A-4)$ was derived from TVA ${ }^{1}$ and Pedco data, ${ }^{3}$ and is based on apportioning the energy requirement for the induced draft fans to the scrubber and non-scrubber loads. The scrubber (three-stage, no bypass) accounts for about 3.45 Mwe of this load. A two-stage scrubber uses about 66.7 percent of this amount, and as the bypass goes from 0 to 100 percent (implying zero sulfur removal) the energy loss for gas flow through the scrubber drops to zero:

Formula (A-5) was also derived from TVAland Pedco data. ${ }^{3}$ Scrubber pumps account for about 5.6 MWe in the TVA design. As the number of scrubber stages is reduced from 3 to $2,1.12$ MWe will be saved. As bypass goes to 100 percent, the energy loss goes to zero.

Formula $(A-6)$ is based on the principle that lower sulfur, levels will allow greater heat recovery from the gases 
exiting the boiler. At. 5 percent sulfur, the exit gases can be reduced from the base case of $300^{\circ} \mathrm{F}$ sufficiently to yield a. $1.2^{\circ}$ increase in steam generating efficiency, due to the lower dew point of the corrosive $\mathrm{SO}_{3}$ gas. ${ }^{2,8}$ This corresponds to $250^{\circ} \mathrm{F}$ flue gas exit temperature.

Formula (A-7) calculates the amount of reheat energy saved when flue gas bypass is possible. Since reheat accounts for about $14.6 \mathrm{MWe}$ equivalent in the base case design, 100 percent bypass saves $14.6 \mathrm{MWe}$. This formula does not take account of the possibilities for utilizing bypassed air for at least partially reheating the scrubbed gases.

\section{A.1.5 Energy Cost Formula}

The energy cost formula is based on an 18 percent capital charge rate per year, a 1.95 percent O\&M factor per year, and a plant factor of .65 . The formula assumes that the O\&M charge does not include the cost of the sorbent.

$$
\text { Energy Cost }(\text { Mills } / \mathrm{kWh})=\frac{35.0368 \times \text { Capital }+ \text { FC.PC + FS.PS }}{\text { POWNET }}(\text { A-9) }
$$

where

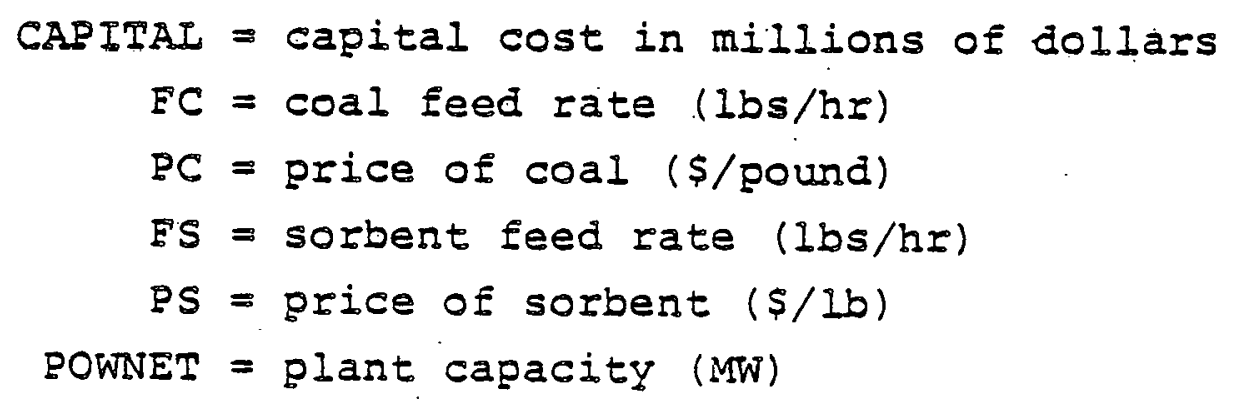




\section{A.1.6 Other Model Outputs}

The outputs of the model include the following:

- Calcium to sulfur ratio

- Number of spare modules

- Investment ( $\$ / \mathrm{KW})$

- Scrubber investment. ( $\$ / K W)$

- Disposal investment ( $\$ / K W)$

- Net output

- Cost of electricity (mills/kWh)

- Cost of disposal (mills/kWh)

- Acres of land for disposal.

- Plant efficiency

- Coal consumption (tons/yr)

- Iimestone consumption (tons/yr)

- Solid waste production (tons/yr)

These items are calculated in the program on the bases of the input assumptions concerning coal characteristics, percent removal of $\mathrm{SO}_{2}$, and prices for coal, limestone and land. The basic assumptions of the program for these parameters are all derived from the baseline design study by GE as revised by TVA.

\section{A.2 Cost Model for Atmospheric Fluidized.Bed}

This section of the Appendix will delineate the methodology involved in constructing the cost model for fluidizedbed power plants. The various scaled components, the scaling factors, the costing assurptions and the net power output equation will all be identified and discussed in turn. 
The method and format of the ERCO cost model has been adopted, for the most part, from a similar model constructed by Westinghouse. 9 Capital equipment costs were taken from the TVA I report that modified the ECAS costs performed by $\mathrm{GE}^{10}$ As mentioned in the text of this report, Westinghouse did not incorporate the TVA revisions into their model; this results in lower total cost estimates from their models: The ERCO models utilized two of the scenarios for the costs of disposal of AFBC and PFBC solid wastes that were analyzed by TVA. The plant net electrical output is specified by the GE-ECAS report. for the base case, with alterations in plant power output due to different volumes of coal of sorbent calculated according to a relationship dem. veloped by Westinghouse and discussed later in the Appendix.

\section{A.2.1 Plant Capital Cost}

The GE-ECAS report utilizes seven plant categories to summarize the FBC capital investment. Table A-2 lists those categories, the GE-ECAS costs and the total TVA costs for the same items (not including disposal costs). As in the Westinghouse model, the costs for categories $2.0,4.0,5.0,6.0$, and 7.0 (turbine generators, electrical and civil and structural, process piping and instrumentation, and yardwork and miscellaneous)) are assumed to be fixed in cost over this range of parameters considered. Only certain components of Categories 1.0 and 3.0 (steam generators and process mechanical equipment) are scaled according to capacity. The scaling is done according to changes-in the coal feed rate, sorbent feed rate, and spent solids flow rate. These changes are measured by the ratios FC/FC $C_{b} \frac{F C+F S}{F C_{b}+F S_{b}}, F S / F S_{b}$, and FSS/FSS $S_{b}$, 
TABLE $A-2$

CAPITAL COST BREAKDOWN - AFBC

(millions of dollars)

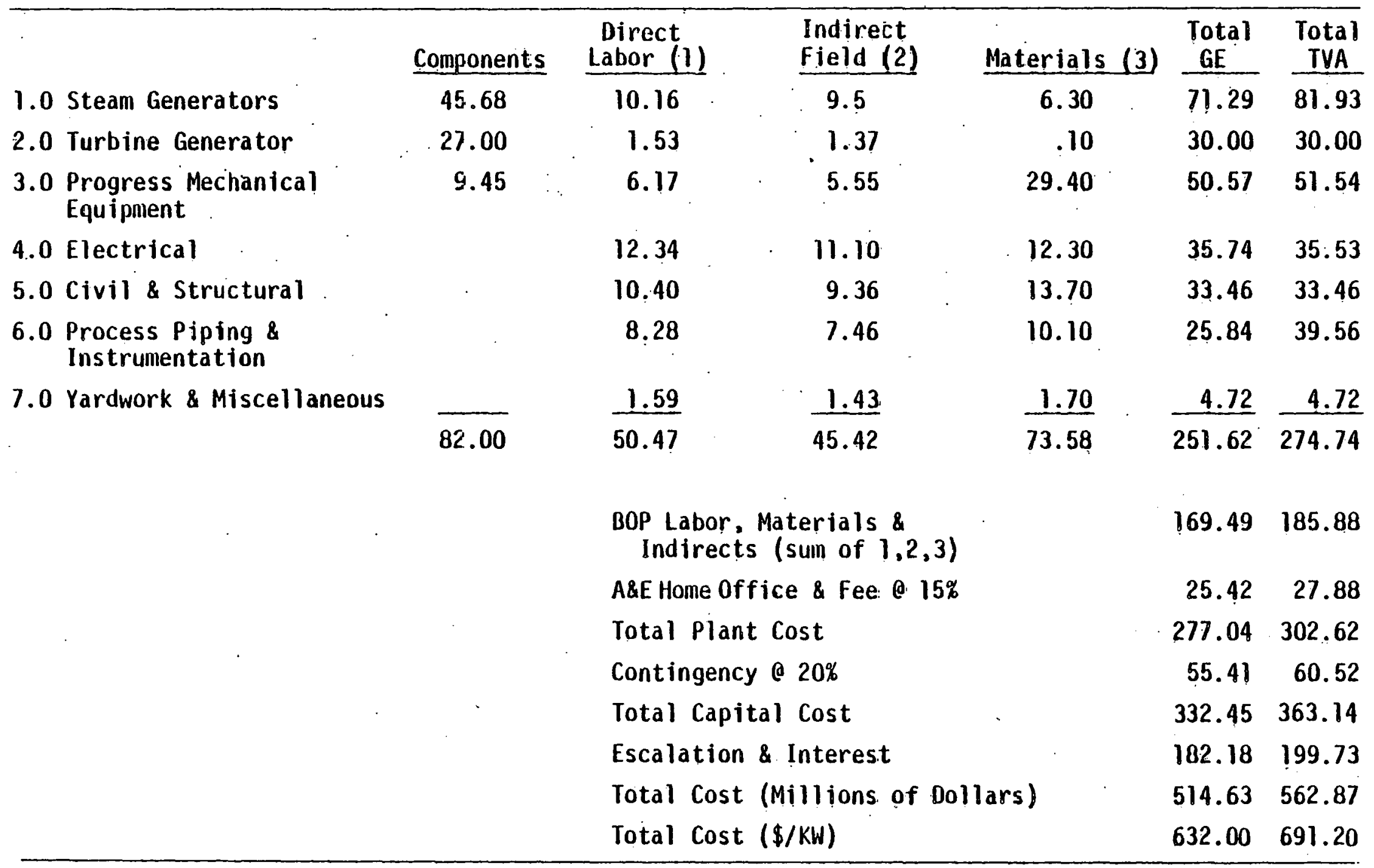


where FC is the coal feed rate, FS is the sorbent feed rate, FSS is the spent solids rate and $F C_{b}$. FS $b^{\prime}$ and FSS $S_{b}$ are the base case (GE-ECAS) feed rates for coal and sorbent and the base case flow of solid wastes respectively. The scaling factors (i.e., exponents) applied are 0.85 for solids handing items, 0.6 for cyclones and auxiliary components and 0.68 for fans and motors. The one exception is for the land for disposal. The cost for this land is scaled in direct proportion to FSS/FSS . $_{\text {. }}$

The capital cost formula consists of a constant followed by nine variable terms. The constant tem represents the sum of all those elements of the AFBC cost that are held constant relative to the parameters considered here. To arrive at the total cost that is held constant, the labor, indirect field cost (at 90 percent of direct labor except for disposal investment) and balance of plant material in the TVA report were summed, multiplied by 1.15 to incorporate the A\&E fee and then sumied to the component costs to arrive at a total plant cost. The total plant cost (of the unscaled items) is increased by 20 percent for contingency and 54.8 percent for escalation and interest during construction. This final figure is the value. for the constant in the capital cost formula.

A similar procedure is used to arrive at the coefficients for the nine variable terms. Note that the 15 percent $A \& E$ fee is not applied to the component costs, but only to the direct labor, indirect field, and balance of plant material. 
Table A-3 lists the elements of each cost item that correspond to the coefficients in the cost formula. It gives the value for the coefficient, the parameter that corresponds to each coefficient and the scaling factor applied. A more complete description of the equipment listed under the heading of Items Included can be found in the TVA I report from which the AFBC plant costs were taken. There are two sets of disposal costs depending upon whether one wishes to calculate the total plant costs with offsite or onsite disposal.

In order to remain consistent with TVA's estimates for disposal costs for conventional power plants, the indirect field expense for disposal has been calculated at 25 percent of the total direct investment and the A\&E fee has not been applied to the cost of land. This is in contrast to the calculation of indirect field expense at 90 percent of direct labor and a 15 percent A\&E fee applied to the land costs for TVA's AFBC disposal costs. The method used in this study is felt to be the most reasonable and consistent method.

Combining the constant term with the coefficients results in an equation expressing the total capital investment for an atmospheric fluidized-bed power plant:

$$
\begin{aligned}
& I\left(\$ \times 10^{6}\right)=499.133+23.676\left(F C / F C_{b}\right)^{.85}+ \\
& \left.9.882\left(F S / F S_{b}\right) .85+9.477\left(\frac{F C+F S}{F C_{b}+F S_{b}}\right)^{.85}+16.552(\text { FSS/FSS })_{b}\right) .85
\end{aligned}
$$

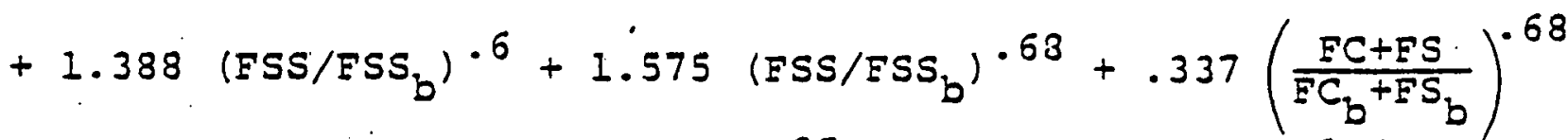

$$
\begin{aligned}
& +\left[\text { offsite disposal } 7.172\left(\text { FSS/FSS }{ }_{b}\right) .85+2.051 \text { (FSS/FSS }{ }_{b}\right) 1.0 \\
& \text { onsite disposal } \left.38.836 \text { (FSS/FSS }_{b}\right)^{.85}+6.219(\text { FSS/FSS })^{1.0} \quad(A-10
\end{aligned}
$$


TABBE A-3

\section{ELEMENTS OF AFBC COST FORMULA}

\begin{tabular}{|c|c|c|c|c|}
\hline \multirow[b]{2}{*}{ Component } & \multirow[b]{2}{*}{ Items Included } & \multirow[b]{2}{*}{$\begin{array}{c}\text { Base Case } \\
\text { Cost }\end{array}$} & \multirow[b]{2}{*}{ Parameter } & \multirow[b]{2}{*}{$\begin{array}{l}\text { Scaling } \\
\text { Factor }\end{array}$} \\
\hline & & & & \\
\hline Coal Handling & $\begin{array}{l}\text { Coal drying and crushing } \\
\text { Coaj handling. } \\
\text { Erect \& supply materials }\end{array}$ & 23.676 & $\left(F C / F C_{b j}\right)$ & .85 \\
\hline $\begin{array}{l}\text { Limestone } \\
\text { Hand ling }\end{array}$ & $\begin{array}{l}\text { Limestone drying and crusting } \\
\text { Limestone handling } \\
\text { Erect \& supply materials }\end{array}$ & 9.882 & $\left(F S / F S_{D}\right)$ & .85 \\
\hline $\begin{array}{l}\text { Coal \& Limestone } \\
\text { Blending \& } \\
\text { Feeding }\end{array}$ & $\begin{array}{l}\text { Coal \& limestone blending \& feeding } \\
\text { Coal \& limestone blend handling } \\
\text { Erect \& supply materials }\end{array}$ & 9.477 & $\frac{F C+F S}{F C_{b}+F S_{b}}$ & .85 \\
\hline $\begin{array}{l}\text { Spent Bed } \\
\text { Material } \\
\text { Cooling }\end{array}$ & $\begin{array}{l}\text { Spout bed material cooling } \\
\text { Spent solids handling } \\
\text { Erect supply materials }\end{array}$ & 16.552 & (FSS/FSS & .85 \\
\hline $\begin{array}{l}\text { Cyclone \& } \\
\text { Auxiliary } \\
\text { Comp. }\end{array}$ & $\begin{array}{l}\text { Two CBC cyclone units } \\
\text { Two surge bins \& dust coolers } \\
\text { Two coolers for CBC }\end{array}$ & 1.388 & $\left(F S S / F S S_{b}\right)$ & .6 \\
\hline Fans \& Motors & $\begin{array}{l}10 \% \text { of two air preheaters } \\
10 \% \text { of two ID fan \& motors } \\
10 \% \text { of two FD fans \& motors }\end{array}$ & .575 & $\left(F S S / F S S_{b}\right)$ & .68 \\
\hline Fans \& Motors & Two PA fans \& motors & .337 & $\frac{F C+F S}{F C_{b}+F S_{b}}$ & .68 \\
\hline $\begin{array}{l}\text { Disposal- } \\
\text { Investment }\end{array}$ & Solids Disposal & $\begin{array}{r}38.836 \text { (onsite) } \\
7.172 \text { (offsite) }\end{array}$ & $F S / F S_{b}$ & .85 \\
\hline Disposal-Land & Land for Disposal & $\begin{array}{l}6.22 \text { (onsite) } \\
2.057 \text { (offsite) }\end{array}$ & $F_{S S / F S S}$ & 1.0 \\
\hline
\end{tabular}


TABLE A-3 (Continued)

\begin{tabular}{|c|c|c|c|}
\hline $\begin{array}{l}\text { Disposal-Land } \\
\text { Onsite }\end{array}$ & Land & 6.22 & $F S / F S S_{b}$ \\
\hline $\begin{array}{l}\text { Disposal- } \\
\text { Investment } \\
\text { Offsite }\end{array}$ & $\begin{array}{l}\text { Direct Investment } \\
\text { Indirect field } \\
\text { Store treated in clay-lined diked } \\
\text { impoundment }\end{array}$ & 7.172 & $F S S / F S S_{b}$ \\
\hline $\begin{array}{l}\text { Disposal-Land } \\
\text { Onsite }\end{array}$ & Land & 2.051 & $\mathrm{FSS} \mathrm{FSS}_{b}$ \\
\hline
\end{tabular}




\section{A.2.2 Plant Power Calculation}

GE-ECAS ${ }^{10}$ estimates show an auxiliary power consumption of 64.4 MWe for their base case. Westinghouse has formulated an equation to predict the total plant power that takes into account power for carbon buxnup cell air blowers and drying, crushing, and handing coal and sorbent, plus energy losses. from carbon losses and calcination of the sorbent. The total plant power is given as follows:

$$
\begin{aligned}
\text { POWNET(MWE) }= & 831.4-18.52\left(\frac{\text { ESS }}{\text { FSS }_{\mathrm{b}}}-1\right)-2.4\left(\frac{F C+F S}{\text { FC }_{\mathrm{b}}+F S_{\mathrm{b}}}-1\right) \\
& -0.3162(\mathrm{Ca} / \mathrm{S}) \cdot \mathrm{PS} \cdot \mathrm{FC} \times 10^{-5}
\end{aligned}
$$

where PS is the percent sulfur in the coal.

The first variable term represents the increase in auxiliary power due to the carbon burnup cell air blower requirements and carbon losses, the second variable term reflects the increased power for coal drying and crushing, and the third variable term represents the calcination energy loss.

\section{A. 2.3 Cost of Electricity}

The cost-of-electricity relationship is based on capital charges of 18 percent per year, operating and maintenance costs of 1.95 percent per year, and a plant capacity factor of .65 . The resulting relationship is:

COE (miIIs $/ \mathrm{kWh})=\frac{3.50369 \times 10^{4} \mathrm{I}+\text { OFC } \mathrm{BH} \times 10^{-3}+.5 \mathrm{SFS}}{\text { POWNET } \times 10^{3}}(\mathrm{~A}-12)$ 
where

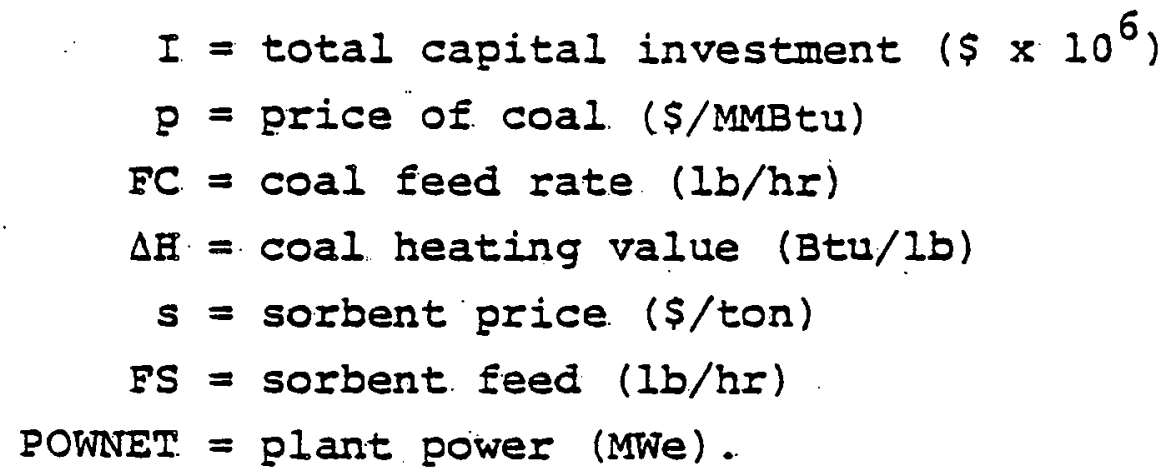

The ERCO model incorporates the previous equations $(A-10)$ through $(A-12)$. to calculate an estimate for the total cost, power output, and cost of electricity for an AFBC power plant designed to accept a certain type of coal and achieve a certain specified emission of sulfur. since it is not clear exactly what calcium-to-sulfur ratios will be required to achieve a specified level of emissions, the model has the capacity to vary the calcium-to-sulfur ratio value while holding other parameters constant in order to establish a range of estimates. The GE-ECAS ${ }^{10}$ base case suggested a. 2-to-1 calcium-to-sulfur ratio for both the atmospheric and pressurized fluidized beds; the cost models were constructed with this value as a base. Thus, with base case coal, sorbent, calcium-to-sulfur ratio and removal efficiencies input into the model, values will result that will be quite similar to the TVA estimate, differing only because of the alteration in the treatment of the disposal costs mentioned earlier.

\section{A. 3 Cost Model for Pressurized Fluidized Bed}

The cost model for the pressurized fluidized bed followed a format almost identical to the one used for the atmospheric fluidized-bed model. There are significant similarities in 
equipment necessary for the construction of PFBC, and similar components between the two were scaled similarly.

\section{A.3.1 Plant Capital Costs}

Table A-4 illustrates the GE-ECAS ${ }^{10}$ categories and costs and compares them to the total. TVA adjusted costs (minus disposal costs) from which the pressurized fluidized-bed cost model was derived.

As was the case for the AFBC cost model, categories 2.0 and 4.0 through 7.0 are held constant in cost over the range of parameters considered, while certain portions of categories 1.0 and 3.0 were incorporated into the coefficients of the cost model in order to be scaled. relative to the coal or sorbent feed rates or the spent solids rate. As was the case with the AFBC cost model, the disposal costs as calculated by ERCO from the IVA estimate are included in the model in the last two terms, the first of which represents the investment in disposal facilities. The second term reflects the cost of land for disposal. Table A-5 lists the elements of each cost item that correspond to the coeficients in the cost model. As mentioned in the section of the Appendix dealing with the AFBC cost model, the indirect field expense for disposal has been calculated according to the procedure used by TVA in their calculation of disposal costs for conventional system, i.e., indirect field expense is calculated to be 25 percent of total direct investment, and the 15 percent $A \& E$ fee is not applied to the cost of the land.

Combining the constant term $(456.435)$ with the coefficients results in an equation expressing the total capital investment for a pressurized fluid-bed power plant: 
TABLE $\dot{A}-4$

CAPITAL COST BREAKDOWN - PFBC

(millions of dollars)

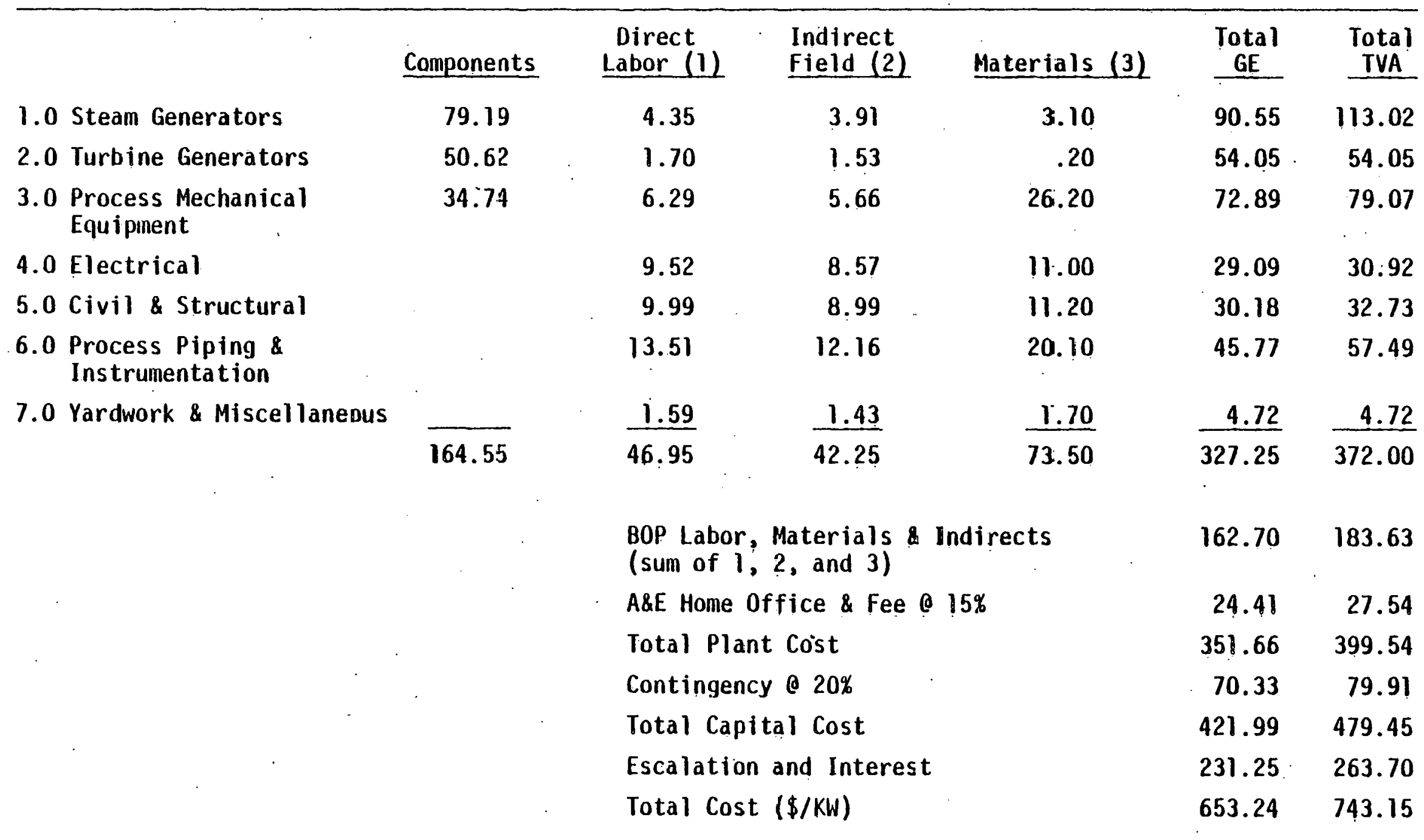


TABLE A-5

\section{ELEMENTS OF PFBC COST FORMULA}

\begin{tabular}{|c|c|c|c|c|}
\hline Component & Items Included & $\begin{array}{c}\text { Base Case } \\
\text { Cost }\end{array}$ & Parameter & $\begin{array}{l}\text { Scaling } \\
\text { Factor }\end{array}$ \\
\hline Coal Handling & $\begin{array}{l}\text { Coal processing and feeding } \\
\text { Coal handling } \\
\text { Erect \& supply materials }\end{array}$ & 59.350 & $\left(F C / F C_{b}\right)$ & .85 \\
\hline $\begin{array}{l}\text { Dolonite } \\
\text { Handling }\end{array}$ & $\begin{array}{l}\text { Dolomite processing and feeding } \\
\text { Dolomite handling } \\
\text { Erect \& supply materials }\end{array}$ & 28.412 & $\left(F S / F S_{b}\right)$ & .85 \\
\hline $\begin{array}{l}\text { Coa \& Dolomite } \\
\text { Handling and } \\
\text { Feeding }\end{array}$ & $\begin{array}{l}\text { PFB heat exchange and pressure } \\
\text { parts } \\
\text { PFG petrocarb cooler economizer }\end{array}$ & 25.284 & $\left(\frac{F C+F S}{F C_{b}+F S_{b}}\right)$ & .85 \\
\hline $\begin{array}{l}\text { Spent Solids } \\
\text { Handling }\end{array}$ & $\begin{array}{l}145 \mathrm{ft}_{3}^{3} \text { collecting hoppers } \\
290 \mathrm{ft}_{3} \text { lock hoppers } \\
290 \mathrm{ft}_{3} \text { collecting hoppers } \\
580 \mathrm{ft}^{3} \text { collecting hoppers } \\
\text { High temperature vibrating feeders } \\
\text { CBC dust coolers } \\
\text { Granular bed filters } \\
\text { Fines letdown and remova } \\
\text { Erect heater exchangers }\end{array}$ & 227.843 & $\frac{F S S}{F S S_{b}}$ & .85 \\
\hline $\begin{array}{l}\text { Cyclones and } \\
\text { Auxiliary } \\
\text { Coniponents }\end{array}$ & $\begin{array}{l}\text { Two-in-one cyclones for beds } \\
\text { Two-in-one cyclones for CBC } \\
\text { Surge bins for dust coolers } \\
\text { CBC dust coolers }\end{array}$ & 39.946 & $\left(F S S / F S S_{b}\right)$ & .6 \\
\hline Fans and Motors & Air compressor for granular beds & .719 & $(F S S / F S S$ ) & .68 \\
\hline
\end{tabular}


TABLE A-5 (Continued)

\begin{tabular}{|c|c|c|c|c|}
\hline Fans and Motors & $\begin{array}{l}\text { Atr dryer precoolers } \\
\text { Air dryers } \\
\text { Booster compressors } \\
\text { Booster compressor spare } \\
\text { Air compressor spare }\end{array}$ & 4.485 & $\left(\frac{F C F S}{F C_{b}+F S_{b}}\right)$ & .68 \\
\hline $\begin{array}{l}\text { Disposal- } \\
\text { Investinent }\end{array}$ & Solld Waste Disposal & $\begin{array}{r}47,192 \text { (onsite) } \\
9,132 \text { (offsite) }\end{array}$ & $\left(\mathrm{FSS}_{\mathrm{FSS}} \mathrm{F}_{\mathrm{b}}\right)$ & .85 \\
\hline Disposal-Land & Land for Disposal & $\begin{array}{l}7.618 \text { (onsite) } \\
2.647 \text { (offsite) }\end{array}$ & $\left(F_{S S} / F^{\prime} S_{b}\right)$ & 1.0 \\
\hline
\end{tabular}


$I\left(\$ \times 10^{6}\right)=456.435+59.350(\text { FC/FC } . b)^{0.85}$

$$
\begin{aligned}
& +28.412\left(\text { FS/FS }{ }^{b}\right)^{0.85}+25.284\left(\frac{F C+F S}{F C_{b}+F S_{b}}\right)^{0.85}
\end{aligned}
$$

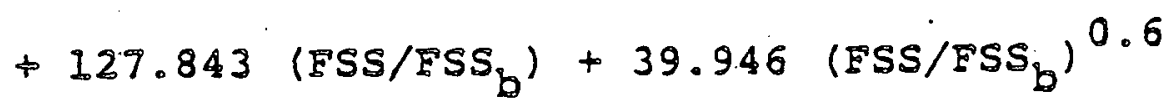

$$
\begin{aligned}
& \left.+.719 \text { (FSS/FSS }_{b}\right)^{0.68}+4.485\left(\frac{F C+F S}{F C_{b}+F S_{b}}\right)^{0.68}
\end{aligned}
$$

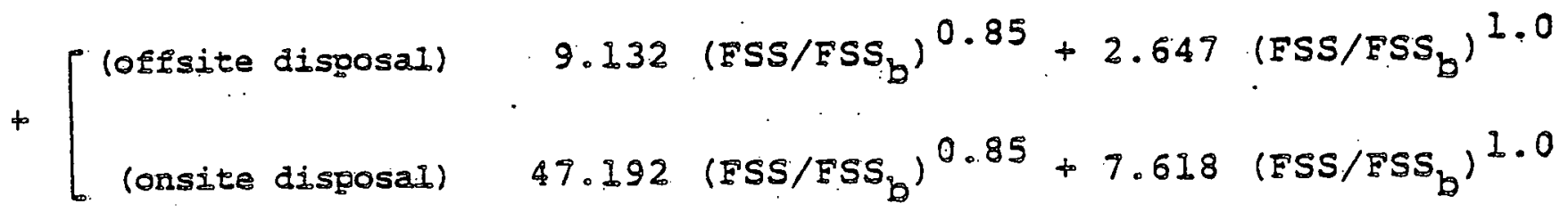

\section{A.3.2 Plant Power Calculation}

Westinghouse ${ }^{9}$ has estimated a plant power relationship for PFBC much as they have for AFBCs:

$$
\begin{aligned}
P(\text { MWe })= & 926.8-16.1\left(\frac{F S S}{F S S_{b}}-1\right)-10.1\left(\frac{F C+F S}{F C_{b}+F S_{b}}-1\right) \\
& -13.2\left(\frac{F S}{F S_{b}}-1\right)-.429(\mathrm{Ca} / S) P S \cdot F C \times 10^{-5}
\end{aligned}
$$

where, again, $P$ is power plant in megawatts; $X_{s}$ is the percent sulfur in the coal; FC, FS, and FSS are coal and sorbent feed rates and FSS is the spent solids rate; and $F C_{b}$ ' $E S_{b}$, and $F_{S S_{b}}$ are the GE-ECAS base rates. 


\section{A.3.3 Cost of Electricity (COE)}

The cost-of-electricity relationship is the same for the pressurized fluidized bed as it is for the AFBC [Equation $(A-12)$ ], since. the same 18 percent capital charge and 1.95 percent operating and maintenance charge were assumed.

The PFBC cost model is based upon the TVA revisions to the GE-ECAS costs. Therefore, inputting base case values for coal, calcium-to-sulfur ratio, percentage removal, and costs of coal and sorbent will. result in a total cost that will be equal (approximately) the TVA total, with the difference arising from the alteration ERCO has made to the total TVA disposal figures. 
$I_{\text {Tennessee Valley Authority, Cost Comparison of Commercial }}$ Atmospheric and Pressurized Fluidized-Bed Power Plants to Conventional Power Plants with Flue Gas Desulfurization, EPA R\&D (March 1977).

${ }^{2}$ General Electric, Conceptual Design and Implementation Assessment of a Utility steam Plant with Conventional Furnace and Wet Lime Stack Gas Scrubbing, EPA, TVA and NASA (December 1976).

3 Personal conmunications, George Gantz, ERCO, with Larry Gibbs, Pedco (November and December 1979).

${ }^{4}$ Pedco Environmental, Particulate and Sulfur Dioxide Emission Control Costs for Large Coal-Fired Boilers, EPA (Decamber 1977).

5 Personal communication, George Gantz, ERco, with Bob Stuart, Foster-Wheeler (December 28, 1977).

${ }^{6}$ Personal communication, George Gantz, ERCO, with Burt Rawdon, Riley-Stoker (December 29, 1977).

${ }^{7}$ Power Magazine, 121 (December 1977) : p. 41.

8 Babcock and Wilcox Company, Steam: Its Generation and Use (1975).

9 Westinghouse RAD Center, Assessment of the Impact of Sulfur Dioxide, Particulate and Nitrous Oxide Emission Standards on FBC Power plant Energy Costs, EPA/IERI (January 9, 1978); and Westinghouse R\&D Center, Evaluation of the Impact of so and Particulate Emission Standards on Fluidized-Bed Combust 2 on System Energy Cost, ERA/IERL (September 1977).

${ }^{10}$ General Electric, Energy Conversion Alternatives Study (ECAS): Phase II, Final Report, NASA, ERDA, and NSF (December 1976). 


\section{THIS PAGE \\ WAS INTENTIONALLY \\ LEFT BLANK}




\section{COMPARISON OF ERCO RESULTS WITH OTHER STUDIES.}

In this appendix, the output of the ERCO cost models is compared with cost estimates from a number of other sources. Section B.l discusses the conventional. system costs and section B.2 discusses the fluidized-bed system costs.

\section{B.1 Cost of a Conventional System}

The first two sources addressed in this section are the $G^{1}$ and TVA ${ }^{2}$ reports which are based on the ECAS assumptions. As these provide the basis for the current study and the ERCO conventional system cost model, the discrepancies are small and easy to explain. The model outputs are then compared to cost estimates published by ERRI, ${ }^{3}$ followed by a comparison of scrubber cost estimates from the cost models with estimates from Pedco's draft report. 4 This section concludes with a comparison of the results of this study with the results of the Westinghouse draft reports. 5

\section{GE and TVA}

Figure B-1 presents a comparison of the final cost estimates for a conventional system from the current study, from the TVA study and from the GE study which served as the original base for both. The figure is based on the estimates for $175^{\circ}$ stack gas temperature. The GE estimate is for lime scrubbing with onsite calcination and is directly comparable to the first TVA estinate. The cost increase is ciue largely to changes in some of he component costs, and in the scrubber and disposal costs. The second TVA estimate is for limestone scrubbing and is directly comparable to the ERCO estimate presented. 


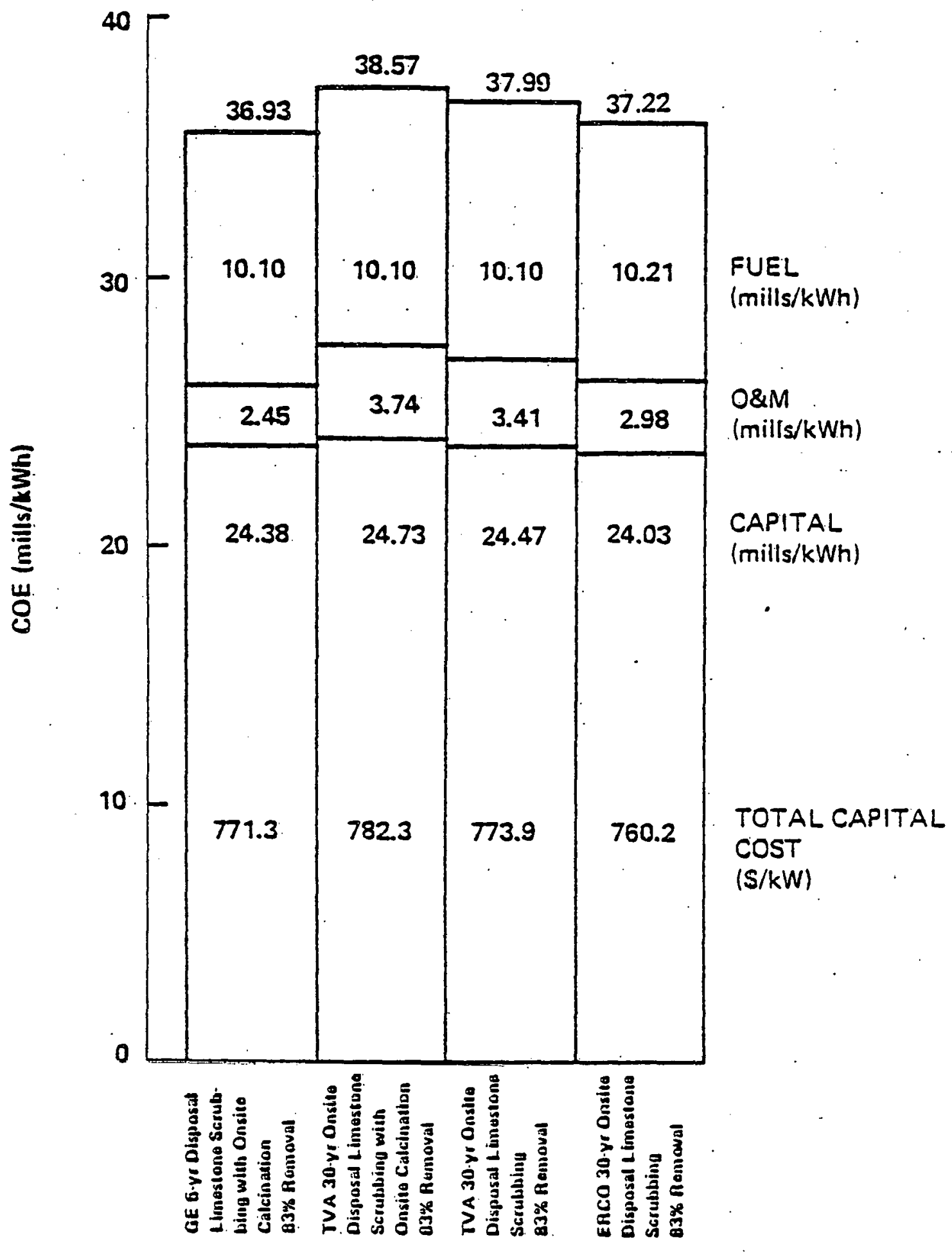

Figure $B-1$. Conventional system cost comparison with 83 percent removal. 
The difference between the TVA and GE estimates are discussed in detail in the TVA report. The differences. between the two TVA cases are also dealt with. The concern here is therefore with the second TVA estimate and the estimates from this study. This estimate is based on an 83 percent $\mathrm{SO}_{2}$ removal.

The difference in the fuel cost (see Figure $B-1$ ) is attributable to minor differences in the calculation procedure. The differences in the capital costs are due primarily to the changes in scrubber system destgn. First, a two-stage rather than three-stage scrubber was assumed by ERCO, thus saving both capital and energy. Second, one spare scrubber module was included. These changes tend to counteract each other's effects, although the overall effect is to reduce capital costs.

The difference in the O\&M cost is also substantial, although the TVA/ERCO difference is considerably less than the GE/TVA difference. TVA used a substantially different methodology for calculating the O\&M costs which is based on a direct assessment of the supplies, labor and materials required at the plant. This study used a 1.95 percent O\&M cost factor applied to the total capital cost, suggested by Westinghouse. It is probable that TVA's O\&M estimate is somewhat more accurate. However, the use of the percentage factor is more appropriate for this study as it provides consistency for conventional and fluid bed system cost estimates. At worst, it could introduce errors in the cost of electricity estimate (of the order of less than $.5 \mathrm{mills} / \mathrm{kWh}$ ).

\section{EPRI}

Two studies published by EPRI were used for purposes of comparison. ${ }^{3,6}$ The cost estimates in these studies are. 
based on enqineering design provided by Bechtel Power Corporation, as are the original ECAS studies. However, different assumptions and calculations were used which make comparison quite difficult. Capital costs are based on a variety of coals and locations, and are quite sensitive to those factors. Also, the estimates are made for two 1000 MWe power plants, are expressed in 1976 dollars and are based on different installation dates than the ECAS studies. The cost of electricity estimates reported are even more difficult to compare due to the fact that ERRI calculated "levelized" busbar costs, which are somewhat lower than costs estimated using the ECAS methodology.

Table B-I presents a comparison of capital costs for conventional systems from EPRI and from the ERCO cost models, using the same coal and FGD system parameters. The EPRI costs have been escalated by 7 percent per year in accordance with a center of gravity for expenditures of 1978, and deflated by 6 percent to 1975 dollars. Busbar costs have not been compared due to the divergent methodologies used:

The cost estimates do not compare well and exhibit differences ranging from 42 to $229 \$ \mathrm{kWw}$. With the exception of sites number 1 and 6 , the ERRI costs are consistently higher. Some of the discrepancy arises from higher labor costs at sites 3,4 and 5 . Sites 3 and 4 in particular, which exhibit the highest cost differences, were identified as "remote" sites in the EPRI report. Costs were therefore considerably higher.

Capital cost at site 5 should be lower than costs at site $I$ because of the lower ash and higher Btu contents of the coal and the lower percent sulfur removal requirements. The variations must then be due to unspecified site location factors. The discrepancies for sites 1,2 and 6 are harder 
TABLE B-1

\section{EPRI AND ERCO CAPITAL COSTS}

\begin{tabular}{lcccccc}
\hline Site & \% Ash & \% Sulfur & $\begin{array}{c}\text { Heating } \\
\text { Value }\end{array}$ & $\begin{array}{c}\text { EPRI } \\
\text { Percent SO } \\
\text { Removal }\end{array}$ & $\begin{array}{c}\text { Capital Cost } \\
(\$ / \mathrm{kW})\end{array}$ & $\begin{array}{c}\text { ERCo } \\
\text { Capital Cost } \\
(\$ / \mathrm{kW})\end{array}$ \\
\hline 1 & 16.0 & 4.0 & 10,000 & 87 & 773 & 875 \\
2 & 6.4 & .48 & 8,020 & 0 & 688 & 637 \\
$2^{\star}$ & 6.4 & .48 & 8,020 & 52 & 795 & 712 \\
3 & 6.4 & .48 & 8,020 & 0 & 807 & 637 \\
$3^{\star}$ & 6.4 & .48 & 8,020 & 52 & 933 & 712 \\
$4^{\star \star}$ & 6.4 & .48 & 8,020 & 86 & 973 & 744 \\
5 & 7.5 & 3.35 & 13,280 & 82 & 874 & 723 \\
6 & 8.2 & 3.4 & 12,730 & 82 & 664 & 736 \\
\hline
\end{tabular}

*Meets a .6 ib S0 ${ }_{2}$ MMBtu emissions limitation.

**Meets a $.34 \quad \mathrm{lb} \mathrm{SO}_{2} /$ MMBtu emissions limitation. 
to identify. The component responsible for most of the EPRI cost variation is the electrostatic precipitator, which was assumed constant in the ERCO model.

Given the variability in the assumptions used in the EPRI study, direct comparison is unwarranted. Nevertheless, examining both sets of data side by side is illustrative. First, the costs for a plant are highly dependent on location. This fact reinforces the emphasis on the ECAS and related studies as comparative and not objective in the development of cost estimates. Second, the electrostatic precipitator costs will charge as the coal changes, even though this effect is not incorporated in the cost models used in this study.

\section{Pedco}

Pedco reported estimated capital and O\&M costs for FGD scrubbers in their draft report. " The bases for these cost estimates vary considerably from those used in the cost models developed for this study. Therefore, they are not strictly comparable. Nevertheless, it is useful to look at the scrubber capital cost estimates derived from both sources and consider the sources of any differences. Table B-2 presents a comparison of scrubber capital costs for two cases.

The costs could not be adjusted to a common base for several reasons: the project life and total escalation for the Pedco system is not reported; the inflation rate used is not reported; although costs are reported for 500 and $1000 \mathrm{MWe}$ plants, the scaling function is neither strictly linear nor logarithmic, and therefore a point for 800 wWe could not be determined accurately. 
TABLE B-2

\section{SCRUBBER CAPITAL COSTS}

\begin{tabular}{|c|c|c|c|c|}
\hline \multirow[b]{2}{*}{ Description } & \multicolumn{2}{|l|}{ PEDCO } & \multicolumn{2}{|l|}{ ERCO } \\
\hline & Assumptions & $\begin{array}{c}\text { Capital } \\
\operatorname{Cost}(\$ / k W)\end{array}$ & Assumptions & $\begin{array}{c}\text { Capital } \\
\operatorname{cost}(\$ / k W)\end{array}$ \\
\hline $\begin{array}{l}\text { 1. A } 1.2 \text { lbs } \mathrm{SO}_{2} / \\
\text { MMBtu NSPS } \\
\text { with high sul- } \\
\text { fur eastern } \\
\text { coal }\end{array}$ & $\begin{array}{l}H V=12,000 \\
\% S=3.5 \\
1000 \text { MWe } \\
\text { Percent Removal = } 82 \% \\
\text { August } 1980 \text { dollars } \\
\text { Construction time - } \\
2 \text { years? }\end{array}$ & 6 & $\begin{array}{l}H V=10.788 \\
\% S=3.9 \\
800 \text { MNe } \\
\text { Percent Removal }=83 \% \\
1975 \text { dollars } \\
\text { Construction time - } \\
5.5 \text { years }\end{array}$ & 111 \\
\hline $\begin{array}{l}\text { 2. A } 90 \% \text { removal } \\
\text { requirement } \\
\text { with high sulfur } \\
\text { eastern coal }\end{array}$ & $\begin{array}{l}H V=12,000 \\
\% S=3.5 \\
1000 \text { MWe } \\
\text { August } 1980 \text { do liars } \\
\text { Construction time - } \\
2 \text { years? }\end{array}$ & 134 & $\begin{array}{l}H V=10,788 \\
\chi S=3.9 \\
800 \text { Ne } \\
1975 \text { dollars } \\
\text { Construction time - } \\
5.5 \text { years }\end{array}$ & 137 \\
\hline
\end{tabular}


The cost difference between the two NSPS levels was. close, however. Two- and three-stage turbulent contact absorbers were used in the 1.2 Ibs/MMBtu and 90 percent cases, respectively, in both studies; an extra module is included in both studies to assure high system availability, although the pedco design was based on seven required modules, and the TVA design on four required modules; disposal is assumed to be in an onsite, lined pond, although Pedco includes chemical fixation costs.

\section{Westinghouse}

Westinghouse developed independent parametric estimates of conventional system costs in their companion study. 5 The ERCO model for conventional system costs was used to develop a comparable set of system costs versus sorbent price. The Westinghouse and ERCO results are presented in Figure B-2. Westinghouse took its data for the 83 percent case directly from the TVA study. The difference in this case was discussed above.

The difference in the 90 percent case for which Westinghouse developed an independent estimate is considerable, and indicates that the scrubber costs have been handled quite differently. Westinghouse indicates that they used cost projection factors derived from the pedco report for scaling-up the 83 percent TVA costs. ERCO and Westinghouse used different assumptions in scale-up.

First, the TVA costs for the base case scrubber system at 83 percent removal assumed the use of a three-stage contact type scrubber. However, the pedco costs for 83 percent removal assumed a two-stage scrubber. The Pedco projection factor 


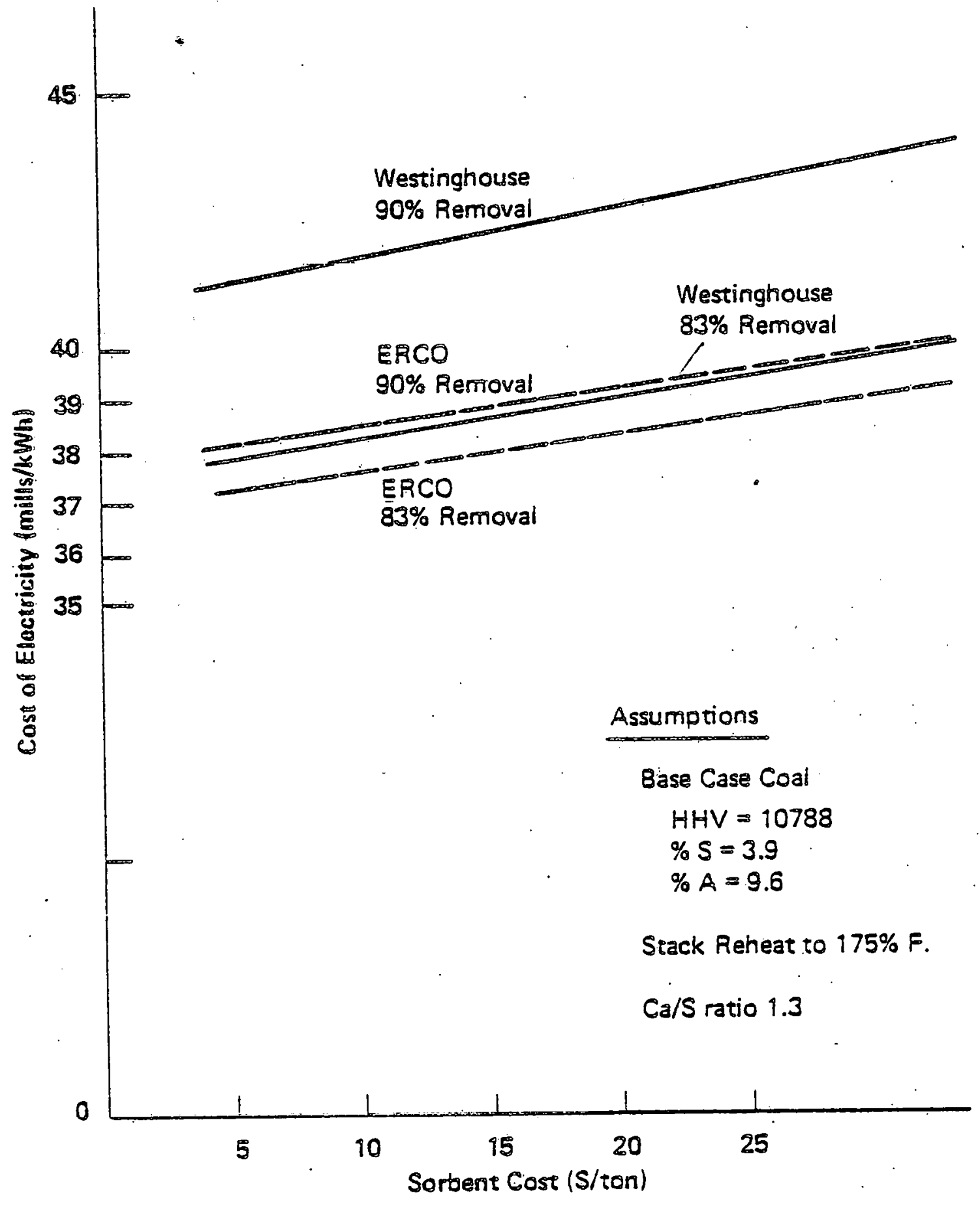

Figure B-2. Comparison of Westinghouse and ERCO Costs for a Conventional System. 
used to scale the 83 percent case to 90 percent is based on a shift. from two to three stages in the scrubber modules. Therefore, this scaling factor should not be applied to a system which already assumes a three-stage scrubber is used. The ERCO cost model includes a correction by adjusting the TVA costs for 83 percent removal in accordance with a two-stage scrubber design. The 90 percent removal case thus reflects a three-stage design.

Second, even when the scrubber system is scaled to reflect three-stage design, the overall increase of scrubber system capital costs is generally 20 percent or less. 7 The: increase in the Pedco costs presented in Table 3-5, which reflects the addition of a contact stage in the scrubber modules, is only 13 percent. A 20 percent increase in scrubber capital costs will increase total capital costs for the conventional system by less than 5 percent as the scrubber. will not account for more than 25 percent of the total system costs. The Westinghouse estimate for the cost of electricity with 90 percent removal is almost 10 percent higher than the estimate with 83 percent removal. It is not clear why the large increase occurs.

\section{B.2 Fluilized-Bed System costs}

Because of the large uncertainty that necessarily accompanies cost projections for FBC, estimates made by various groups show considerable variability. This study has chosen to base its cost model upon the ECAS report prepared by $G E^{8}$ and the TUA revisions ${ }^{2}$ to it. The ECAS study was presented in sufficient detail to identify each major component of the total cost. This facilitated the development of a model that could adjust the base case cost as parameters such as coal, emission standards, calciumto-sulfur ratio, disposal means, etc., varied. Other cost 
estimates. for fluidized-bed combustors, although not studied in the same degree of detail, are also compared with the results from these models.

The section will first present several estimates for capital costs of AFBC and PFBC and then examine more closely the difference between ECAS, TVA and ERCO figures. Operating costs and the costs of electricity are not compared directly for other estimates for two reasons.

First, the assumptions as to operating characteristics, coal, sorbent, etc., can have a substantial effect on the eventual cost figures and make it unwise to directly compare such costs. While the same can be said for capital costs, it is felt that they are more comparable, because there are fewer assumptions that can be varied.

Secondly, due to limitations in the scope and time frame of this study, the other estimates were not examined in detail. It was believed that the TVA revisions of the ECAS figures represented the best figures from which to develop a comparative analysis of AFBC, PFBC and conventional power plants with flue gas desulfurization. The relative response of $A F B C$ and PFBC to changes in NSPS are the main focus here, and detailed analysis of the other existing cost figures (which would prove much more difficult due to the lack of specificity of costs in the published reports) was not seen to significantly add to the analysis. The capital cost comparison, then, is intended to serve as a reminder that all figures for AFBC and PFBC are only estimates, and should be considered together in order to establish a probable range for the future cost of atmsspheric and pressurized fluidized bed. 
Table B-3 lists various estimates for AFBC systems and for PFBC. The values in the original references have been adjusted for escalation and interest during construction with escalation at 6.5 percent/year and interest at 10 percent/year during the construction period. These factors were applied in order to lend some measure of standardization to the costs.

It can be seen that there is a significant difference between the various estimates with a range between high and low of approximately 180 million dollars. As mentioned earlier, however, the main concern here is a comparison between atmospheric and pressurized fluidized-bed systems based on a common set of assumptions, and the other estimates are included to point out the uncertainty that exists in regard to the actual cost of the fluidized-bed systems constructed in the future.

\section{GE and TVA}

Figure $8-3$ illustrates the final cost estimates both for capital and for the cost of electricity, for atmospheric fluidized-bed combustors based on ECAS, TVA and ERCO calculations. Figure B-4 illustrates the similar case for pressurized fluidized beds. The design parameters are those specified in the ECAS report prepared by GE.

The changes in cost between ECAS and TVA.are dealt with in detail in the TVA report. Essentially, TVA revised certain portions of GE's costs upward due to uncertainty in the particular processes and associated equipment and revised some other cost components downward to bring the costs more 
TABLE B-3

ESTIMATES FOR AFBC AND PFBC SYSTEMS

\begin{tabular}{|c|c|c|c|c|}
\hline & $\begin{array}{l}\text { Atmospheric } \\
\text { Net Power }\end{array}$ & $\begin{array}{l}\text { Unit } \\
\text { Cost } \\
\$ / k W\end{array}$ & $\begin{array}{l}\text { Pressurized } \\
\text { Net Power }\end{array}$ & $\begin{array}{l}\text { Unit } \\
\text { Cost } \\
\$ / K W \\
\end{array}$ \\
\hline $\operatorname{ECAS}^{8}$ & 814 & 632 & 903.8 & 722.8 \\
\hline$T V A^{2}$ & 814 & 691.2 & 903.8 & 839.1 \\
\hline ERCO & 814 & 701.6 & 902.4 & 835.9 \\
\hline MLTRE (From TRW) ${ }^{9}$ & 800 & 519 & NS* & 641.6 \\
\hline $\begin{array}{l}\text { MITRE/METREK! } \\
\text { (BaSEd, in part, } \\
\text { on ECAS) }\end{array}$ & 814 & 520 & NS & 679.2 \\
\hline EPRI 11 & 800 & $450-665$ & & \\
\hline Westinghouse ${ }^{5}$ & 894 & 647 & 904 & 635 \\
\hline
\end{tabular}

*Not specified 


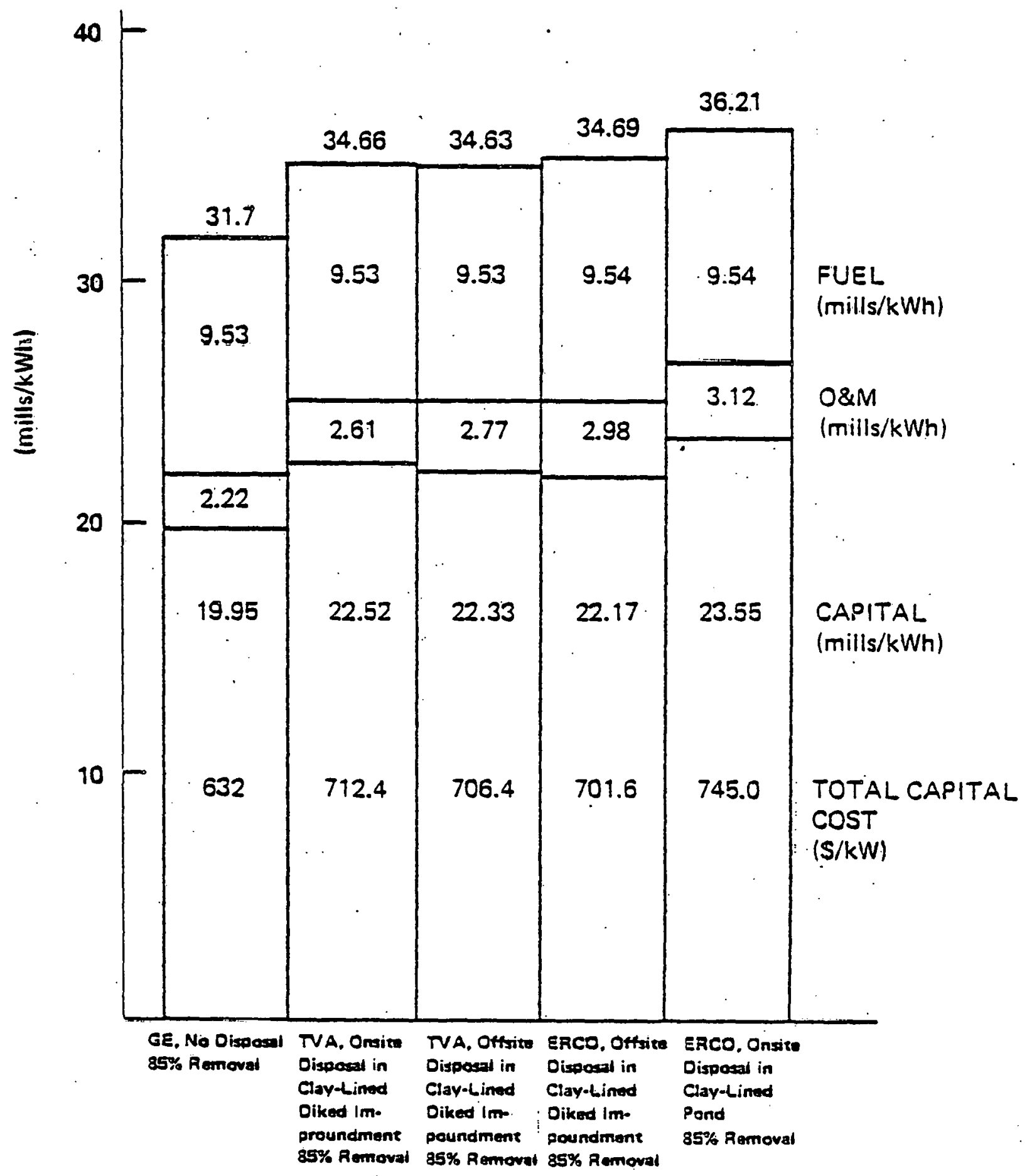

Figure B-3. Atmospheric Fluidized Bed Costs 


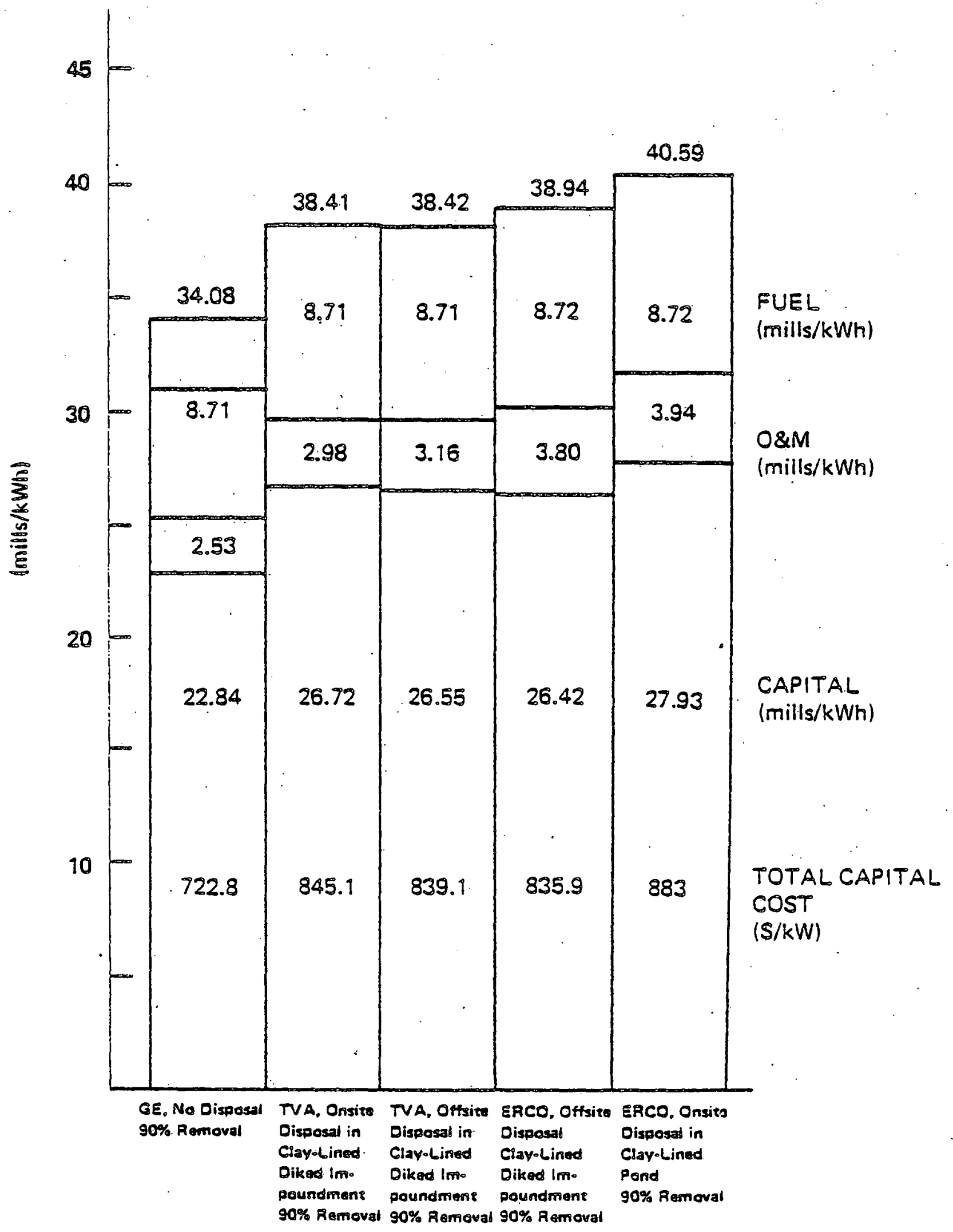

Figure 3-4. Pressurized Fluidized Bed Costs. 
in line with what they felt were "reasonable" estimates. The net effect was to increase the cost estimates in both the pressurized and atmospheric fluidized-bed cases.

TVA developed three alternative disposal system costs. In descending order of cost they are:

1. Store untreated in a clay-lined pond.

2. Store on-site, treated in clay-lined, diked impoundment.

3. Haul off-site, store treated in clay-lined, diked impoundment.

These three disposal systems apply to the wastes from atmospheric fluidized beds as well as pressurized fluidized beds, since the nature of the wastes is quite similar. The graphs in Figures $B-3$ and $B-4$ include alternatives 2 and 3 for the TVA onsite and offsite disposal cases, while the ERCO costs include alternatives 1 and 3 . This was done in order to incorporate the most and least expensive alternatives into the cost model to establish a range of possible disposal costs. This accounts for the marked increase in the ERCO onsite disposal costs for both $A F B C$ and $P F B C$, as disposal alternative $I$ (above) is substantially more expensive than alternative 2 .

TVA developed detailed costs for the disposal of conventional power plant solid wastes as well. However, they calculated the indirect labor, architect and engineer's fees and total investment for disposal in a different manner than for $A F B C$ and PFBC. Thus, ERCO has altered the formulation of the total disposal costs for $A F B C$ and PFBC to conform to TVA's conventional power plant case, which represents the most reasonable method. This change has resulted in 
slightly lower figures for the total disposal costs for $A F B C$ and PFBC. Further detail on the change can be found in Appendix A.

As can be seen from Figures $B-3$ and $B-4$, ERCO's O\&M costs are higher than those for TVA or GE. This results from ERCO's cost model which assigns 1.95 percent of the total capital cost as yearly O\&M charge, whereas ECAS (and therefore TVA) have calculated o\&M directly for each component. The 1.95 percent figure was suggested by Westinghouse ${ }^{5}$.

Since ECAS, TVA and ERCO all used the same coal input and price of coal, the total cost of electricity charge due to fuel is essentially the same for all five cases with any variation due to rounding differences in the actual calculation of the cost of fuel.

Thus, differences in costs between the TVA projections result from:

1. A change in the disposal system for onsite disposal.

2. A change in the calculation to determine the total capital investment for disposal from the direct investment.

3. Calculation of O\&M at a rate of 1.95 percent of total capital investment rather than calculating it explicitly.

4. Rounding and mathematical differences due to the parameterization of the ERCO costing model.

Westinghouse

Since ERCO has adopted much of the methodology in the construction of its cost model from a similar model used by 
Westinghouse ${ }^{5}$, this section will examine where and why ERCO's results deviate from those of Westinghouse.

Both cost models involve parameterizing the components of the power plants and scaling the costs according to the coal and sorbent feed rates. Both ERCO and Westinghouse used the ECAS study prepared by $\mathrm{GE}^{8}$ as a primary basis. for the capital components, labor and materials involved in constructing utility-sized $A F B C$ and $P F B C$ power plants. As Eigures $B-5$ through $B-8$ illustrate, however, there are. substantial differences in capital cost estimates as well as for the cost of electricity for both systems between the ERCO and Westinghouse models. In viewing these curves. the reader should note that ERCO and Westinghouse used. somewhat different coal composition. The heating value of the. Westinghouse coal with 3 percent sulfur (10842 Btu/Ib) is significantly lower than the 3.35 percent sulfur, 13280 Btu/lb coal used by ERCO. Westinghouse used a linear relationship to determine the heating value of the coal as a function of the percent sulfur in coal, while ËRCo used a typical value of actual coals (in this case a high Btu West Virginia coal). This dictates a higher coal feed rate for the Westinghouse 3 percent sulfur coal than the ERCO 3.35 percent sulfur coal, which biases Westinghouse's costs upward in that particular case. This should be kept in mind when comparing the graphs in Eigures $B-5$ through $B-8$.

One primary difference that applies to both the PFBC as well as the AFBC is that westinghouse did not incorporate TVA's adjustments to the ECAS figures into their cost model, as was done in this study. This difference innediately 


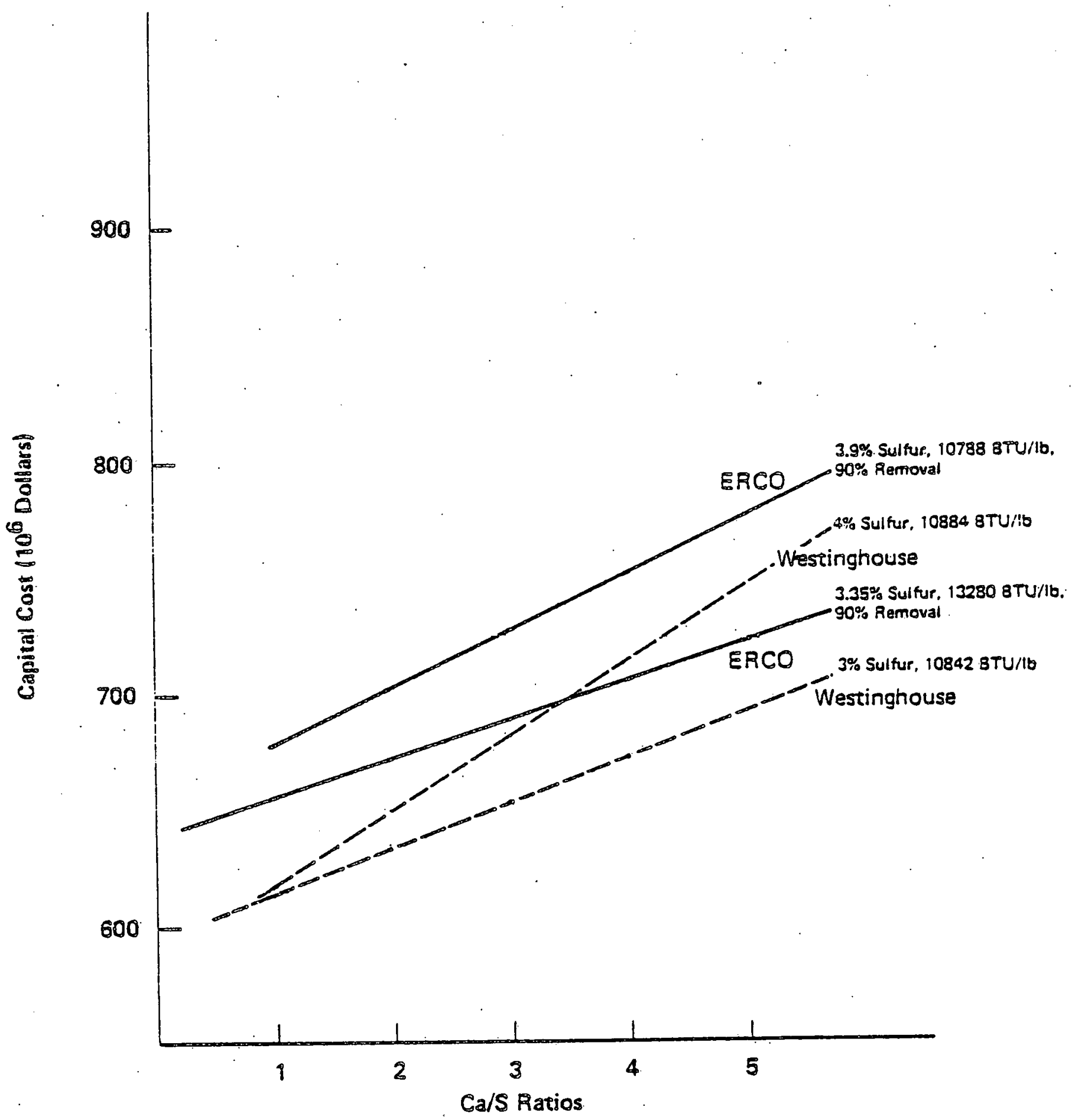

Figure B-5. Comparison of Westinghouse and ERCO Capital Investment for AFBC with Eastern Coals. 


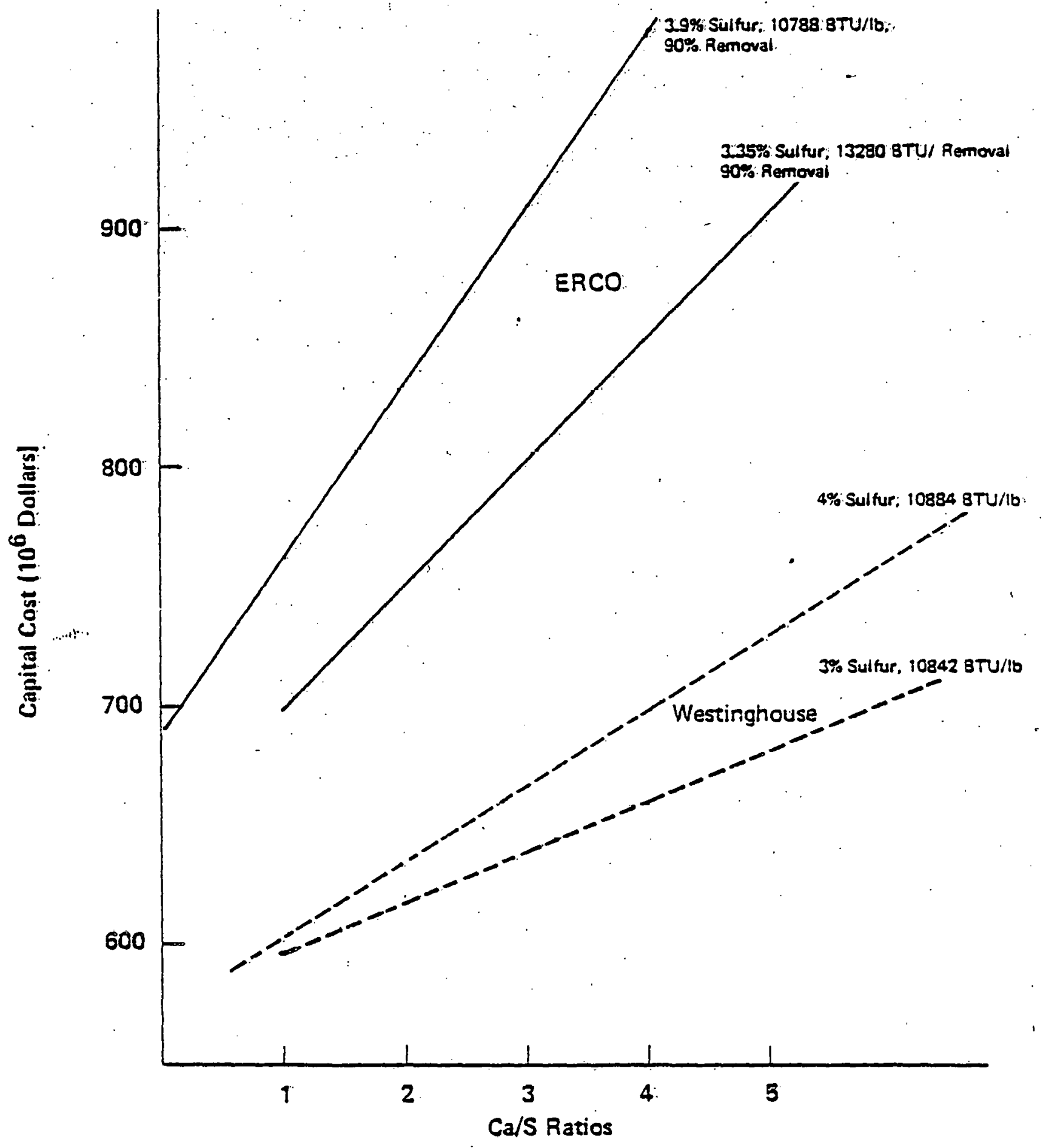

Figure B-6. Comparison of Westinghouse and ERCO Capital Investment for PFBC with Eastern Coals. 


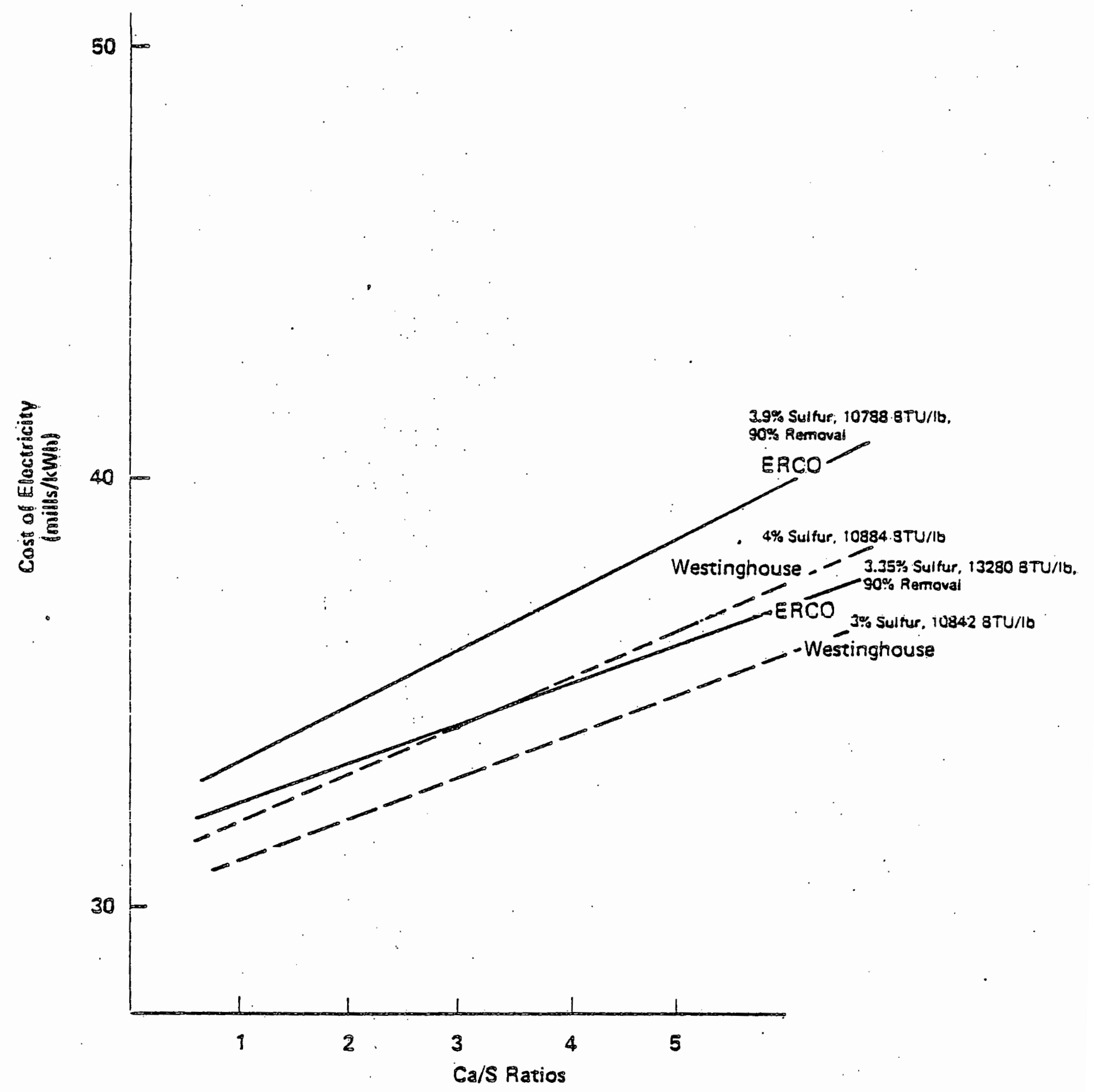

Figure 8-7. Comparison of Westinghouse and ERCO Energy Costs for AFBC with Eastern Coals. 


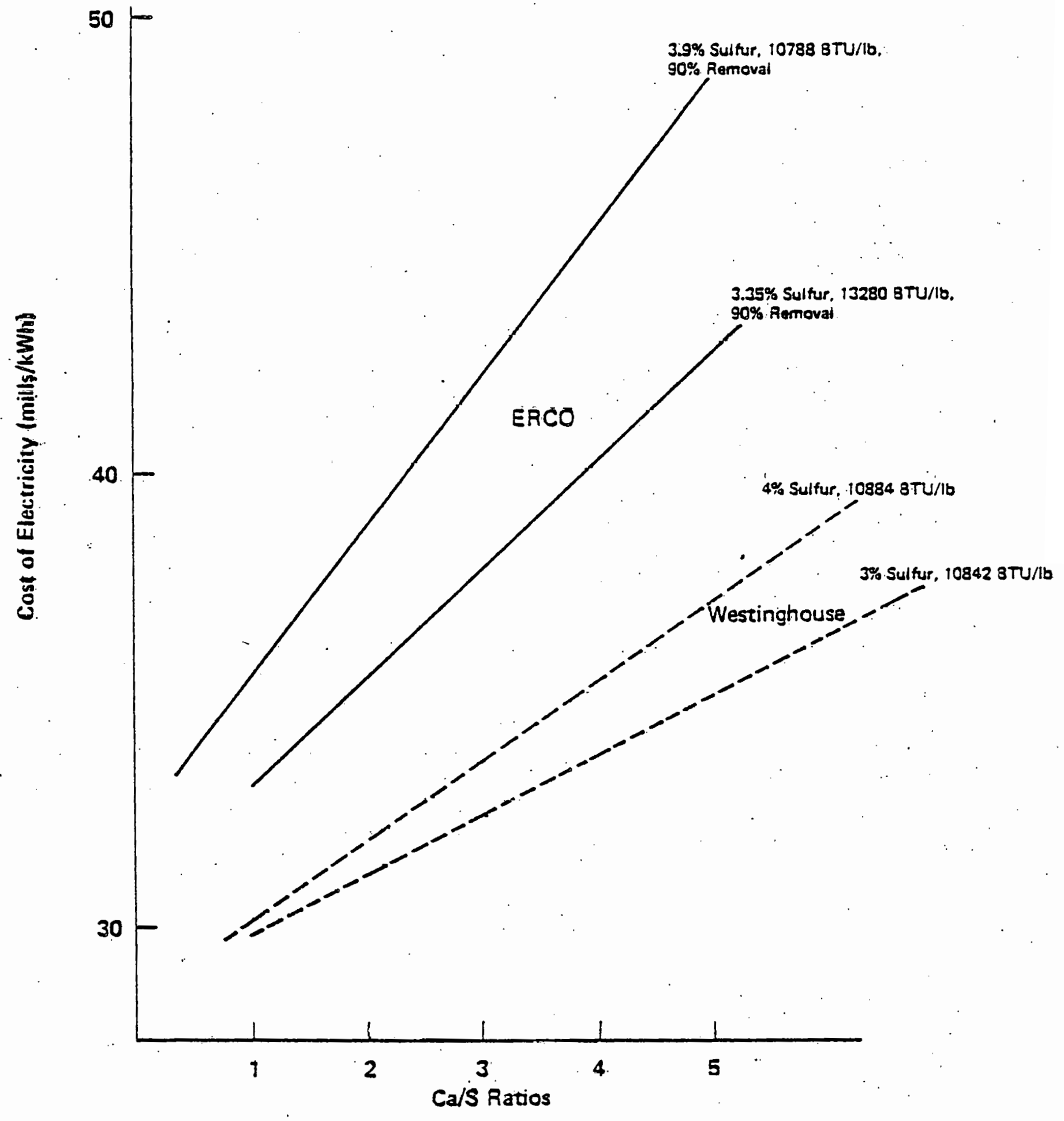

Figure B-8. Comparison of ERCO and Westinghouse Energy Costs for PFBC with Eastern Coals. 
introduces a capital cost difference of approximately $\$ 60 / \mathrm{kW}$ for $A F B C$ and $\$ 100 / \mathrm{kW}$ for $P F B C$.

Although the methodology was quite similar in determining the cost coefficients for each scaled variable (see Appendix A), there were some minor differences in which components were scaled and which were left constant and in the final value for the coefficients. These differences are based upon the engineering judgment of both companies. However, consistency was maintained, as far as possible, in the treatment of similar components of the $A F B C$ and PEBC. Thus, a meaningful comparison between the two systems can be made fairly confidently.

A major difference in the cost model for, the PFBC results from Westinghouse's decision to reduce the costs for the granular bed filters and the solids handing (coal and sorbent) systems. This change served to lower the cost of the PFBC system by approximately 10 percent. This reduction was substantial enough to lower the estimate of the total cost of PFBCs below the total cost estimate of AFBCs at low calcium-to-sulfur ratios. Since PFBCs will most probably require calcium-to-sulfur ratios below 2 , Westinghouse's model would predict lower capital ( $\$ / K W$ ) costs for PFBCs than for AFBCs. This is contrary to the ERCO model, which has PFBCs more expensive for all values of the calcium-to-sulfur ratio. The ERCO result is heavily dependent upon the $G E$ and TVA figures; since no new engineering of change in design other than that implicit in the cost. scaling process was performed, the ERCO model is consistent with the ECAS and TVA figures in predicting that PFBCS will be more expensive than $A F B C$ on a dollar/kN basis, as well as on a cost of electricity basis, as shown earlier in the main text. 
As mentioned earlier, ERCO included the most expensive (onsite) disposal method in one of the cases studied. This further increases ERCO's cost estimate over the Westinghouse figures by approximately $\$ 30$ million for the AFBC and about $\$ 45$ million for the PFBC when the onsite disposal option is chosen.

In summary, even with common ground upon which to start, differing assumptions can change the total cost substantially, reducing comparison to a question of which assumptions one chooses to hold as valid. If the assumptions are held constant, as has been done in this study for all three power plant systems, the relative economics should tend to remain in the correct order as the variables are changed.

The cost estimates developed in the ECAS studies and subsequently modified by TVA, Westinghouse and ERCO serve primarily as comparative costs. Cost estimating methodologies and assumptions in the literature vary quite widely, and there is considerable debate as to which particular method is more realistic than another. Therefore, comparing ECAS-derived cost estimates with other estimates in the literature does not yield any useful indication of the "accuracy" or "objectivity" of the costing procedures.

The most important requirement of a comparative cost analysis is the consistency of the costing methodology used. In this sense, the ECAS study provides a valuable tool for cost analysis which is not duplicated in the literature. The ECAS base assumptions were uniformly applied to reasonable engineering designs for conventional and fluidizedbed systems. The results should, therefore, also be 
uniform and should fairly indicate the competitive positions of conventional and fluidized-bed systems. 
${ }^{I}$ General Electric, Conceptual Design and Implementation Assessment of a Utility Steam Plant with Conventional Furnace and Wet Lime Stack Gas Scrubbers, EPA, TVA and NASA (December 1976 .

2 Tennessee Valley Authority, Cost Comparison of Commercial Atmospheric and Pressurized Fluidized-Bed Power Plants to Conventional Power Plants with Flue Gas Desulfurization, EPA R\&D (March 1977).

${ }^{3}$ Bechtel Corp., Coal-Fired Power plant Capital Cost Estimates, EPRI (January 1977).

${ }^{4}$ Pedco Environmental, Particulate and Sulfur Dioxide Emission Control Costs for Large Coal-Fired Boilers, EPA (December 1977).

5 Westinghouse R\&D Center, Evaluation of the Impact of SO, and Particulate Emission Standards on Fluidized-Bed Combustion System Energy Cost, EPA/IERL (September 1977); Westinghouse R\&D Center, Submission to John Ehrenfeld, ERCO (December 1977); and Westinghouse R\&D Center, Assessment of the Impact of Sulfur Dioxide, Particulate and Nitrous Oxide Emission Standards on FBC Power plant Energy Costs, EPA/IERL (January 9, 1978).

${ }^{6}$ Electric Power Research Institute, Coal and Nuclear Generating Costs (April 1977).

7 Personal communication, Larry Gibbs, Pedco Environmental, to George Gantz, ERCO (December 1977).

${ }^{8}$ General Electric, Energy Conversion Alternatives Study (ECAS): Phase II, Final Report, NASA, ERDA, and NSF (December (1976).

${ }^{9}$ TRW, Electric Utilities Study: An Assessment of New Techniques from a Utility Viewpoint, ERDA (November 1976).

10 MITRE Corporation/METRER Division, Analyses of Benefits Associated with the Introduction of Advanced Generating Technologies: Description of Methodologies and Summary of Results -Final Report: Electric Utility Study, ERDA (March 1977).

${ }^{11}$ Babcock and Wilcox Company, Summary Evaluation of Atmospheric Fluidized-Bed Combustion Applied to Electric Utility targe Steam Generators, Volumes I and II, EPRI (October 1976). 